Illinois State University

ISU ReD: Research and eData

Theses and Dissertations

2-4-2019

\title{
Women In Pk-12 Educational Leadership: Identity And Insight
}

Amanda K. Jarvis

Illinois State University, akh74@aol.com

Follow this and additional works at: https://ir.library.illinoisstate.edu/etd

Part of the Educational Administration and Supervision Commons

\section{Recommended Citation}

Jarvis, Amanda K., "Women In Pk-12 Educational Leadership: Identity And Insight" (2019). Theses and Dissertations. 1037.

https://ir.library.illinoisstate.edu/etd/1037

This Dissertation is brought to you for free and open access by ISU ReD: Research and eData. It has been accepted for inclusion in Theses and Dissertations by an authorized administrator of ISU ReD: Research and eData. For more information, please contact ISUReD@ilstu.edu. 
WOMEN IN PK-12 EDUCATIONAL LEADERSHIP: IDENTITY AND INSIGHT

\section{AMANDA K. JARVIS}

182 Pages

Because the number of female educational leaders is disproportionate to the number of males, I conducted a qualitative study about the experiences of female educational leaders. After inquiring about these experiences and analyzing the data, I made recommendations about how to recruit and interest more women to go in to those roles. The study involved participating in faceto-face interviews with fifteen women. With participant consent, I recorded the interviews and transcribed them so that further analysis could take place. I asked approximately five questions and the interviews lasted approximately sixty minutes apiece. The women conveyed many different responses and helped in the attempt to explore female educational leaders' experiences. The data remained confidential and was coded and analyzed by me as part of the qualitative study. The study helped in gaining useful knowledge about the nature of female educational leaders' experiences. Chapters IV, V, and VI cover the results of this study. The findings yielded a greater understanding of why and how women become educational leaders, including examining how they identify themselves as leaders and led to recommendations for encouraging more women to seek out and obtain those positions. All stakeholders involved in education will benefit from the findings, including school board members, women, teachers, administrators, families, students, and legislators.

KEYWORDS: women in educational leadership; gender identity theory; female educational leaders 
WOMEN IN PK-12 EDUCATIONAL LEADERSHIP: IDENTITY AND INSIGHT

AMANDA K. JARVIS

A Dissertation Submitted in Partial

Fulfillment of the Requirements

for the Degree of

DOCTOR OF EDUCATION

Department of Educational Administration and Foundations

ILLINOIS STATE UNIVERSITY

2019 
(C) 2019 Amanda K. Jarvis 
WOMEN IN PK-12 EDUCATIONAL LEADERSHIP: IDENTITY AND INSIGHT

AMANDA K. JARVIS

COMMITTEE MEMBERS:

Elizabeth Lugg, Chair

Lydia Kyei-Blankson

Aime`e Julian

Neil Sappington 


\section{ACKNOWLEDGMENTS}

Because the plight of women in the world continues to be ever-present and relentless, I feel this work is important to people now and to future generations. My wish is that it makes an impact in the field of education and beyond.

Thank you to my children, Samuel and Elizabeth, who encouraged me to pursue the research and waited patiently (although sometimes unwittingly so) as I worked through the many required tasks. I am grateful to them for understanding my will to complete this work and I hope the part of life we went through while I took classes, passed exams, conducted the study, and wrote and wrote (and wrote some more) inspires them to pursue their own work and joy in life.

Thank you to my mother who helped me with many home and life tasks as I worked on this study and this research, in addition to helping direct my attention to this topic and process. She always exhibits a high level of understanding of the importance of highlighting women's struggles and victories.

Thanks to all the people who encouraged me to keep going and understood that the work is important, even if it feels as if no one is paying attention. Thanks to one particular mentor who listened to me as I agonized over the steps and doubted my decisions about what was next. That help was invaluable and helped spur progress.

Thank you to my professors at Illinois State University. They allowed me to see that I had options and were always willing to talk through the processes and the steps so the research would turn out to be valid and insightful.

Lastly, thanks to the study participants for being open, trusting, vulnerable, reflective and willing to share their insight with me and the audience. Your aid is priceless and treasured.

\section{A. K. J.}




\section{CONTENTS}

Page

ACKNOWLEDGMENTS

TABLES

FIGURES

CHAPTER I: INTRODUCTION 1

$\begin{array}{ll}\text { Research Problem } & 2\end{array}$

$\begin{array}{ll}\text { Research Questions } & 4\end{array}$

$\begin{array}{ll}\text { Type of Study } & 4\end{array}$

$\begin{array}{ll}\text { Conceptual Framework } & 5\end{array}$

$\begin{array}{ll}\text { Theoretical Framework } & 7\end{array}$

$\begin{array}{ll}\text { Key Terms and Concepts } & 10\end{array}$

$\begin{array}{ll}\text { Chapter I Summary } & 10\end{array}$

CHAPTER II: LITERATURE REVIEW 12

Gender Identity Theory and Female Leadership $\quad 12$

Qualitative Research about Women in Educational Leadership 15

Existence of Disparity $\quad 15$

Possible Causes of Disparity 16

$\begin{array}{ll}\text { Barriers } & 17\end{array}$

$\begin{array}{ll}\text { Reflections about Identity } & 18\end{array}$

Ethnicity and Age $\quad 21$

$\begin{array}{ll}\text { Leadership Styles } & 21\end{array}$

Lack of Research $\quad 22$

$\begin{array}{ll}\text { Chapter II Summary } & 23\end{array}$ 
Research Problem

Research Questions

Theoretical Framework

Type of Study

Contributions of a Pilot Study

Researcher Positionality

Interviewing

Question Development

Field Notes and Analytic Memos

Data Collection

Participants

Data Analysis

Authenticity and Credibility

Validity/Trustworthiness

Member Checking

Clarify the Bias

Limitations 
BP 52

$\begin{array}{ll}\text { BT } & 53\end{array}$

$\begin{array}{ll}\text { DC } & 55\end{array}$

$\begin{array}{ll}\text { DI } & 56\end{array}$

$\begin{array}{ll}\text { EX } & 57\end{array}$

$\begin{array}{ll}\mathrm{KH} & 57\end{array}$

$\begin{array}{ll}\mathrm{KD} & 58\end{array}$

$\begin{array}{ll}\text { MB } & 59\end{array}$

$\begin{array}{ll}\text { MI } & 60\end{array}$

$\begin{array}{ll}\text { ML } & 61\end{array}$

$\begin{array}{ll}\text { MP } & 62\end{array}$

$\begin{array}{ll}\text { MT } & 63\end{array}$

$\begin{array}{ll}\text { NM } & 64\end{array}$

$\begin{array}{ll}\mathrm{ON} & 66\end{array}$

$\begin{array}{ll}\text { TU } & 67\end{array}$

$\begin{array}{ll}\text { Chapter IV Summary } & 68\end{array}$

$\begin{array}{ll}\text { CHAPTER V: DATA ANALYSIS } & 69\end{array}$

$\begin{array}{ll}\text { Types of Analysis } & 69\end{array}$

$\begin{array}{ll}\text { Reflection about the Data } & 70\end{array}$

$\begin{array}{ll}\text { Reflection about Positionality } & 72\end{array}$

$\begin{array}{ll}\text { Coding the Data } & 74\end{array}$

$\begin{array}{ll}\text { Description of Participants } & 78\end{array}$

$\begin{array}{ll}\text { Leadership roles. } & 78\end{array}$ 
Demographic data.

Career history.

$\begin{array}{ll}\text { Key Themes } & 81\end{array}$

$\begin{array}{ll}\text { Path to Leadership } & 81\end{array}$

$\begin{array}{ll}\text { Personal experiences. } & 81\end{array}$

$\begin{array}{ll}\text { Opportunities to lead. } & 82\end{array}$

$\begin{array}{lr}\text { Childhood experiences. } & 84\end{array}$

Family background. $\quad 86$

$\begin{array}{lr}\text { Pivotal moments. } & 88\end{array}$

$\begin{array}{ll}\text { Mentoring. } & 90\end{array}$

$\begin{array}{ll}\text { Encouragement by others. } & 90\end{array}$

Discouragement by others. $\quad 91$

Observations of leaders. $\quad 93$

$\begin{array}{lr}\text { Purpose. } & 94\end{array}$

$\begin{array}{ll}\text { Negative experiences. } & 96\end{array}$

$\begin{array}{ll}\text { Reluctance to leave teaching. } & 97\end{array}$

$\begin{array}{ll}\text { Self-doubt. } & 98\end{array}$

Isolation/separation. $\quad 99$

$\begin{array}{ll}\text { Good Leaders } & 100\end{array}$

$\begin{array}{ll}\text { Defining good leaders. } & 106\end{array}$

$\begin{array}{ll}\text { Building relationships. } & 106\end{array}$

$\begin{array}{ll}\text { Effective communication. } & 108\end{array}$

$\begin{array}{ll}\text { Empowerment of others. } & 109\end{array}$ 
Navigating with and through people.

Good listening.

Trust.

Identity as leaders.

Building relationships.

Servant leadership.

Decisiveness.

Focus and vision.

Support (or lack of).

Crying.

Women in Leadership

Expectations of women.

Gender influence on interactions.

Perceptions of females versus males.

Other

Awareness of gender roles.

Dress.

Ethnicity.

Having children. 
$\begin{array}{ll}\text { Gender Influence on Leadership } & 148\end{array}$

Gender Identity and Leadership Roles, Styles, Skills, and Qualities 152

$\begin{array}{ll}\text { Staying comfortable. } & 152\end{array}$

$\begin{array}{ll}\text { Lacking confidence. } & 153\end{array}$

$\begin{array}{ll}\text { Emotional leadership. } & 153\end{array}$

$\begin{array}{ll}\text { Communication skills. } & 154\end{array}$

$\begin{array}{ll}\text { Work ethic. } & 154\end{array}$

Recommendations from the Women 155

$\begin{array}{ll}\text { Pathways } & 156\end{array}$

Exposure to leadership opportunities. 157

$\begin{array}{ll}\text { Find the passion. } & 159\end{array}$

$\begin{array}{ll}\text { Mentoring } & 159\end{array}$

$\begin{array}{ll}\text { Personal Development } & 160\end{array}$

$\begin{array}{ll}\text { Building confidence. } & 160\end{array}$

$\begin{array}{ll}\text { Find strengths and voice. } & 162\end{array}$

$\begin{array}{ll}\text { Explore possibilities. } & 162\end{array}$

$\begin{array}{ll}\text { Future Research } & 163\end{array}$

$\begin{array}{ll}\text { Interview Male Educational Leaders } & 164\end{array}$

$\begin{array}{ll}\text { Examine Competitiveness } & 164\end{array}$

$\begin{array}{ll}\text { Examine Leaders as Nurturers } & 164\end{array}$

$\begin{array}{ll}\text { Explore Male Success in Leadership } & 165\end{array}$

Study “Bossy” Women 165 
Implications for Practice/Practitioners

Chapter VI Summary 


\section{TABLES}

Table

Page

1. Pilot Study Summary

2. Path to Leadership: Mentoring

76

3. Leadership Roles

78

4. Participant Demographic Data

5. Participants: Career Starts

80

6. Role-Ordered Matrix: Good Leaders

101

7. Conceptually Clustered Matrix: Crying

124 


\section{FIGURES}

Figure $\quad$ Page

1. Women's Perspectives on Knowing in Five Major Epistemological Categories $\quad 8$

2. Tesch's Eight Steps in the Coding Process 44

3. Conceptually Clustered Matrix: Thoughts about Women in Leadership 126 


\section{CHAPTER I: INTRODUCTION}

Imagine you belong to a group of people who possess many great qualities and characteristics, such as intelligence, compassion, dependability, cooperativeness, determination, imagination, ambition, courage, caring, maturity, loyalty, self-control, and independence. Then, imagine you are never given a chance to show and use those gifts in the world, rarely permitted to contribute to society in a productive manner with those qualities, and looked upon with bias that inhibits your participation as a human being. The thought that this ignorance is possible in our world today may be unsettling because, logically, a person with all of those traits should be allowed and should be given the opportunity to shine and present himself or herself in the best possible way. Unfortunately, that basic, deserved opportunity is not presented to women in educational leadership. That fact is not new and it is not unstudied. A great number of researchers have studied women and leadership in society (Shakeshaft, 1989, etc.). An April 2017 search of "women and leadership" in the dissertations catalogued by ProQuest, a wellknown research database, reported 376,515 results, citing abundant research on the topic. Countless articles, books, blogs, institutions, meetings, and think tanks exist to study the subject of women and leadership in the world. While acknowledging the large amount of studies and other information about this topic, it is logical to question its importance. Women account for over half the population of the world, but continue to be under-represented and often ignored in virtually every aspect of living. Women have proven themselves to be effective leaders, but continue to be dismissed and discounted. Pondering about these issues is not a new pastime; since the time that humans were able to speak and write about it, hundreds of writers, scholars, and activists have questioned, analyzed, and found that women and leadership is a worthwhile subject upon which much time should be spent. For example, in 391 B.C., Aristophanes offered 
Assemblywomen, his play about women coming to power in government and the relationship between war, power, and gender (A. \& Henderson, 1998). In order to comment about social issues, Shakespeare often placed his female characters in different roles, sometimes ones of power and leadership. As this proposal is submitted, women and leadership are still observed, questioned, hotly debated, and written about (Zenger \& Folkman, 2012).

\section{Research Problem}

However, despite the aforementioned facts about coverage of the topic, there is a gender problem in educational leadership. Despite progress towards sex equity, there is a lack of women serving as educational leaders in the pre-kindergarten through 12th grade levels (PK-12) as evidenced by recent statistics reported by various, reputable researchers and organizations, such as the American Association of School Administrators (AASA) (Glass, 2016; Superville, 2016). The disparity is mammoth; Superville (2016) describes the present situation:

Even though K-12 education is largely a female enterprise, men dominate the chief executive's office in the nation's nearly 14,000 districts, numbers that look especially bleak given that the pool of talent is deep with women. Women make up 76 percent of teachers, 52 percent of principals, and 78 percent of central-office administrators, according to federal data and the results of a recent national survey. Yet they account for less than a quarter of all superintendents... (para. 4).

This problem has negatively affected women, students, and school districts because the representation by women in educational leadership is extremely disproportionate compared to the numbers of male leaders and their influence does not reflect or match their presence in teaching (Glass, 2016). The disparity is a global issue because women represent half of the world's population, while accounting for seventy percent of its poverty-stricken (Scott, 2015, para. 1). Since women of all races and cultures fall into this category, it stands to reason that putting them into positions of power and influence would directly affect them, their families, their bodies, their schools, their economies, and more (Scott, 2015, para. 2). Empowering women 
is a key move in the effort to enrich the lives of all people all over the world. These women could act and speak on behalf of others who cannot do those things for themselves. Some women of certain ethnicities may have more opportunity than others, especially considering that being female and part of a race that has been traditionally more marginalized, such as AfricanAmerican, may inhibit participation in such matters and on certain levels. Closing the gap has to start with women from all parts of the world being encouraged, promoted, or tapped; taking those steps is a start in the effort to close the gap.

In the United States, in regards to educational leadership, research suggests causes of this problem/issue may be that gender discrimination is practiced and present in communities. Women are not mentored or "tapped" or encouraged to seek out leadership positions, and/or that women do not identify themselves as educational leaders (Ibarra, Ely, \& Kolb, 2013; Komives, Owen, Longerbeam, Mainella, \& Osteen, 2005; Wallace \& Wallin, 2015). However, do women who are currently in the leadership positions agree? Perhaps, there is more to the matter, including circumstances, influences, choices, etc. Researchers tend to focus on deficit thinking when it comes to the research problem and examine factors that may inhibit women from pursuing leadership roles, rather than questioning how the women get to the leadership roles and what may happen to propel them into the positions. Investigating the disparity with women who are currently in educational leadership positions using interviewing would bring a greater understanding of why and how women became educational leaders in PK-12, including examining how they identify themselves as leaders, and could lead to recommendations for encouraging more women to seek out and obtain those positions. 


\section{Research Questions}

Following are some questions that helped in the research of this topic:

1. What is the nature of female educator experiences in becoming PK-12 educational leaders?

a. What was the women leaders' paths to leadership?

b. What are the female educators' thoughts about women and educational leadership?

c. How do the female educators identify themselves as leaders?

d. How do the female leaders define what makes a good leader?

e. What recommendations do the women educators have for increasing the number of women in leadership positions?

\section{Type of Study}

I conducted a qualitative study in which a small group of PK-12 female educational leaders (fifteen participants) were interviewed about the nature of their experiences, inquiring as to why and how they became educational leaders, including examining their backgrounds, goals, personal life choices (career, family, etc.), the challenges and obstacles they experienced, the paths to their roles, their treatment as females, their definition of good leadership, and any mentoring (selection, encouragement, etc.). The participants varied in age, ethnicity, and years of experience in their roles, but the pool was limited to include principals and PK-12 school district central office personnel, such as assistant superintendents and superintendents. The participants were limited to this group because they are specifically assigned to fulfill the duties of educational leaders by their school boards and are expected to carry out prescribed leadership responsibilities in their buildings and school districts. The interviews were recorded and 
transcribed. Participants were interviewed at least once and were asked to possibly interview again if more information, clarification, or time was needed.

\section{Conceptual Framework}

Researchers have thought about and should continue to think about leadership positions women have been in, are currently in, and how they got there. There have been similar studies and collections of studies that explored the ways in which female educational leaders shared their experiences (Beatty, 2000; Brown \& Irby, 1993; Dana \& Bourisaw, 2006; Murphey, 2005; Regan, 1995; Shakeshaft, 1989). Dana and Bourisaw (2006) shared stories they had gathered from women who were aspiring leaders, but were in different environments and even different parts of the world. They try to explain the concepts of "glass ceilings" and "glass walls," which they describe as "horizontal and vertical barrier" women confront in their journeys. Murphey (2005) collected data from four white women for the purpose of reflection about leadership development:

... [the study participants] engaged this topic by conducting a dialogical analysis of their experiences in leadership. They dialogued from what were technically different positions in the hierarchy...and implemented a research process to speak across or marginalize those technical differences to produce a text that explored the rich terrain of leading in which they shared experiences of growth, the conceptual frameworks that guide their leading, and their differing interpretations of gender's role in the leadership process. ( $\mathrm{p}$. 273)

Shakeshaft (1989) conducted in-depth research on women in educational leadership. She was interested in the history of women in administration, how women became educational leaders, what types of leaders they became, how they thought they compared to male leaders, how others thought they compared to male leaders, the obstacles they may have experienced and how those encounters influenced their handling of the roles and responsibilities. Also, she explored how they overcame the obstacles. Brown and Irby (1993) brought together a set of women and 
collected details about their stories and other interesting notions in a commentary about women and their experiences in school leadership.

After exploring the content of those studies, I further wondered about the nature of the experiences of other female educational leaders. I began to propose that interviewing a group of women who are currently in (or recently retired from) the higher ranks of PK-12 educational leadership and inquiring as to the nature of their experiences, including examining their backgrounds, goals, personal life choices (career, family, etc.), the challenges and obstacles they experienced, and mentoring (selection, encouragement, etc.) would provide insight to researchers and prospective female educational leaders and how they identified themselves as leaders. Their stories, advice, and reflection would provide valuable data so that recommendations may be made to school districts about how to foster an environment that encourages more women to pursue higher-level educational leadership positions. As Reinhartz and King (1993) demanded, "We need to see women in leadership roles and when we don't, we need to ask why...This change will bring diversity to organizations which in the long run will result in bringing... 'fresh ideas, new and different perspectives (to) old problems...because they are not blinded by the familiar..."” (p. 8).

Since very few researchers have looked at why women are compelled to go into educational administration (and I have only had one type of experience), I remained curious about their journeys and about the details of others' experiences. There are a few studies that explored the area of ideals and purpose, asking if women were driven to pursue leading because of a sense of purpose and ideals (Ibarra, et al., 2013; Komives, et al., 2005; Wallace \& Wallin, 2015). It stands to reason that if women put forth thoughts about why they are motivated to pursue the role, educational institutions could find ways to advertise about that and entice others 
to consider the role. Attracting women who, perhaps, never thought about that journey could be a key strategy to reducing the disparity.

\section{Theoretical Framework}

This topic is recognized and studied using a framework that helps with the study of questions with gender. That lens helped to set up what questioning is used and how data is collected and analyzed. This qualitative study is grounded in the paradigm of Gender Identity Theory, which dictates that people and their experiences are shaped by their identification with gender. The theoretical framework of Gender Identity Theory made sense to use as the model/basis of this study, as this study is concerned with understanding and analyzing how identity with gender affects women, their leadership, their journeys, and their opportunities. Furthermore, and more specifically, the work disseminated in the book, Women's Ways of Knowing (Belenky, Clinchy, Goldberger, \& Tarule, 1986) $(W W K)$ is the orienting lens used in this study. Belenky et al. (1986) interviewed women, collected/coded that data, and sought to understand their perspectives with the intent to call for action and change; they examined “women's ways of knowing and describe five different perspectives from which women view reality and draw conclusions about truth, knowledge, and authority" (p. 3). Their work was also grounded in gender identity theory:

In recent work Gilligan and her colleague, Nona Lyons (1983), have extended their study of gender-related differences in moral perspectives to the area of identity development. They have shown how the responsibility orientation is more central to those whose conceptions of self are rooted in a sense of connection and relatedness to others, whereas the rights orientation is more common to those who define themselves in terms of separation and autonomy. Although these differences in self-definition do not necessarily divide themselves along gender lines, it is clear that many more women than men define themselves in terms of their relationships and connections to others, a point which has also been made by Nancy Chodorow (1978) and Jean Baker Miller (1976). When men define themselves in terms of connection, they also frame their moral judgments in terms of responsibility rather than rights. (Lyons 1983). (p. 8) 
After establishing background for the audience, Belenky et al. (1986) proceeded to conduct a study that explored five areas in regards to women's ways of knowing. Figure 1 explains the five areas.

\begin{tabular}{|ll|}
\hline Women's Ways of Knowing & $\underline{\text { Definition }}$ \\
Silence & total dependence on whims of external authority \\
Received Knowledge & receive and reproduce knowledge \\
Subjective Knowledge & truth and knowledge are conceived of as personal, \\
private, and intuited \\
Procedural Knowledge & rely on objective procedures for obtaining and \\
comstructed Knowledge & commicating knowledge \\
& \\
& view all knowledge as contextual; value subjective \\
& \\
&
\end{tabular}

Figure 1: Women's perspectives on knowing in five major epistemological categories. This figure summarizes the five areas Belenky et al. (1986) explored and reported findings about in their book, Women's Ways of Knowing: The Development of Self, Voice, and Mind.

Since my goals are similar to Belenky et al. (1986), I referred to their questions and methods to help answer the research questions posed in this study.

Researchers used WWK (Belenky et al., 1986) as a theoretical framework in studies prior to this one. Belenky et al.'s (1986) “ways of knowing” have provided a foundation for some researchers from which they could theorize about questions concerning different types of 
learning (Frkal, 2016; Khine \& Hayes, 2010), differences between male and female leadership (Teagan, 1996), different ways women approach decision-making (Lebo, 1994), and approaches to different schools of thought, such as postformal and relativistic (Orr \& Luszcz, 1994). The "ways of knowing" have not been free of criticism. The most common critique demands to know why Belenky et al. (1986) did not address race in their study. In response, they explained that they “...included a number of disadvantaged and forgotten women whose ways of knowing and learning, identity transformations and moral outlook have seldom been examined by academic researchers" (p. 11). In addition, they interviewed women who were currently students in formal educational settings as well as in what we came to call the 'invisible colleges' - human service agencies supporting women in parenting their children" (p. 12). However, they did not comment or explain how race influenced or did not influence their study, their questioning, or the responses. Belenky et al. (1986) was mostly silent about race throughout their development of the "ways of knowing". They did explain that, due to having to limit their sample size for the study, they did not consider working women in the study, but acknowledged their contributions and cited other studies that gave credence to that population and their worth in research (p. 12).

Another criticism about Belenky et al.'s (1986) work is that the voices of men were not factored into the findings. Critics argued that the work is biased because men were not necessarily referenced as the "ways of knowing" were developed. Belenky et al. (1986) defended their choice to focus on sampling only women by referencing Steinem (1981): “...it may be that when women talk, their behavior is not compared with men's but is assessed against a standard that holds that women should be seen and not heard. When women deviate from a standard of absolute silence, they are thought to be loquacious and out of line" (p. 45). 


\section{Key Terms and Concepts}

$P K$-12: This acronym stands for pre-Kindergarten through twelfth grade levels in public education in the United States. In the United States, all children are expected to attend public school from Kindergarten through twelfth grade.

Educational leadership: "Educational leadership involves working with teachers and other education professionals on systemic plans to improve educational programming and outcomes. From K-12 to higher education, leaders in the industry include: teachers, superintendents, principals, administrators, department chairs, provosts and deans" (Creighton University, 2017, para. 2).

Gender Identity Theory: a theory that dictates people and their experiences are shaped by their identification with gender.

\section{Chapter I Summary}

This Chapter I introduction previewed the research problem, the disparity between the number of women and men in PK-12 educational leadership and proposed research questions that will help in guiding the qualitative study addressing the following research questions:

1. What is the nature of female educator experiences in becoming PK-12 educational leaders?
a. What was the women leaders' paths to leadership?
b. What are the female educators' thoughts about women and educational leadership?
c. How do the female educators identify themselves as leaders?
d. How do the female leaders define what makes a good leader?
e. What recommendations do the women educators have for increasing the number of women in leadership positions? 
The conceptual and theoretical frameworks were explained, providing definitions of those frameworks and explanation about how they connected to this study. Current statistics were provided as well. Key terms and concepts were also defined. Next, Chapter II will provide further review of the literature that surrounds this topic. Chapter III will explain the research methods to be used in this study. The methodology will illustrate the importance and relationship between the research problem, research questions, research paradigm, type of study with justification, researcher positionality, data collection, data analysis, authenticity/credibility, ethical issues, and contributions. References are provided. 
CHAPTER II: LITERATURE REVIEW

\section{Gender Identity Theory and Female Leadership}

As I examined the research questions for this proposed study, and since I wanted to understand how women identify themselves as leaders and what makes a good one whilst in the role, it made sense to focus on the area of Gender Identity Theory. Gender Identity Theory is a theory that dictates that people and their experiences are shaped by gender. The ways that this theory plays out in research are varied, but for this study, I centered on how gender identity performs in educational leadership concerning power structures and how it relates to other social identities (Warner, 2016, p. 1). As early as adolescence, gender identity may have a direct effect on career choice decisions, which, in turn, contribute to "segregation in the labor market" (Sinclair \& Carlsson, 2013, p. 465). As discussed in WWK, Belenky et al. (1986) understood that gender identity theory was active in the lives of the women they studied as those researchers sought to understand women's ways of knowing and thinking. As recently as 2015, Wallace and Wallin studied female educational leaders; they examined how gender identity affected their professional lives, especially in a highly patriarchal setting. Their work explored how the identities were transformable as each entered into an established culture and how their values were shaped and held (p. 412). However, researchers have not keyed into the fact that gender identity matters. Vantieghem, Vermeersch, and Van Houtte (2014) argued that researchers had recently forgotten gender identity theory, but that it should be an integral part of studies, especially when examining gender gaps. They pointed out that there is currently a scarcity of research using the theory (p. 357). Coleman (2005) also highlighted the fact that gender identity theory does not often play a role when researching becoming and acting as an educational leader (p. 3). Sinclair (2004) lamented "...the limitations of leadership discourses [are] - too often 
disembodied, de-gendered and de-sexualized" (p. 7). Lumby (2010) echoed others when he claimed that "...theorists in education leadership have remained relatively uninterested in multiple aspects of identity and diversity" (p. 3). Yet, Gaetane (2013) found that gender continues to be a persistent factor in educational leadership (p. 615). Grogan (2014) pushed for the "reinvigorated use" of theories concerning gender and identity in studying women in education, even promoting the added benefit that the field will better understand men in education as well (p. 3).

Still, there is some evidence of gender identity theory playing out in professional development models that encourage women to become educational leaders, helping them to identify their motivation, influences, and opportunities (Simon, 2015, p. 53). Lopez (2010) set out to examine how gender played a role in how effective leadership behavior is perceived ( $\mathrm{p}$. 21). In research that examined women in leadership and how gender identity theory operates within that work, researchers have found positive results. Karelaia and Guillén (2014) found that positive gender identity “...reduced identity conflict...and...by lessening identity conflict, positive gender identity reduced stress, increased life satisfaction, and caused women to construe leading more as an attractive goal than a duty" (p. 204). Terpenny (2014) acknowledged that women and men are different and, therefore, will execute different leadership styles (p. 1). Even staff who train people in leadership techniques should be aware of the role gender identity plays in that professional development (Lovette-Colyer \& Lovette-Colyer, 2017, p. 71). Shea and Renn (2017) recommended that the process of developing leaders should most definitely include awareness about gender and how it is conceptualized (p. 83).

Despite the efforts of those researchers, Young (2005) warned that progress of women in educational leadership was limited and that there may be evidence of a backlash, even with 
efforts to make the global community aware of the disparities (p. 31). Lumby (2011) highlighted the recent attitude of researchers and existing power structures and noticed “...a focus on women and equity of representation within the workplace has been attacked as inappropriately essentializing women or as redundant in the light of advances in gender equality"; he argued that this attitude was unfounded and linked gender representation in educational leadership to "ideological and power flows" (p. 921). That attitude is dangerous considering the known impact of gender identity and its interaction in educational leadership.

In addition, researchers have studied how people, particularly women, construct their gender identities in relation to leadership and, at times, race. Horsford (2012) wrote about “...the intersectionality of race and gender identities alongside context as important indicators in the development of leadership philosophies, epistemologies, and practice" (p. 11). Just as Hill Collins (2000) acknowledged that gender and race are factors to consider when focusing on leadership and organizations, Sanchez-Hucles and Davis (2010) factored race into the problem; they described, “...the challenges that women and women of color face in their quest to achieve and perform in leadership roles in work settings". Also, they discussed "...the barriers that women encounter and specifically address the dimensions of gender and race and their impact on leadership”. Along with, “...the factors associated with gender evaluations of leaders and the stereotypes and other challenges faced by White women and women of color". They used, “...ideas concerning identity and the intersection of multiple identities to understand the way in which gender mediates and shapes the experience of women in the workplace" (p. 171). Reed (2012) interviewed three African-American female principals about their shared gender identities, which provided insight about their leadership behaviors (p. 39). Davis et al. (2010) explained the experiences of African-American women and gender identity in professional 
settings and, in turn, promoted the need for continuing support of women of color in leadership (para. 5). Although much more work is needed in studying African-American women in the field, other groups exist in educational leadership that may have similar plights. Liang and PeterHawkins (2017) studied such a group when she looked at Asian-American women and asked to understand their constructed meanings in regards to their professional lives as school

administrators. She discovered journeys that were personal and developing, definitively not void of struggle (p. 40). However, despite these studies and the acknowledgment from the academic establishment that gender and identity is important, Reid, Lewis, and Wyche (2014) pressed that it is still largely missing from multicultural study and research. Most study centering on women of color used theoretical frameworks such as black feminist thought, leadership theory, and intersectionality (Horsford \& Tillman, 2012, p. 1).

\section{Qualitative Research about Women in Educational Leadership}

Since this study was conducted qualitatively, I deemed it useful to examine existing qualitative studies about women in educational leadership. In doing so, my review elicited several approaches of study and results. Following is a discussion of many areas garnered by researchers as a result of studying women in educational leadership, including the existence of disparity, causes of the disparity, barriers, reflections about identity, the impact of ethnicity and age, leadership styles, and lastly, the lack of research.

\section{Existence of Disparity}

Despite the passage of Title IX (1972) and other laws enacted since then that are in effect to prohibit discrimination based on gender, along with the impact of the women's movement in the 1960s, and the overwhelming presence of females as teachers in public education, disparity persists. 
Glass (2016) offered statistics: “Of our nation's 13,728 superintendents, 1,984 today are women. Yet 72 percent of all K-12 educators in this country are women, according to the U.S. Department of Education" (para. 1). Looking back further, Cubillo and Brown (2003) also verified the existence of disproportion: "The underrepresentation of women in positions of senior management within educational institutions continues to be a matter of some concern, particularly as the teaching force is largely dominated, nationally and internationally, by women" (p. 1). The problem is evident in instances where gender and race are considered in the data as well. Hill Collins (2000) pointed out, "Exclusion from basic literacy, quality educational experiences, and faculty and administrative positions has limited U.S. Black women's access to influential academic positions" (p. 254). Growe and Montgomery (1999) deduced that the problem is not restricted to the realm of education; they found that the number of qualified women in leadership positions is extremely disproportionate compared to males, hence creating a gender gap (p. 1). The problem does not just affect women in American society; there is an impact for students as well. Kirkham (2005) claimed, "Pupils are growing up with an 'accepted' view of a sexist society because of the lack of women in senior positions in schools...” (p. 8).

\section{Possible Causes of Disparity}

Naturally, as researchers dig deeper into the discrepancy, the subsequent question is: what is the cause? Superville (2016) asked why so few women occupy higher level educational leadership positions. She explored possible reasons why this shortage persists and speculated through relating stories from female educational leaders:

Some [potential female educational leaders] simply don't want it. They prefer teaching and being close to students. The hours are punishing, school board politics can be brutal, and public scrutiny is intense. The average superintendent stays on the job less than five years. For some women, that uncertainty is not worth uprooting their families...The search for superintendents also traditionally has pulled from districts' pool of secondary school principals. Women, who were more likely to be elementary principals, were less 
likely to be immediately tapped. Part of the problem stems from districts' lack of planning for long-term leadership, which makes it difficult to spot talented educators, including women, who could be groomed to be in charge. Educators also see subtle biases in how school boards and search firms recruit candidates, and negative stereotypes about women's abilities to lead large institutions are still pervasive. And with so few women in the top job, prospective female leaders have limited opportunities to networklosing out on mentors who can advise them on applying for the job, getting the right experience, and navigating difficulties. (para. 8-10)

As predicted, the causes are complex and present on many levels, which makes studying it a challenge. In a broader sense, Growe and Montgomery (1999) looked at women in leadership across the board (not just in education) and they speculated that "Society has determined that only males make good leaders; therefore, it continues to deny easy access for women seeking leadership roles because they do not fit the norm. Women who seek leadership positions face barriers and many times give up because they become overwhelmed in dealing with obvious barriers” (p. 1). Kirkham (2005) pointed out that typically, “...it is accepted again for women to take the caring positions and for men to have the more valued positions" (p. 8). Reinhartz and King (1993) asserted, "With such limited access to corporate and educational executive positions, women have not had the opportunity to demonstrate their leadership skills on a broad scale and so it goes - limited opportunity and fewer role models to emulate" (p. 8). Though not a complete list, these causes are some of the possibilities that hinder women from being in leadership roles.

\section{Barriers}

Through these studies, researchers have also uncovered barriers women face as they navigate through educational leadership. However, some the studies report that the barriers are not as obvious as they used to be and once recognized, harder to confront and deal with. In addition, studies have explored the ways in female educational leaders shared the ways they experienced discrimination and sexism. Cubillo and Brown (2003) shared "...narratives drawn 
from women aspiring to leadership and management in different educational contexts, from very different parts of the world. Their study examined the "'glass ceilings' and 'glass walls'; that is, horizontal and vertical barriers faced by each of the women within their cultures and environments" (p. 278). Though not in the United States (Pakistan), like Cubillo and Brown (2003), Rashid (2010) also attempted to interpret "glass ceilings" and "glass walls" (p. 207). They all used the term "glass" because they noticed that women could not always see the barriers in plain sight and this acknowledgement had side effects, including discouragement.

The barriers can still be obvious and blatant, but some are inconspicuous, especially as different generations proceed through work and people adjust their behaviors. Through her analysis of interview data, Blair (2018) argued that women now face more "hidden" forms of barriers. They are veiled and harder to respond to after recognition, if that occurs at all (p. 2). Before Blair's study, Gaetane (2013) recognized that the African American women she investigated encountered sexism, racism, and ageism in their experiences as educational leaders, all of which were often indistinct (p. 615). Brown and Irby (1993) compiled a collection of fourteen articles in Women as School Executives: A Powerful Paradigm, in which they challenged society “...to rethink the prevalent paradigm and proposes that women's skills and characteristics are particularly suited for dynamic leadership" (p. 10). Transforming the paradigm was the main recommendation.

\section{Reflections about Identity}

Through major effort, researchers asked women about how they form their identities as educational leaders, in regards to various factors. Often, the questioning was tied to race, age, and other characteristics and asked women to reflect about how they came to their perceptions and thoughts regarding identity. Lumby (2015) interviewed fifty-four school principals in South 
Africa and asked them extrapolate about how they arrange their identities as leaders. The women explained that they had to take many actions to combat low status, convince others of their value, downplay stigmas, contradict disadvantages, and be realistic about their position in their culture (p. 28). Murakami and Tornsen (2017) looked at two female educational leaders with a similar lens, asking them about how they developed their professional identities. Their approach was to conduct the research with one woman in Sweden and another woman in Texas, USA. Their findings communicated that the women were often evaluated negatively (p. 806). Loder (2005) reviewed research about African American women leaders from a historical perspective over time. After asking the women to reflect about their roles as principals during recent educational reform in Chicago, Loder (2005) found that they were particularly susceptible to the impact that accompanied along with that reform and that their identities, especially considering their race, age, and gender, made it so (p. 298). Weiner and Burton (2016) asked male and female participants about their gender identities within educational leadership and found that, while they thought similarly about how effective leadership should look and act, they thought about other issues differently, including how they saw themselves, feedback about their leadership skills, and access to the career itself (p. 339). Armstrong and Mitchell (2017) inquired with two black female Canadian principals in order to understand how they constructed their professional identities and how they negotiated with those identities in their jobs: "Both principals encountered gender and race-related pressures to fit normative expectations of administrators as white males. Navigating their intersecting identities was described as a precarious balance of accommodating and asserting: this involved authoring and effacing identity and standing up and standing tall for personal and professional values" (p. 825). These studies displayed the many angles researchers used in pursuit of curiosity about identity. 
Research has also centered on examining the complicated reflections of women as they experience different facets of the profession. Murphey et al. (2005) collected data from four white women for the purpose of reflection about leadership development: they "...engaged this topic by conducting a dialogical analysis of their experiences in leadership. They dialogued from what were technically different positions in the hierarchy...and implemented a research process to speak across or marginalize those technical differences to produce a text that explored the rich terrain of leading in which they shared experiences of growth, the conceptual frameworks that guide their leading, and their differing interpretations of gender's role in the leadership process" (p. 273).

Beatty (2000) employed interviewing methods to examine "...the emotionality of educational leadership by exploring administrators' recall of key junctures in their lives as leaders, and was designed to begin to investigate the associations between an individual's philosophy of leadership and his/her experience of emotionality in leadership...the study uses stimulated recall of emotional experiences associated with leadership work. An assessment of the situations that evoked emotions, patterns associated with the emotions themselves and the act of reflection, led to noteworthy conclusions that may hold important implications for further research in the sociology of emotions and educational leadership theory and practice" (p. 331). Regan (1995) described the female leadership experience in her book, Out of Women's Experience: Creating Relational Leadership. She examined the "...the qualities that women bring to leadership roles and show[ed] how these can be used to improve the practice and teaching of educational leadership for men and women. Using 11 case studies, the book describe[d] how women conceptualize leadership and practice it in their roles as educational leaders" (para. 1). Brown and Irby (1993) brought together a set of women and collected their 
“...insights, perspectives, and advice on the powerful paradigm of women as school executives"

(p. 9). In addition, they documented barriers the women were up against and offered suggestions about how to navigate around them.

\section{Ethnicity and Age}

Qualitative research about women in educational leadership cannot focus on gender identity alone. Race and age are factors that may influence how a woman views herself in the leadership role and how everyone else views her, judges her, extol her, discourage her, etc. Jones (2013) interviewed African American women to determine if race had any effect on them as they pursued leadership positions in upper levels of educational administration. "The findings from this study determined that African American women make meaning of their role and career path to the superintendency in a multitude of ways: preparation, leadership, core principles, relationships, positional strategies, and challenges. The participants revealed that relationships are essential to their leadership" (p. 1). Reed and Evans (2008) studied how the leaders themselves and others perceive female leaders of color. They found that race and gender impacted perceptions when it comes to female principals (p. 487).

\section{Leadership Styles}

Often, studies garnered information about aspects of the profession that are impacted by gender. A few studies uncovered insights about how women defined leadership styles. WaldronAsuncion (2017) focused on African American female administrators in Florida in order to understand their leadership styles. She found that the styles varied among the women and that gender mattered in that variance (p. 1). Fowler (2012) decided to concentrate on just one woman's story and examined her path into and through administration. Along with other insights, out of that questioning came a description of her leadership style (p. 1). Though Bass 
(2012) mainly discussed the benefits of "Black feminist caring (BFC)" in educational leadership in her study, she uncovered their leadership styles as well and found that they often took on an activist style, taking risks and mothering students (p. 73).

\section{Lack of Research}

After reviewing past and current research, it is clear that there is more work to be done. Conducting a study through qualitative methods is required and necessary for many reasons. Just as Hill Collins (2000) explained that "Individual African-American women's narratives about being single mothers are often rendered invisible in quantitative research methodologies that erase individuality in favor of proving patterns of welfare abuse", so are women in educational leadership often dismissed and their stories replaced or glossed over (p. 255). Shoulders are shrugged and heads are shaken. Grogan and Shakeshaft (2011) found that few studies have focused on the fact that women must employ strategies to help themselves when overcoming obstacles or barriers in educational leadership. They also realized that little research had been conducted to discover how their approaches may be different from traditional approaches, whether by male or female. Blackmore (2013) acknowledged, "Over time, key feminist theories and research have been appropriated in education policy and are now embedded in the mainstream literature, with little recognition of their provenance or political intent” (p. 139). Brown and Irby (1993) highlighted, "Traditionally, school executive literature has been based on the world of the male administrator with women being largely ignored" (p. 10). Finneran (2018) asserted that, despite the disparity between male and female numbers, a minor amount of research is in existence that could be helpful in suggesting strategies to increase the number of females, especially when it comes to developing female educational leaders in the first place ( $\mathrm{p}$. 1). Boggs (2010) went further than Finneran (2018) eight years earlier when she claimed that 
there is almost no research on female superintendents once they obtain the role (p. 4126). Fowler (2012) noted that "documentation of their [female school principals] specific stories and perspectives is infrequent" (p. 1). Wheat and Hill (2016) claimed to have conducted a study that was the first of its kind - one that applied a postmodern feminist framework as they studied female leaders at the university level (p. 1). Considering how recent some of these observations are, researchers cannot ignore the fact that there is a lack of investigation into the topic and that much more can be done.

\section{Chapter II Summary}

Chapter II consisted of a review of the major literature centered on the use of Gender Identity Theory in research and the body of qualitative studies on women in leadership. The areas that surfaced throughout this review included the existence of disparity, causes of the disparity, barriers, reflections about identity, the impact of ethnicity and age, leadership styles, and lastly, the lack of research. Next, Chapter III explains the research methods used in this study, illustrating the importance and relationship between the research problem, questions, research paradigm, type of study with justification, researcher positionality, data collection, data analysis, authenticity/credibility, ethical issues, and contributions. References are provided. 


\section{CHAPTER III: METHODOLOGY}

\section{Research Problem}

Now that the case has been made that the problem in educational leadership is the lack of women serving as educational leaders in the PK-12 levels and that there is a lack of research into how women seek out, attain, and hold those positions, I proposed this study fill that gap by investigating women who are currently in educational leadership positions. After questioning them through interviewing, including asking about how they identify themselves as leaders, and

analyzing the collected data with approved methods, I hoped to bring a greater understanding of why and how women became educational leaders in PK-12, and made recommendations for encouraging more women to seek out and obtain those positions.

\section{Research Questions}

Again, following are the research questions that I asked of the women:

1. What is the nature of female educator experiences in becoming PK-12 educational leaders?

a. What was the women leaders' paths to leadership?

b. What are the female educators' thoughts about women and educational leadership?

c. How do the female educators identify themselves as leaders?

d. How do the female leaders define what makes a good leader?

e. What recommendations do the women educators have for increasing the number of women in leadership positions?

\section{Theoretical Framework}

The theoretical framework that guides this research is Gender Identity Theory. Gender Identity Theory is a theory that evaluates how an individual's gender factors in with their 
identities and their experiences. Depending upon many variables, women may have differing involvement within their gendered experiences and that involvement can be positive or negative. The effects of such participation may significantly impact how the world works. For instance, women make up over half of the world's population, yet are continuously marginalized all over the world in many cultures, in many ways: they may not get paid the same amount as a man for the same job; they may not receive the same education or have access to the same educational opportunities; their healthcare needs are consistently overlooked, debated, legislated, and denied;

they may not have been granted the same rights as others in a cultural context. They are often undervalued as human beings in general (Clifford, 2007). The purpose of this research is to ensure that marginalized voices are heard (Hatt, 2017, Class Handout). The research will take into account the perceptions of knowledge that society knows to exist: transforming society demands that people explore power relations (Hatt, 2017, Class Handout).

\section{Type of Study}

This study was a qualitative one that involved interviewing at least fifteen female educational leaders, so that a greater understanding of their journeys were gathered and given audience. The participants varied in age, ethnicity, and years of experience in their roles, but the pool was limited to include principals and PK-12 school district central office personnel, such as assistant superintendents and superintendents. The participants were limited to this group because they are specifically assigned to fulfill the duties of educational leaders by their school boards and are expected to carry out prescribed leadership responsibilities in their buildings and school districts. The design of inquiry in this study was phenomenological, “...in which the researcher describes the lived experiences of individuals about a phenomenon as described by participants. This description culminates in the essence of the experiences for several individuals 
who have all experienced the phenomenon. This design has strong philosophical underpinnings and typically involves conducting interviews" (Creswell, 2014, p. 42). It was an imperative task to ask women questions about their experiences in order to give them an audience which may hear their perspectives, their feelings, their insights, their challenges, and their observations. Interviewing accomplished much more than surveying because surveys do not allow participants to go deeper and more elaborately analyze, which may often lead to other discoveries. Survey questions and answers speak for the participants. Interview questioning allowed the participant to speak for herself. Critics may say the topic of gender inequity has been hashed and rehashed, yet the disparities still exist today. Many have found that the reasons for that may have to do with the fact that women are repeatedly marginalized.

\section{Contributions of a Pilot Study}

I conducted a pilot study prior to this one in which I interviewed two female educational leaders with different questioning. I had not yet formulated some of the current methodology that will be in use for this approved study. The point of the pilot study was twofold: 1) to find out if interviewing participants would yield any data about my area of interest - what makes a woman go into leadership? and 2) to allow me to practice qualitative research, interviewing, analysis, etc. After one of the interviews, I answered a few questions about the experience and the data: 1) what were the main issues or themes that struck you in this contact? My answer: The participant became an administrator early on; she did not seem "shy" about explaining her accomplishments. She seemed aware of some of the issues faced by female educational leaders.

2) Summarize the information you got (or failed to get) on each of the target questions you had for this contact. My answer: See Table 1. 
Table 1

Pilot Study Summary

Question Topic

Background

Life Choices

Challenges, obstacles, barriers

Leadership style
Information

Early thoughts about becoming a principal and seemed to finish her education goals early in her life. She had much to say about goals. She exhibited much ambition to accomplish goals and encountered supportive people along the way. She used the word "strive" more than once, mentioned being raised in poverty as a motivator, and shared remarks about hard work and being action-oriented. Pregnancy and motherhood influenced her decisionmaking. Surprised by events in her life that helped her make choices. Thinking of her family and what could have been had she done things differently; contemplated regrets at times. Emotional responses often came through in answers, apparent through the use of words like "devastated", "boohooed", "sorry", "struggle", "sacrifice", etc. In discussing access to education and professional development, she gave credit to others more than once, took many classes, and explained much collaboration with others.

She came from a place of poverty and fear of failure was prevalent at times. She refers to the confusing lessons that presented themselves and that she often failed to understand them until much later. Other noticeable instances of challenge included her apparent lack of knowledge about certain opportunities, lack of time, encountering other women in the field who were not helpful or competed in a negative way with her. She spoke of bad leadership models she experienced along the way. Job opportunities would present themselves and she struggled with whether or not she was making the right decisions. She described how her leadership style (actionoriented, forging ahead) could present problems and how she used it to handle situations with defiant employees and cultural differences with school families. On the personal side, she spoke of much sacrifice in her social life, family life, time with children and husband, and health. Family and living difficulties would present themselves and pose dilemmas with hard choices. Spoke about who helped her be a good leader. Action-oriented leader who encouraged people to try

(Table Continues) 


\begin{tabular}{ll}
\hline Question Topic & Information \\
\hline & things, even if it was messy. Tried to lead by example, \\
never asking anyone to do anything she wouldn't do. & Crossed paths with people who mentored her and taught \\
her about leadership. Supportive people helped her get jobs, & survive in them; helped her finish her educational \\
endeavors and told her when she was at fault. These people \\
had different personalities and most of them were ones she \\
sought out and identified as mentors; most were unofficial. \\
Expression of surprise
\end{tabular}

3) Anything else that struck you as salient, interesting, illuminating, or important in this contact? My answer: Themes that I expected to surface through her answers, did - certain challenges, life choices, etc. She mentioned having more issues with other female educational leaders, which I had just read about in my research ("queen bee syndrome").

4) What new (or remaining) target questions do you have in considering the next contact with this site? My answer: What were the differences in how you interacted with males and females in your field experiences? Why do you think you learned more about leadership from bad models than good ones? Did you have more unofficial mentors than formal ones? Why? Why do you think you are surprised by some events or thoughts?

Predictably, I had a long way to go from that point to this point. The pilot study results and reflection that I did gave me further direction. The feedback I got from others about the pilot study helped me better understand what I was trying to find out, who to talk to, and question why I chose to focus on this topic and this research.

\section{Researcher Positionality}

Due to the nature of qualitative research design, every qualitative researcher must consider his/her positionality. Throne (2017) explained positionality: “...researchers must especially take account of their own position in relation to the research participants and research 
setting. In particular, the reconstructing of insider/outsider status in terms of one's positionality in respect of education, class, race, gender, culture and other factors, offer us better tools for understanding the dynamics of researching within and across one's culture (England, 1994; Merriam et al., 2001; Rose, 1997)" (para. 1). In regards to this study, I am a female educational leader and have encountered experiences related to my gender as an educational leader.

As a female PK-12 educational leader with ten years of teaching experience and ten years of administrative experience behind me, I find the reality of the disparity and previously mentioned report findings shocking (Superville, 2016). Despite the fact that the human resources, specifically the number of female teachers, are abundant, I am curious as to why the numbers of female leaders is lesser. Even though I have worked with many qualified and capable female educators in the past twenty years, I wonder why more of them do not go into PK-12 leadership positions. Consequently, that curiosity leads to me to reminisce about my own journey in my career and to my position as a female educational leader. I ask myself, "How did I get here? What events led to this state of being in my career and field? What path did I take? What impact did my gender have on the experiences? Was the journey easy or made difficult because of my gender? Was I treated differently because of my gender (as a teacher, as an aspiring leader, as a leader)? What is my definition of a good leader? What type of mentoring experiences have I experienced? Who helped me in my journey?" Asking these questions causes me to reflect about what I know and perceive to be true about my identity as a female educational leader. It also causes me to weigh how much my gender influenced events and experiences that led me to this place.

My path to the place I currently reside in as a secondary education administrator is one about which I am continuously surprised. As the oldest of six children, I was the first person in 
my family to go to college and I started at a four-year university as an undecided undergraduate. My parents knew that obtaining a college degree would be important, but that was the extent of their knowledge about how to navigate post-secondary life. After first semester of my first year, I reached a decision that, since I had previously excelled in reading and writing and enjoyed working with children, teaching English would be an enjoyable option for me. Once I became a high school English teacher, I never spent much time thinking about other career goals or advancement. About two years into teaching, I realized I could move up on the teacher's salary schedule in the contract if I returned to college and completed a Master's degree. I decided to take classes for a general administrator's certificate and degree purely because it was convenient (there was a cohort of people who were taking classes on Friday evenings/Saturdays). I knew I would learn some things that related to my field, but I had no intention and never saw myself as an administrator. Only one person ever expressed their sentiment that they could see me in that role. During and after obtaining that degree, I still did not intend to pursue anything other than teaching. The school district I worked in during that time did not encourage me to lead or train me, nor did anyone mentor me to pursue leadership opportunities. After eight years there, I moved back to my hometown, into another school district that had a reputation for being a difficult one to work in because of contentious union-administration relations and high poverty; they were experiencing high turnover and there was no end in sight. There, I moved up in the ranks quickly, becoming the English department head after one year and was the most experienced person in that department. I quickly became a mentor to several inexperienced teachers, receiving training in that area. The school district sent me to many other professional development offerings, covering a wide range of topics (AP teaching, literacy, curriculum development, etc.). 
After two years, a female central office administrator had a conversation with me that prodded me to apply for a dean's position that was set to turn into an assistant principal position. I did apply, but with great hesitation. On the one hand, I loved teaching and felt very effective at it. I was comfortable, self-assured, and knowledgeable in that role. It had been six years since I had obtained the Master's degree so I felt disconnected from that learning and from thinking about matters of school from that lens. On the other hand, I needed a new challenge and people obviously saw something in me that I did not see in myself. The woman who encouraged me to apply reminded me that I had been thinking with that lens regardless and that she saw me making the leap in a much easier fashion that I did. She boosted my confidence and I leapt. I became an assistant principal and spent four years in that part. The school and school district continued to struggle with high poverty and high turnover. They applied for and won a federal school improvement grant. One of the stipulations in the grant was that the school district must exchange the administration. Although I received performance ratings of an effective administrator and had good references, I had no choice but to look for other employment. I became an associate principal at another high school in another community and have been there up to this date. I came there highly recommended, and though I sought the promotion out of necessity, it has proven to be a good career move and others recognize me as a valid and capable leader with a good reputation. I have had more opportunity to grow and can see myself fulfilling other leadership opportunities at this point. Now that I have lived as an administrator for ten years, I see more and more how women are treated differently, have different experiences, and have to think differently in the role, therefore bringing different insights and have different definitions of what it means to be a good leader. They do that with or without mentoring and/or encouragement. 
As I went through the process to become an administrator and while performing those duties, I lived and witnessed many examples of how men and women have different experiences in educational leadership. For example, on one occasion, my male superintendent and I, along with a male athletic director were casually chatting at a football game. The superintendent asked us for an opinion about something relevant to the athletics program. He directed the question to me and the athletic director next to whom I was standing because the superintendent looked at both of us as he spoke. After a moment of thought, I began to verbalize those thoughts. The superintendent looked at me very seriously, cut me off in the middle of a sentence, and said, "I was asking him (pointing to the athletic director), not you (pointing at me)." Both the athletic director and I expressed shock on our faces; I stopped talking and the athletic director proceeded to answer. The two of them carried on the conversation and I remained silent, eventually excusing myself, embarrassed. The next day, the athletic director came to me in my office and apologized for the superintendent who the athletic director felt had clearly silenced me because of my gender. I communicated my thanks, but explained that the athletic director was not at fault and that I agreed that the way I was treated was because I am female. (I have never brought up the incident with the superintendent because he is my superior and I am not sure what consequences it would bring about, positive or negative. I only hope that I am in a position at some point to give him feedback about it as one that made me feel inferior because I am a woman.)

Another example that illustrates the difference gender makes in this field is that I am often the only woman in the room in meetings and have to be aware that my voice is different from others in that environment. People may look at me differently upon my entrance into a room; I usually notice that male eyes will look up and down my person, lastly landing on my 
eyes. Consequently, I am careful about my dress, wearing conservative clothing in order to ensure that I am taken as seriously as possible. Despite my efforts, males (and females) have commented upon my appearance at work (superiors and subordinates) and they have told me about my beauty, my smile, my hair, and have called names like "sweetheart" and "honey".

Often, as I made the journey to an administrator role, I recall several times when a committee of administrators, teachers and other staff hired a man instead of me because they explained they felt more comfortable with someone "manhandling" discipline with students or with someone coming across as more powerful with difficult students and families. In addition, once I became an administrator, I know of at least two males who were hired after I was and who were paid more for doing the same job.

I have been in countless situations where a man has felt the need to explain something to me, often in a condescending or patronizing way, even though I had already indicated I understood the situation and may have further questions. I have been talked over, cut off, and not given the opportunity to share my thoughts aloud. I have had to make myself clear that I was still speaking, not finished, and remind people at the table that I still need the chance to contribute.

Despite these experiences, I have learned many valuable lessons about leadership. I am careful to consider my gender and others when I work to lead in good ways. I think good leadership comes from drawing on valuable personal experiences that shape how we communicate and influence others. A good leader should be intuitive, a good listener, inquisitive, highly reflective, and able to manage balance. These skills require patience, organization, kindness, and openness. 
Considering the nature of my experiences, I took the following approach to pay attention to my positionality: I attempted to be "...acutely tuned-in to the experiences and meaning systems of others - to indwell - and at the same time to be aware of how one's own biases and preconceptions may be influencing what one is trying to understand" (Dwyer \& Buckle, 2009). Because I know the field and situations so well, firsthand, my positionality enhanced the research process in how the interview questioning came about or was enriched. I conducted "backyard" research (Glesne, 2011, p. 41) by studying female educational leaders who are in the same work setting (or field) as myself: PK-12 education. I was aware of the fact that this type of research could have led to issues with my understanding and analysis of the data collected; personal bias could have edged itself into the research. Also, I needed to consider possible adjustment and concession on the part of confidentiality. Bhopal (2010) examined the researcher as an outsider and an insider and how that role impacted the rapport between the researcher and the subject.

She argued that shared gender, identity, and experience between the two could create a high level of trust (p. 188). I agreed with Bhopal (2010) that trust can be established and I had the responsibility to protect the study participants; the data they provided could not be compromised as it could lead to placing them in a risky position. For example, if a leader reveals details about an encounter with her supervisor that could be considered discriminatory or unsavory, then I had to make certain that information was kept completely confidential and not allow it to expose her as it could be perceived as negative and someone may wish to retaliate in some way. Lastly, I made my position known to the participants before the interviews took place.

\section{Interviewing}

In a conventional qualitative study, interviewing is a tried and tested way of understanding the participants and their experiences. Having face-to-face, one-on-one contact as 
human beings is intimate and personal for both parties. People are social and open up to other people, especially those who attempt to understand them, their memories, and their experiences. However, a researcher cannot just throw any types of questions to the subjects and expect good, quality responses. Glesne (2011) recommended approaching quality interviewing in this way:

Think of interviewing as the process of getting words to fly. Unlike a baseball pitcher whose joy derives from throwing balls that batters never touch, you toss questions that you want your respondents to 'hit' and hit well in every corner of your data park, if not clear out of it - a swatted home run of words. As a researcher, you want your 'pitches' your questions - to stimulate verbal flights from the important respondents who know what you do not. (p. 102)

Interviewing well can elicit answers that are both expected and unexpected. A researcher can be flexible with the questioning as well, which helps ease shifts in the interaction, allows for different flows and pacing during the exchange of words, may dictate how far the interviewer can probe, and increases depth of inquiry. Interviewing allows people to be open about a topic and researchers may capitalize on the opportunity in order to garner the best possible set of data (Creswell, 2014, p. 45).

However, there are caveats with interviewing to which researchers must pay heed.

Creswell (2014) warned,

Interviewing in qualitative research is increasingly being seen as a moral inquiry (Kvale, 2007)...As such, interviewers need to consider how the interview will improve the human situation (as well as enhance scientific knowledge), how a sensitive interview interaction may be stressful for the participants, whether participants have a say in how their statements are interpreted, how critically the interviewees might be questioned, and what the consequences of the interview for the interviewees and the groups to which they belong might be. Interviews (and observations) should begin from the premise that a power imbalance exists between the data collector and the participants. (p. 137)

As long as the researcher is cognizant of Creswell's points and the dynamics involved, the interviewing should go well and the data will be useful. Lastly, Patton (2015) added to Creswell's warning and this caveat especially applied in my study: "Experiencing the program as 
an insider accentuates the participant part of participant observation. At the same time, the inquirer remains aware of being an outsider. The challenge is to combine participation and observation so as to become capable of understanding the setting as an insider while describing it to and for outsiders" (p. 338). Being an insider, I had to pay careful attention to Patton's advice and maintain a balance.

Lastly, I used semi-structured, open, and depth-probing interviewing (Glesne, 2016, p. 134). It was semi-structured in that I had a specific set of questions I wanted to use, but I left the options open so I was able to ask other questions. It was open interviewing because I was inclined to change or offer up questions as we talked, paying attention to the flow of the conversation and looking for openings to follow ways into their thoughts, anticipated or unanticipated. I interviewed in a depth-probing manner, looking for openings to ask questions in a scrutinizing, yet comforting, way.

During the summer of 2018, I conducted fifteen interviews with female educational leaders, each lasting approximately one hour. The total time spent interviewing came out to approximately twenty hours. In addition, I spent time in the work of contacting the women, scheduling the appointments, securing the locations, and transporting myself to the events. Throughout the study, I set out to collect data by recording the answers given to me by the participants.

I used a type of interviewing that was topical, which determined that I stay focused on an issue (Glesne, 2011, p. 104). I made certain to explain the purpose of the study to all involved prior to the interview so that they would have that information and context before they answered the questions (Glesne, 2011, p. 129). This step was important to the study because I asked the women involved how to address the research problem, so I needed them to know about the 
problem itself. Because I asked particular, pre-written questions within a social interaction, I had an active role in producing the data (Glesne, 2011, p. 47). Additionally, I asked questions in a natural progression so that people would feel comfortable speaking first about what they know for sure: describing their personal paths to leadership, the leadership qualities they possess, etc., then moving on to deeper topics: descriptions of good leaders, the role of gender identity in educational leadership, etc. I kept in mind that my role as the interviewer was one of participant. "A poststructuralist theoretical assumption about interviewing is that if interviewers take a neutral stance, 'they create a hierarchical, asymmetrical (and patriarchal) relationship in which the interviewee is treated as a research 'object'" (Glesne, 2011, p. 106). Instead, I chose to align my interviewing tasks, with the "...perspective [that] suggests that the researcher engage with participants in cooperative projects that focus on dialogue, collaboration, and mutual selfdisclosure" (Glesne, 2011, p. 106). That interaction included sharing stories, commenting on insights, validating information, and keeping a conversational tone between the study participants and me. Glesne (2011) also reminded me to be aware of the nonverbal feedback that may have been present during the interviews (p. 119). I paid close attention to the body language of the women and my own, looking for signs of inattention, discomfort, or confusion. Fortunately, I was able to conduct the interviews during the summer. This timing made a difference because, although, at that time, educational leaders still have many work demands, students and most of the staff are gone from the buildings at that time and people generally tend to be more relaxed, as if taking a deep breath. I believe this setup made it possible for me to sit with these women for an hour or more at a time and I never sensed that anyone felt rushed or bothered. In fact, I was surprised that so many busy, in-demand leaders would be so generous with their time - not for lack of caring, but for lack of spare time. Schools, districts, and its 
administrators are bound to rushed deadlines and the cyclical forces that often require their immediate attention.

As I asked questions, I tried very carefully to model some of the qualities of a good interviewer that Glesne (2011) mentions in her explanations of qualitative research methods (p. 121-128). She shared that a good interviewer is 1) analytic: I asked for more explanation when unique answers came up; 2) therapeutic: "Some situations lend themselves to, and indeed, call for more self-disclosure and sharing during the interview. Whatever the situation, you work to set the tone and to build relationships are that your respondents can be as protective of spotted owls or as supportive of loggers' rights as they really are" (p. 123); 3) patiently probing: I often paused at length and used what teachers call "wait time" to allow interviewees time to think about their answers and process questions in their heads; 4) aware of power and hierarchy: I understood the relationships between me and each individual woman and how the dynamics of that relationship could impact or influence the outcomes of the interview and the data; for example, I work with some of the women and have served under a few of them as well. I am cognizant of the fact that I am placing them in a position that is vulnerable and one that dictates strict use of discretion and confidentiality; and 5) caring and grateful: I am constantly reminded of the fortunate position in which I have been placed and how having access to all kinds of people is a rewarding part of research, even if I did not anticipate meeting some of them and I did not see the benefit of speaking with them (p. 128).

\section{Question Development}

I thought about the questions I would use in the interviews carefully, as I wanted to elicit responses that would provide abundant insight about how the women came to where they are now, where they've been, and how their gender identity interacted with those experiences. In a 
pilot study I conducted during my dissertation coursework, I interviewed two female educational leaders who were willing to allow me to practice with them. I produced a list of questions I thought would be helpful in garnering the information I needed. The list ended up being long and wordy in places. The questioning was very broad and sometimes vague. After interviewing, I sensed I had not collected the answers I needed to report relevant findings. I spent more time speaking of details that did not actually get to the heart of the research. As I thought about the questions for this study, I knew I had to complete a few steps in order to present the best questions. Glesne (2011) recommended shaping questions by making sure none might be answered by just "yes" or "no", rewriting questions that have too many questions within them, and ridding the interviewing of leading questions (p. 106-107). My opening question was what Glesne (2011) called a "grand tour" question: one that asked the "...respondent to verbally take the interviewer through a place, a time period, a sequence of events or activities, or some group of people or objects" (p. 108). (I found that question to be one that put the participants at ease, one they could easily answer without hesitation: what was your path to leadership? It turned out to be a great starting point and I was able to easily transition to some of the harder questions.)

Additionally, I consulted with my methodologist and, after some wordsmithing, I was able to craft questions (see Appendix C for Interview Protocol) that were grounded in the theoretical framework of Gender Identity Theory. Glesne (2011) acknowledged that "The theory...underlying some behavior is an important source of questions" (p. 105).

\section{Field Notes and Analytic Memos}

As I conducted the face-to-face interviews, I kept field notes in a notebook as we talked so I could refer back to them during and after the interview (Glesne, 2011, p. 71). Often, a participant would mention something that I wanted to know more about. Instead of interrupting 
her, I would allow her to continue her explanation and I would jot down a note or two and try to come back to it later in the conversation. Additionally, after the interview, I referred to the field notes and thought about how or if the ideas would come up in the remaining interviews. In turn, I wrote analytic memos and began to list themes (Glesne, 2011, p. 189). Both the field notes and the memos helped me think about and formulate follow-up questions throughout the study.

\section{Data Collection}

I interviewed participants using a bank of approximately five questions that inquire about the nature of their experiences as female educational leaders. Miles, Huberman, and Saldana (2014) explained that qualitative data is typically collected "...in the form of words - that is, language in the form of extended text...The words we collect and analyze are based on observations, interviews, documents, and artifacts" (p. 10-11). The interviews took place between the individual participants, each and me separately, and within a closed-door environment such as an office or in a home, where confidentiality, privacy, and recording quality were well-maintained. If a potential participant wished to interview in a specific, preferred location of her choice, I tried to accommodate the request, as long as anonymity, confidentiality, privacy, and recording quality were well-maintained. Miles et al. (2014) recommended this type of setup for interviewing to be “...carried out in close proximity to a local setting for a sustained period of time" (p. 11). It served the study well to allow the potential participants to be involved in a preferred place of comfort to them, so it was reasonable for me to accommodate that preference and that happened when possible. Miles et al. (2014) described characteristics of sound qualitative data by explaining that it is present when there is a "...focus on naturally occurring, ordinary events in natural settings..." (p. 11). Prior to the acts of interviewing and recording, I ensured the location was acceptable and usable. 
Participants and I engaged in interviews face-to-face, one-on-one. Participants answered a set of interview questions in person, asked by me, inquiring as to the nature of their experiences as women in educational leadership. Their voices were recorded during the interview. The participants were asked to clarify their answers and/or possibly be interviewed more than once. I was hopeful that participants would be able to provide historical information and context through their responses. It proved to be advantageous to interview participants because they were able to provide historical information and context through their responses. The questioning was controlled as well. For instance, if so inclined, participants were able to get clarification from me as we talked. Some limitations of interviewing included the fact that the collected information was filtered through the participant's views. Typically, interviewing took place in an area that was designated and, perhaps, not in a natural setting. The fact that I am also a female educational leader could have impacted responses, as bias may present itself. Lastly, some participants may not have been as articulate or clear in their answers, which could be problematic during data analysis.

Designed by me, the interview protocol included five general questions with probing questions included as a subset of each general question. The general questions, which were formulated from the literature review and based on my experiences as a female educational leader, prompted open-ended answers/data. In addition, as I worked with the Gender Identity Theory that is connected to the framework for this research, I kept in mind that "The theory, implicit or explicit, underlying some behavior is an important source of questions." Gender Identity Theory and the disparity helped form the questions (Glesne, 2011, p. 105). Glesne (2011) also confirmed “...theoretical assumptions of your methodological approach also shape the questions you ask" (p. 105). For example, I assumed that gender identity has an influence on 
how the women perform in their roles as leaders. Therefore, I asked questions that garnered their thoughts about that assumption.

The questions (items) were validated for content validity before they were used for interviewing. In addition, the interview protocol was semi-structured, which Glesne (2011) explained to be interviewing in which "Questions may emerge in the course of the interviewing and may add to or replace pre-established ones" (p. 102). The interviews were recorded on an approved recording device and later transcribed so that the words could be analyzed as data.

\section{Participants}

I interviewed fifteen current and retired (former) female educational leaders of various ages (over the age of eighteen) and different ethnicity. They were building administrators, principals, and assistant superintendents. The reasoning in choosing such a population is that they have the first-hand account and knowledge of the experiences the research seeks to understand and analyze. I have encountered individuals through my work in education for the past twenty-five-plus years. I have met the individuals through work in the field of education such as committee work, meetings, and day-to-day operations in schools. Contact information for all the potential participants was obtained by referring to websites, email addresses, and school phone numbers, all of which are publicly displayed on the Internet in public school directories (online or in paper format). The type of purposeful sampling I used is referred to in qualitative research as snowball sampling. Snowball sampling involves obtaining "knowledge of potential cases from people who know people who meet research interests" (Glesne, 2011, p. 45). Patton (1990) explained it as an approach used

...for locating information-rich key informants or critical cases. The process begins by asking well-situated people: "Who knows a lot about ? Who should I talk to?" By asking a number of people who else I should talk with, the snowball gets bigger and bigger as new information-rich cases accumulate. In most programs or systems, a few 
key names or incidents are mentioned repeatedly. Those people or events recommended as valuable by a number of different informants take on special importance. The chain of recommended informants will typically diverge initially as many possible sources are recommended, then converge as a few key names get mentioned over and over. (p. 176)

I aspired to allow the "snowball" in this study to become no bigger than ten to fifteen participants because I believe the interviews would be rich enough to reap quality data. Snowball sampling is a logical choice for me to use in this study as I have access to many female educational leaders in different types of surrounding school districts, all of whom have diverse backgrounds. I approached all of the participants in person, over the phone, or via email.

\section{Data Analysis}

Data analysis happened in approximately six steps, as recommended by John W. Creswell (2014) in his text, Research Design: Qualitative, Quantitative, and Mixed Methods Approaches, Fourth Edition.

First, I organized and prepared the data for analysis. Since I recorded all of the fifteen interviews, I was able to transcribe them into word-processed documents. Afterwards, I scanned and surveyed all of the material to ensure completion and that they accurately reflected the wording used in the actual interviews. The twenty hours of interviews produced two-hundredseventy total pages of raw data.

Secondly, after I completed the transcriptions, I read them again in order to get a general sense of what was available and presented. I reflected about the data, with the goal of understanding the overall meaning of the data. I used Creswell's (2014) suggested questioning, asking, "What general ideas are participants saying? What is the tone of the ideas? What is the impression of the overall depth, credibility, and use of the information?" (p. 247). As I strived to answer these questions, I made side notes and wrote analytic memos. 
Third, I coded the data. Creswell (2014) defined coding as, “...the process of organizing the data by bracketing chunks (or text or image segments) and writing a word representing a category in the margins (Rossman \& Rallis, 2012)” (p. 247). I gathered groupings of words (sentences, and possibly, actual quotes) and categorized them with labels, named in the form of terms. This coding is descriptive coding. Miles, et al. (2014) defined descriptive coding: "A descriptive code assigns labels to data to summarize in a word or short phrase - most often a noun- the basic topic of a passage of qualitative data" (p. 74). In addition, I used Tesch's (1990) eight steps used in forming codes (Figure 2).

1. Get a sense of the whole. Read all the transcriptions carefully. Perhaps jot down some ideas as they come to mind as you read.

2. Pick one document (i.e., one interview) - the most interesting one, the shortest, the one on the top of the pile. Go through it, asking yourself, "What is this about?" Do not think about the substance of the information but its underlying meaning. Write thoughts in the margin.

3. When you have completed the task for several participants, make a list of all topics. Cluster together similar topics. Form these topics into columns, perhaps arrayed as major, unique, and leftover topics.

4. Now take this list and go back to your data. Abbreviate the topics as codes and write the codes next to the appropriate segments of the text. Try this preliminary organizing scheme to see if new categories and codes emerge.

5. Find the most descriptive wording for your topics and turn them into categories. Look for ways of reducing your total list of categories by grouping topics that relate to each other. Perhaps draw lines between your categories to show interrelationships.

6. Make a final decision on the abbreviation for each category and alphabetize these codes.

7. Assemble the data material belonging to each category in one place and perform preliminary analysis.

8. If necessary, recode your existing data.

Figure 2: Tesch's eight steps in the coding process. This figure lists Tesch's eight steps in the coding process.

In addition, Creswell (2014) explained that codes could fall into three categories:

1. Codes on topics that readers would expect to find, based on the past literature and common sense,

2. Surprising codes (ones that were not anticipated at the beginning of the study),

3. Unusual codes that may be interesting to readers. (p. 248) 
Furthermore, since I delved into the arena of social sciences, I took Creswell's (2014) advice, the traditional route, and "...develop[ed] codes only on the basis of the emerging information collected from participants" (p. 248). Building patterns, categories, and themes, I organized the data into abstract units of information. The participants helped in the analysis by identifying themes as well. Through their interview answers, they provided formation of themes that helped with data analysis. It was a possibility that the initial plan for research could change, depending upon how the participants answered and how well I articulated and presented the interview questions to them.

Fourth, during and after coding, I formed a description of the participants and the themes. It is useful for readers to have a description that explains the details that make up the data for the study. Context is important to readers. In addition, descriptive codes were turned into themes that were then included and discussed in the findings (or recommendations) of the study. I provided more than one perspective from participants and supported the presentation of those perspectives with direct quotes and other specific evidence. I analyzed themes in the individual cases and across different cases. I also formed theme connections.

Fifth, I represented the data in a variety of ways in the study and during analysis. The description and themes were detailed in a narrative for the audience. The narrative discussed chronology, if needed, and an explanation of themes. I included paraphrasing of ideas and direct quotes from individuals. Visual text supported the discussion of the data and conveyed analysis in the formats of tables, charts, matrices, and figures. For instance, descriptive details about participants are displayed in matrices/tables (Glesne, 2011, p. 200). By pulling themes from the first data set that explained the paths women took to leadership, I was able to use that 
information and formulate descriptions of the participants in a narrative format and displayed descriptive details in a visual way.

Lastly, I interpreted the data. Creswell (2014) recommended:

Asking, "What were the lessons learned?" captures the essence of this idea (Lincoln \& Guba, 1985). These lessons could be the researcher's personal interpretation, couched in the understanding that the inquirer brings to the study from a personal culture, history, and experiences. It could also be a meaning derived from a comparison of the findings with information gleaned from the literature or theories. In this way, authors suggest that the findings confirm past information or diverge from it. It can also suggest new questions that need to be asked - questions raised by the data and analysis that the inquirer had not foreseen earlier in the study. (pg. 249)

One of my goals in this study was to make recommendations based on the findings and address the research problem. The research problem is one that calls for reform.

\section{Authenticity and Credibility}

\section{Validity/Trustworthiness}

There are several strategies qualitative researchers may use in order to check the accuracy of their findings. These steps are necessary in qualitative studies so the audience and academia know that the research is valid. Since qualitative procedures rely on text and image data, some people may question it in ways they would not question qualitatively-collected data. I also considered how to address trustworthiness in this study. I considered Glesne's (2011) nod to work by Hollway and Jefferson (2000). Hollway and Jefferson (2000) identified four questions that researchers should ask themselves when working with data:

1. What do you notice?

2. Why do you notice what you notice?

3. How can you interpret what you notice?

4. How can you know that your interpretation is the "right" one? (p. 210) 
I asked myself those questions throughout the interviews, in writing field notes, in writing analytic memos, and in analyzing and interpreting the data.

Following are three strategies I used to convey accuracy in the data (Creswell, 2014, p. 251-252).

\section{Member Checking}

After I completed an extensive analysis of the data, I proceeded to complete the next step of member checking in order to further validate of the data analysis, “...taking the final report or specific descriptions or themes back to participants and determining whether these participants feel that they are accurate" (Creswell, 2014, p. 251). I did not ask the participants to look at the raw data (interview transcripts), as this request would be time-consuming for the participant. Instead, I asked each participant to peruse the final report, descriptions, and/or, the themes. This request came after I analyzed the data and wrote up a final report, descriptions, and themes. Using email especially, contacting the participants to check accuracy was very feasible. I communicated some highlights of the analysis with the interviewees. I asked them to read the summary and share their thoughts about the accuracy of the information. Several replied to me about the findings in a mostly generic manner and commented about specific points they found interesting, e.g., crying and competitiveness.

\section{Clarify the Bias}

Creswell (2014) recommended clarifying any bias I may bring into the study by explaining how my role as a female educational leader played into it (p. 251). I attempted to do so in the section of this paper that regarded positionality. Also, since bias can often present itself during questioning, I tried very hard to remain objective during questioning so that participants would be allowed to answer as frankly and as descriptively as possible. At a certain point, 
however, I realized that I could not completely remove the mantle I wear as a female leader. It was true that I was able to speak in a common language to the women and that questioning and interviewing fell into a conversational rhythm at times, but this effect benefitted the data collection by producing more frankness in the answers. We often engaged in banter that used common terminology and references related to the field of education, educational leadership, women, etc. It is true that I presented a question differently to another female educational leader than I would to, for example, an accountant. It was also true that less explanation or context was given when I questioned the participants because all involved have had exposure to similar experiences in the career field at least. I noted that the women disclosed richer, deeper insight. For example, I did not have to explain the process people must follow in order to obtain an administrative position. The requirements are typically standard in the field and would not differ as the women followed their paths to leadership. Therefore, the women were free to talk about other factors that played a role in their journeys.

\section{Spend Prolonged Time in the Field}

I have worked in the field of PK-12 education since 1995. I have first-hand knowledge about the inner workings of public education in the United States through my experience as a teacher and an administrator. Because I have this experience, spending prolonged time in the field was a very reliable way to check for accuracy and aid in proving the validity of the findings (Creswell, 2014, p. 252). I was able to complete this step by simply remaining on my career track and continuing my long tenure as an educational professional and leader, especially as I conducted this research. I understand the inner workings of public education and what it means to be a teacher and an administrator - while doing it as a woman. As the women spoke about their experiences, their gender identity, and its relation to their work, I was able to empathize, 
probe, and compel them to express themselves in the deepest ways possible. In turn, I was able to validate their answers because I am one of them and have shared experiences with them in similar ways.

\section{Limitations}

There were limitations throughout the study (Glesne, 2011, p. 212). For example, I was not able to ask some questions during the interviews because I had limited time with the individuals. In addition, there were people I wanted to interview who were unavailable or unwilling to make time to sit and talk with me, although I am certain their insight would have proved valuable to this study. I reached out to a few superintendents and they were indisposed at the time of the study. I would have liked to talk with them and get their perspectives. Due to my own time and transportation issues, I was unable to go as far away from my own locale as I would have preferred. In addition, I was unable to get in touch with any female administrators in their 20s, and although harder to come by, I would have preferred to gather information from someone in that position.

\section{Consideration of Ethical Issues}

In any research process, there may be ethical issues to consider. First, I sought out participants who I do not supervise directly. I am an active member in the field of education and have had many interactions with a number of female educational leaders. I am also one of them. At times, I interviewed participants with whom I have worked on committees and involved myself with in various education-related activities, events, functions, etc. I approached each potential participant and explained the purpose of the study, along with the methods of collecting data. Because the study involved research with human subjects, ethically, I followed the proposed set of steps submitted and required through the Institutional Review Board (IRB) at 
Illinois State University. One of the steps included procuring training and certification through the Collaborative Institutional Training Initiative (CITI), which I completed. The training covered potential ethical issues and how to avoid compromising the participants and the study. In soliciting participation from identified subjects, I followed a script that asked participants to engage in the study without receiving compensation in any form. I predicted that most participants involved themselves because they trust me and/or they want to help identify themes and solutions regarding the research problem/question. That trust in me was present because my reputation is known to be trustworthy. I have spent years working closely with and building relationships with colleagues, male and female. I also have a friendly, approachable, humorous personality around which people tend to feel comfortable. I did not anticipate that not providing compensation would be problematic because, being educational professionals, the participants are typically naturally helpful in teaching and learning situations and they understand the value of research such as the kind proposed. In addition, since the interview questions asked about personal, first-hand experiences, the participants felt very comfortable in sharing tales and examples. Each participant was asked to sign an Informed Consent form (see Appendix C). The participants were allowed to withdraw from the study at any time. In order to minimize personal or professional risk as a result of merely participating, the data collected was anonymous, indicating that the participants were not identified either directly or through identifiers. The anonymity helped to increase their ability to provide honest and more meaningful data. Pseudonyms were used in place of participant names and institutions. Additionally, any potentially identifiable information was redacted from the report. Depending on its nature, data was kept in different places. The interview recordings and transcriptions were saved on the coprincipal investigator's password-protected laptop computer and in the co-principal 
investigator's Illinois State University's Microsoft Office 365 account in Microsoft Office Word program. The signed informed consent forms were kept in the co-principal investigator's home. They were filed in a container and stored away in a closet.

\section{Chapter III Summary}

Chapter III explained the methodology used in the qualitative study. After re-stating the research problem and research questions, I described the research paradigm used to guide the research. I justified why a qualitative study works best to address the research problem and questions. As in any qualitative study, I discussed my positionality and how it may influence the study. Regarding data, I explained how the data was collected, what it consisted of, the research context, and the participants. After data was collected, it was analyzed. Data analysis happened in several steps that I explained. Furthermore, I explained the ways I tested the data collection and analysis for validity, utilizing a few strategies. Before reporting the findings, ethical issues were explored. Next, Chapter IV will provide descriptions of each participant. References are provided. 


\section{CHAPTER IV: PARTICIPANT DESCRIPTIONS \\ Descriptions of Participants}

In this chapter, I provide some context about the study participants, expanding upon the initial basic information shared in Chapters I, II, and III. It is important to give background knowledge in this study as it helps the research become fuller and more complete. "Description involves staying close to data as originally recorded...draw[ing] on field notes and interview transcripts, allowing the data to somewhat 'speak for themselves' (10). This approach answers the question, 'What's going on here?' (12) and the narratives of descriptive analysis often 'move in and out like zoom lenses' (17) selecting and portraying details that resonate with the study's purposes" (Glesne, 2011, p. 208). The following description includes details that can place readers into the lives and experiences of the participants and the study.

\section{BP}

$\mathrm{BP}$ was interviewed just before she began duties as a building administrator. She previously taught at the secondary level (grades 6-12) in three different school districts for several years. During her time as a teacher, she was able to serve on several committees. Early in her career, she made it a point to surround herself with people who were like-minded which she believes helped her become an educational leader who focused on what is good for students and the school. Since she had experience in more than one district and some were larger, some smaller, she had the opportunity to lead in various ways with a lot of freedom. She was able to tap into and perpetuate her love of creating systems, implementing protocols, and working with best practices. Over the course of her career, she encountered many female administrators who she credits with encouraging ("nagging") her to pursue her administrative licensing. She describes the leap to pursue the administrative route as "biting the bullet", as if she was fighting 
against a current with which she did not quite want to go along (BP, personal communication, May 31, 2018). Unlike many of the older participants in this study, she was required to participate in a newly-required semester-long administrative internship in which she was able to experiment with her talents and areas of interests to try to implement with different projects. She garnered great satisfaction from that work and felt the effects of quality support for her endeavors in that experience. When it came time to apply for positions, she ended up having a few options and settled on a job in the district in which she had interned. As far as the influence of gender throughout her career and leadership pursuits, she was able to share details about specific experiences. She learned afterwards that she had beaten out a male for a job. She also learned that she had almost lost leadership opportunities because she was not a male. She could cite instances where she knew people perceived males and females differently and perpetuated misconceptions (i.e., females are nurturers and, therefore, cannot be disciplinarians). She could point to occurrences in history that she was aware of in which women were considered less than qualified or capable. All that knowledge played a role in how she navigated within her position. She also attributed her success and need to help others in leadership to the fact that she had a baby at the end of her senior year of high school, has a supportive family (mother, father, siblings), and works as a single mother.

\section{BT}

BT is an educational leader who has taken a non-traditional path to where she is today. She began her adult life working in the food service industry. After experiencing setbacks in that field and having her own child be diagnosed with special needs, she thought about how she could participate in more meaningful work, so she decided to pursue her degree in education. Once in the teaching field, she found she enjoyed working with teams of teachers, often collaborating. 
More and more, she took on the role of expert, especially regarding use of technology. Her motivation to focus on that area was that of thinking about how to help students with special needs and how technology could be the "great equalizer" for those kids. Down the line, she began to hear encouragement from others that she had the potential to fill a leadership position in the district, one that would focus on instructional coordination. Once in that role, she slowly began to feel isolated, as she was the only person in a solo position: "I didn't have a colleague in anyone...I really have felt like I've been on my own a lot. Don't really fit in with the support staff and then I'm not part of the administrative staff" (BT, personal communication, June 7, 2018). Though she was expected to show leadership, she had no peers to share duties with or with which to collaborate. Eventually, she was promoted to assist another director in the same district, a leadership position in which she has been encouraged and supported and in which she has a bit more authority to make certain decisions. Throughout her interview, a sense of self-doubt and lack of assertiveness pervade, mainly because she perceives she has been placed in positions that discourage a strong voice. She is aware of the fact that she considers herself a people-pleaser and is aware that her gender may perpetuate that kind of behavior. She recognized that her greatest supporters were mostly women, who convinced her time and again to do things she still does not feel she is capable of doing. She referenced her family background and childhood experiences quite a bit and explained the influence her mother had over her choices. That influence was mainly negative, with her mother discouraging her from a career in education while she herself held a job as a principal. Her father was always present and positive, but she does not credit him with making a lasting impact as far as guiding her towards leadership. 


\section{DC}

DC is a district leader who I interviewed just as she was taking on a new position, a promotion at that. She knew at a young age that she wanted to be a teacher and never wavered from that goal. She enjoyed teaching and had no interest in pursuing educational leadership until a colleague decided to go back for a degree in educational administration and wanted her to join him so he would not be alone in the endeavor. After much persuasion, she eventually agreed to join him. As she went through the process, she discovered that her career interests were piqued through coursework and that she could do more to help more students as a leader. She referenced several mentors along the way, mostly male, who helped her focus on her priorities and guided her to arrive where she is presently. Those mentors include her father, a principal, a superintendent, and athletic coaches. Since she had also been an athlete, she was able to share details about experiences in that realm and how it helped her in leadership, experiences that the other study participants were not able to reference. One of her insights about how gender has played a role in her leadership came about as she shared that she had been labeled a "bossy" child and that her school principal tried to help her manage with that moniker by suggesting she collaborate in the work to be done. She did not debate that she was a "bossy" girl and implied that it was a personal quality that had been cultivated over time. Throughout her interview, she conveyed that her overall feelings about how gender plays a role in educational leadership are very matter-of-fact. She did not blame or express frustration. "So yeah, through my whole journey I've always been encouraged by men and women and I've never felt like I'm any different" (DC, personal communication, July 7, 2018). After a certain point, however, she begins to acknowledge that recent events in her career path were influenced by bias and that perceptions about gender were beginning to play a role in the interactions, and not in a 
productive manner. She had begun to understand that being a woman in certain situations was not always an advantage.

\section{DI}

DI was one of the older women who agreed to participate in the study. She was less than one month from retiring when we sat down and talked. Achieving the age of 60 now, she had worked in the public school system since she was in her 20 s, taking time off in the middle for several years to stay at home with her children while they were young. One of her most pivotal moments as she grew up involved being denied the opportunity to participate in a soapbox derby because she was female in the small, rural town in which she grew up. She recalled being upset by that rule and decided that from that point, she would not consider herself different from the boys any longer. She went on to major in teaching a content area that was not one traditionally pursued by women, then served on the school board in a district that eventually consolidated with other smaller districts around them. She was the only woman on that board and she cited that experience as one that would later influence her decision to leave teaching (after her return to it) and purse an administrative role. Upon her return to teaching in a larger district and during her journey, she felt much support from others and was able to be promoted to various positions in leadership throughout her career. She had struggles, too, especially as she navigated in the field as a woman. She spoke to one of those struggles: "I think, as a woman, fortunately or unfortunately, sometimes you straddle this line of you can be a certain amount of assertive. But being too assertive is not as acceptable for women as it is for men. And so you have to realize that and understand it. I don't always remember it [laughter]. I wish I remembered it more often, probably. But I think I've tried to combat that from just being as honest and transparent as I can be" (DI, personal communication, June 1, 2018). 


\section{EX}

EX began her adult life outside of education, but eventually became interested in teaching. She obtained her education degree and procured a job in teaching. While there, she was encouraged to take out after her administrative degree, never intending to use it. After a while, she was offered an opportunity to use her other skills at the district level, after which she moved on to a regional position of leadership, working with schools across counties. One of the most valuable lessons she learned from that time was that empowering people along the way is the responsibility of all leaders, especially women. If that does not happen, we risk losing valuable, effective programming and influence for students. Her view of herself is a topic she touched on several times throughout the conversation. She described herself as a generalist, someone who knows very little about lots of things, but is able to articulate faster than most people. Since she's been able to understand that about herself, she has been able to move up and along the leadership chain. She is very aware of the differences in working with men and women and puts different strategies in the works throughout her dealings. "The one thing that I've learned about working with men is you just quit talking. You just say it. Well, lucky for me, I'm pretty direct anyways... Women, you have to get more of a personal relationship with men, especially being a woman; there's a fine line on that relationship [piece]" (EX, personal communication, June 4, 2018).

\section{KH}

$\mathrm{KH}$ is a principal at an elementary school in a high need district (students in poverty, diverse learning needs, etc.). She taught elementary school for several years, serving on committees and subbing for other elementary principals. In addition, she worked with a teacher who she felt did not "do right by kids" and what she witnessed on that end inspired her to apply 
for administrative positions so she could try to combat those bad practices. She encountered many leaders along the way who encouraged her to lead; however, a principal who was retiring made it a point to discourage her by telling her husband that she would never get the job from her first interview attempt. KH proceeded to believe him; she did not feel good about the interview she attended and told herself she would not get the job. Therefore, she was very surprised when she, in fact, did get the job. She found out later that her previous building suffered in her absence and that knowledge, depressing to her as it was, affirmed for her that she had made an impact, even while she was teaching. During the talk with me, she spent quite a bit of time wondering why people did not build each other up and pointed to her experience in trying to get a job, along with other situations she had observed in which women did not support each other. She felt that even though she received some good mentoring, the negative experiences were more powerfully ingested and were catalytic in her reality.

\section{KD}

$\mathrm{KD}$ is a building administrator who taught at the secondary (grades 6-12) and postsecondary level (college) for many years before deciding to go after her degree in educational administration. Her original intent was to obtain an instructional coaching position, which she did not get. At that point, she essentially asked herself: What now? Where do I go from here? After hearing an administrator ask her if she would ever be interested in being a leader, she asked herself: Why not me? Like others who participated in this study, KD observed a leader who was ineffective and, therefore, became inspired to do better because she believed she could do so as a result of learning what not to do from him. She got further confirmation she was making the right choice when she was immersed in her coursework and her professors seemed to value her 
opinion and supported her stances in many instances. She pointed out that her interactions with

her male professors were often different than those of her female classmates:

Because I feel like there were other females in the program with me, and-- I'm trying to kind of figure out how I can phrase this. Because some of the women in the program, my colleagues in the program, they could be kind of abrasive, and I feel like that was kind of a product of-- they felt like they had to make sure their feelings were heard, and their opinions were heard. In dealing with the male professors, I think it's just-- yeah, I was thinking about how I communicated with them, you didn't have to worry so much about how you might phrase something. It was more just get kind of to the-- get to the nuts and bolts of what your question is, don't worry about phrasing it a certain way, or hurting anyone's-- [feelings]. (KD, personal communication, June 27, 2018)

Another unique perspective KD brought up as she thought about her journey into

leadership is that the further along she got, she began to feel more and more a sense of separation from her peers, as if she knew she thought differently about education and what is best for students:

And even my friends, my colleagues, when I taught. I always felt like there was kind of a separation. I never really felt like I fit in. Even though I had got along very well with them. But I never was the one that they were like, 'Oh, let's go hang out. Let's do this.' I was always kind of treated a little bit differently. Probably because I was doing so much professional development with them. From my second year in that district, I was leading professional development. Doing things with curriculum. I was put on our staff development committee. I was put on our district leadership team. And I think that kind of started setting me up too. (KD, personal communication, June 27, 2018)

\section{MB}

MB never intended to go into educational leadership. She was interested in guidance counseling and, after substitute teaching for a bit, intended to go back to graduate school. While teaching, though, she was identified by the building administration as possibly having a knack for leading. They called her to perform within different positions and put her into places where she had to practice leadership, which she continually thought was only a temporary situation. Later, she found out that those people were informally testing her to find out if she had what it took. They were mentoring her all along, but trying to guide her to see what she did not see, that 
she could lead. She was persuaded to procure her degree in educational administration while filling in for administrators who were absent in the office. Soon after, she was hired full-time and was happy with her appointment. Still, she never saw herself going further (principalship, etc.) and eventually applied for and obtained a leadership position at the state level in school athletics. In that position, she brings a perspective her colleagues do not have, that of a building administrator. At first, she found it difficult to be heard by the existing team, but after being joined by another male who also had worked as an administrator in schools, that predicament seemed to subside. She wonders, though, if that happened because he is a male and if her voice was ignored subconsciously because she is a woman. Along the way, she did receive mentoring and always felt she took advantage of the support that was available.

But I felt like there was always that opportunity to talk with somebody if I needed to... So I think just having those various people to talk to that would lend support. And it wasn't always the pat on the back, 'Hey, you can do this.' It was truly, 'I don't have a lot of expertise or background in this, so I'm going to need to pick your brain.' I think that's one of the things that was most helpful to me. (MB, personal communication, June 11, 2018)

\section{MI}

MI is a director in a school district, whose main focus is to oversee the capacity of a major required function in the district. She began her career in teaching, but soon after took thirteen years off to raise her children while her husband ran a business. She re-entered the profession as a paraprofessional (an aide) in a classroom, but did not stay there long, as she was soon sought after to fill a full-time teaching position. After a bit, she was inspired to get a Master's degree by someone she knew to be a sub-par teacher down the hall who was making more money than she, which made MI resentful. She channeled that resentment into productivity. The degree she sought was not in educational administration, but did require her to take a class on school law, which peaked her interest. Like others, her intent was to stay in 
teaching and use her knowledge to support other leaders, not to be the leader. During her time as support personnel, she began to understand that she enjoyed the administrative role more than she originally thought she would; she acted on that desire to move ahead by applying to be a building administrator and was able to get it through consulting about recommendations to change current bad practice in her school district at that time. She credited a female mentor with pushing her to pursue leadership roles about which she would have otherwise not thought twice. Upon MI's expression that she did not feel ready to move forward, that mentor said to MI, “A man would never say he wasn't ready", which prompted MI to consider herself qualified. The mentor reminded MI that she had completed the coursework, she had earned the degrees, she had the experiences, and therefore, she was qualified, which MI took to heart. The mentor pointed out that a man would just apply, just go for it and not think twice about it. MI considered the advice and ended up in her current position as a director for a fairly large, urban school district. Now that she has been in her current position for four years, she agrees with her mentor. She understands that you learn much on the job and you will never be "ready". She struggles to understand how she had so much self-doubt and how she let that inhibit her progress:

I've learned a lot. Yes, and I think there's things you can learn. Do you know what I'm saying?...I don't know how I could have been more ready. So I agree with her on that...I do believe that the preparation and the experiences I had helped me in this role. I'm still learning. I'm still going to learn. This is a field that you always are learning, but I don't know how I could have been more prepared. Do you know what I'm saying? So I think I was prepared well. But yes, I see her point of why did I doubt myself? (MI, personal communication, June 8, 2018)

ML

ML is a building administrator assigned to handle typical duties (supervision, discipline, instructional decision-making) and oversees more specialized services. She began teaching after college, although she admitted to going into teaching only because the university she attended 
did not have a nursing program. She moved away from teaching and considered another position in education because, after observing a colleague's poor performance in a coordinator's position, ML knew she could do better. She applied for and secured that position, which she enjoyed fulfilling for several years. Then, in order to broaden her scope and ability, she pursued her current position, which allowed her to experience split tasks: that of an assistant principal and that of special services coordinator. Even though she did not originally have any intention of teaching, she now believes that watching her brother struggle with a learning disability may have influenced her to seek out a role in a helping profession. She noted that most of the people in her degree program are female and pondered that status:

There is a definite difference as far as gender is concerned, not only in education, but in [her content area]... at the university, as I was going through classes and whatnot, there were way more females than there were males. Similar, I think, to probably what elementary ed[ucation] would have been. Not that that is necessarily still the same case, but it was when I was [going through]. So, I think there is that maybe that caretaker, nurturer aspect of a female, an innate caretaker, nurturer aspect of a female versus a male as far as not only education, but students with special needs. So that's maybe once I got into the education piece of college, learning to be, I think that's where I saw differences as far as gender is concerned, but it isn't something that I think led me to it (ML, personal communication, June 26, 2018)

\section{MP}

MP began teaching in 1995 and is now an assistant superintendent in a smaller, rural school district. As she began her career, she sought a Master's degree in curriculum and instruction; at this point in the interview, she, along with others in this study, expressed that she had no desire to become an administrator. She taught for several years before being prompted by her principal to earn her Master's degree in educational administration. At that time, there was a push for department heads to have their Type 75 , the license that certifies a teacher to be an administrator, so MP had a reason to add that item to her resume. After she became the head of her department, she engaged in a lot of professional development, teaching adult learners about 
best practices and she began to think about the how much she enjoyed it, even more than working with students. Another principal recognized this behavior in her and made it a point to say something to her about becoming a principal, which she took seriously. Over the next several years, she took three administrative positions in two different school districts, which gave her perspective and practice. She encountered a mix of male and female mentors along the path, all of whom understood her abilities and gave her insight about herself that she had not yet realized. She is acutely aware of how women are perceived in administration and how they are expected to eliminate emotions from decision-making, which she classifies as a male response:

...the perception is if you are someone that can remove emotions from some of your decision making, then you're stronger. That's definitely a male characteristic. And in my most recent past, I've had some board members say things to me like, "Basically, you need to make decisions. Take the emotion out of it." And in my mind, that was a slam against what we [women administrators] were trying to do. We were advocating very strongly for something we thought would make the teachers' lives easier. And yes, we may have gotten emotional, but we have the relationship with them. (MP, personal communication, July 2, 2018)

\section{MT}

MT is a building administrator who did not join the ranks of educational administration until much later in her career, even though she obtained her teaching degree in her undergraduate years. After spending much time in her first career, which involved leadership at the collegiate level, she decided to leave it as it was draining and felt like too much time (80-hour weeks and travel) spent on the job. She reactivated her teaching license and worked in a school as a teacher. She knew she should take advantage of the free tuition provided for her and obtain a Master's degree. Upon deciding in which program to enroll, she landed on educational administration, but not because she wanted to fulfill a role in it. She decided that out of all the options, it was the programming that best fit her interests, more so than curriculum and instruction or counseling or reading. Once in the classes, though, she began to understand that, perhaps, there was more to it 
than just a general interest. She perceived that her professors challenged her to think differently about her influence and abilities:

So I started working on the degree. My first couple classes in, I thought, yeah, I don't want to be a principal [laughter]. I'm not interested in this. But then, the more classes I took and the more discussions I had, and then some discussions with some of the professors, kind of building that confidence that says, you would really be good at this. I think at some point in time during my course work I thought, you know what? I think I do want to do this. I think this is something that I would do well and be successful. It seemed to be kind of in my nature. (MT, personal communication, June 5, 2018)

As she began her first administrative job in a building, she was also forming her family by having a child. She knew it would present challenges and juggling family and job became a topic she discussed time and again throughout the interview with me, as if it weighed heavy on her conscience:

Because whether we like it or not, as women, that maternity leave poses a problem. When we look at somebody coming in and we know they're going to spend the first six to eight weeks of the school year out, and we have a building to run and positions to fill, that's a challenge. And to be honest, that's a challenge that we face as women that men don't have to face. (MT, personal communication, June 5, 2018)

\section{NM}

I interviewed $\mathrm{NM}$ as she was about to begin her first job in educational administration as a building administrator. She previously taught for about seventeen years at the elementary level before accepting an administrative position. During her time as a teacher, she was asked to play a role in implementing many initiatives at her own school and across the district, serving time on committees, getting and giving training. She became interested in furthering her own education after collaborating with a colleague at another school, one who challenged her in ways she had not experienced with her current principal. After that series of encounters, she knew to set out to earn a Master's degree in educational administration, but with no intention to change anything 
about her status at that time. As she took classes, she sought out feedback from her principal who discouraged her from going into educational leadership. She recalled the conversation:

So during one of my last [evaluation] conferences...I asked him. I said, 'Well, I'm just kind of exploring options for myself'...there had been talk of teacher leadership becoming a program at [the local university] but it wasn't there yet and it was years off. And I said, 'What do you think about administration? About me going into administration?' And I just asked him. And his response just let the air out of me. He said, "I wouldn't recommend anybody go into administration." I was like, "Oh, okay then." And we just left it at that and there was never any-- I just felt like obviously he doesn't think I'm fit for it so that's his way of saying it. Is there so much red tape, and paperwork, and all that stuff? And there is, of course, but I was kind of like, "Oh, all right. Well thanks for putting it to me in a nice way." So I just really didn't consider it and was still thinking "Hmm, what's my end game here?" I'm getting to the point where 13 years in-what am I going to do? Am I going to be a teacher in this classroom for the duration of my career or do I want to do something bigger? (NM, personal communication, June 1, 2018)

She attributed that conversation with delaying the urge to stay in leadership. If it had not been for others who prompted her to continue, she would not have further explored it: "So I just really didn't consider it and was still thinking 'Hmmm, what's my end game here? I'm getting to the point where 13 years in-- what am I going to do? Am I going to be a teacher in this classroom for the duration of my career or do I want to do something bigger?'" (NM, personal communication, June 1,2018$)$. She was actually surprised when people approached her and galvanized her, provoking her interest. In addition, a fellow teacher asked NM to join her as they began the coursework, so that helped her to further dive into the programming. NM explored how her gender interacts within her decision-making, her interactions. She communicated an internal struggle to understand if gender identity actually plays out as she described, willing herself to stop crying on the job, and whether or not she is masculine in some ways:

And I don't cry as easily as [my mother] does but I can tear up on a dime or just whatever. But yeah, I think that in-- I can't say I've never cried at school. I've never cried when I've been in that leadership role. My students have never made me cry. I mean, things about them definitely have, but not because they wouldn't be quiet...I mean, I'm just really-- in some ways I feel like, yeah there's that gender identity but sometimes I 
feel too, there's some qualities about myself that I feel like, well it's kind of masculine, just, I don't know. I mean, I can't really identify any of those but just with so many of the topics, so many of the conversations in the world right now about identity, about gender so you just kind of-- I'm starting to think oh well, is it really feminine, is it masculine? What does it matter? It's just who people are but I'm not super cuddly and I mean, I like touch but I don't go out and seek, I'm not going to be hugging every kid that comes to the door. (NM, personal communication, June 1, 2018)

\section{ON}

$\mathrm{ON}$ is a building administrator and has served in that capacity for six years. Like three of the other study participants, she had a different career before entering education. She cited childhood experiences and her personality as geared toward leadership. She was gives credit to being motivated by a person who she considered a bad leader to go into educational administration. She felt she could do better and make a positive impact upon the school. Therefore, she applied for and eventually got into a position in which she received mentoring. She shared that she felt it was important to have support from people who could relate to her.

She was able to point out several examples about how she is perceived in different ways and that there are situations female educational leaders must consider differently than their male counterparts (choices in dress, interactions with male students, nagging men). She commented on her ability to be assertive often and how it is not always well-received.

...this might be more of my personality and DNA. However, I've been told this so many times. So when we are in meetings, and this is usually in larger district meetings...I am not good at keeping my mouth shut. If something needs to be said or something needs to be pointed out, I am not good at just sitting there and letting it slide. When everybody is looking at each other around the room, saying who's going to say it? Who is going to-right? So I tend to stick my neck out there and say it, and I get very-- I'm a very passionate person, so I'm not really good at staying calm and even-keeled. So oftentimes I am viewed by other people in leadership as just being an emotional female. As opposed to it being like coming from a place of professional knowledge or passion, I'm often joked about and discarded as just being...People joke about it...But whereas some of the females in the room would instead be like, "I'm just so glad you're willing to say something because no else is." Whereas the men are like, "Oh, here she goes." And some of the guys in the room would say things like, "Oh, she can only have two turns to talk today." That kind of thing. (ON, personal communication, June 6, 2018) 
Lastly, she brought up an awareness of possible discrepancy in pay between male and female educational leaders in her current school district, which is the first time I heard description of such a matter.

TU

TU is a building administrator who taught for about four years before going into administration, poked and prodded by mentors all the way. She was often unsure about her direction and usually went along with others' ideas about what she should be doing. Her reluctance was a typical reaction of many of the women in this study; they had mastered teaching - why mess with a good thing? However, one mentor in particular, TU's building principal, kept up the pushing and eventually TU gave in; after consulting a few friends, she applied for and got a job as an administrator. She has now been in administration three times as long as she taught, about sixteen years. She is also a black woman and is keenly aware of many examples where her leadership is questioned and perceptions of her are skewed because of her race and gender. For instance, she shared that a white male subordinate administrator is taken at his word when a decision is made, whereas she is questioned more often. She also sensed that staff take her to be an emotional leader:

I know a part of it is just because it's my nature. That's who I am. I'm very open with staff and expressive. And they'll know if I'm feeling some kind of way about something, I'm not going to shy away from that. I'm going to tell them. In a faculty meeting, if you're ticking me off or this or that, guess what? Then we're going to sit down and we're going to talk about it and this is what it's going to be. And I'm going to tell you, versus-- I think, just with the males that I've worked with, they don't operate that way. They do not operate that way. And so it's a blessing and a curse. It's a dual-edged sword. While, of course, they like it and appreciate that I'm pretty open, there are also going to be, I think, more opportunities where they kind of take advantage of that. Because you are open. And it's like, "Oh, I know. I can talk to TU" Or, "I'm going to try to push something and see if I get called on it." You know, just certain things that I do, I think, are absolutely different. 
I think are absolutely different for females. I think, as a minority female, there's another layer--. (TU, personal communication, May 31, 2018)

She credited her parents with facilitating conversations about and encouraging independence and advocacy.

And the funny thing is because my dad was the type-- For my sister and I-- I know how to change a flat. I know how to change the oil in my car. I cut the grass, shoveled the snow, raked the leaves, whatever. He was very much-- It was equal opportunity. It wasn't girls' chores, boys' chores. It was, "You're going to be educated. You are going to know how to do these things." One of the things he always said-- Because, of course, on Saturday morning, the last thing I want to do is get up and go to the garage and work on this car with you. Are you kidding me? But his thing always was "You're going to learn it, so you know how to do it. But you're going to get an education because at some point you're going to make enough money to pay somebody else to do this.' And that was just always what he said. And I was like, "Okay. All right. I got it." (TU, personal communication, May 31, 2018)

\section{Chapter IV Summary}

Chapter IV consisted of descriptions of each of the fifteen women who participated in this study. I included details that are pertinent to understanding the fuller picture of who these women are, what they do, what they believe in, what they have been exposed to, and where they are headed. I included direct quotes that emphasize their belief systems and give the research a more complete significance. These descriptions lend credibility to the women and to this study. Next, Chapter V will explain the data analysis of the study. References are provided. 


\section{CHAPTER V: DATA ANALYSIS}

\section{Types of Analysis}

For the data analysis phase of this research, I followed Creswell's (2014) six steps that he explains in his book, Research Design: Qualitative, Quantitative, and Mixed Methods

Approaches, Fourth Edition (also mentioned earlier in Chapter III: Methodology). In addition, I looked to Glesne's (2011) Becoming Qualitative Researchers: An Introduction for ways to analyze the data effectively. Glesne (2011) presented options to researchers, varying forms of analysis, ranging from conversation, narrative, and semiotics (p. 184-188). For this study, I determined thematic analysis worked best with the methodology and data:

In thematic analysis, the researcher focuses analytical techniques on searching through the data for themes and patterns. One of the most important aspects of this work is data coding. With data coded, you read through all the pieces of data coded in the same way and first try to figure out what is at the core of that code. Then you might look at all the data scraps coded the same way for one case and see how it changes or varies in relationship to other factors, for example across events or times. Finally, "you can explore how categorizations or thematic ideas represented by the codes vary from case to case, from setting to setting or from incident to incident" (Gibbs 2007, 48). (Glesne, 2011, p. 187)

Thematic analysis also helped with removing my own "assumptions, values, and perspectives" (Glesne, 2011, 188).

As I engaged in thematic analysis, I kept the theoretical framework of this research in mind: Gender Identity Theory. Because I asked questions that asked the women to consider gender, I garnered answers that included reflection and insight about women's experiences and how gender shaped those experiences. At times, the women would bring up the influence of gender without my prompting. I included those answers in the data analysis as well.

Furthermore, I took a note from Belenky et al. (1997) in WWK and engaged in what they termed contextual analysis. They "reassembled the interviews and reread them many times, 
paying particular attention to the life story" (p. 16). In addition, they "adopted a stance of trying to honor each woman's point of view, method of explanation, and standard of evaluation even as we grouped their responses" (p. 16). They asked themselves questions about the responses that aided in their analysis. By prefacing and including direct quotes from many of the women, evaluating what they meant, and grouping them into key themes, I was able to connect the data to the findings. I tried to do what Belenky et al. (1997) did in their work and that led to the findings discussed in Chapter VI.

To aid data analysis, I also began to create and maintain analytic files, specifically quotation files (Glesne, 2011, p. 190). For example, I noticed some of the women addressed crying on the job. I created a quotation file that housed the quotes they uttered about that topic, which helped me analyze and write about it later.

\section{Reflection about the Data}

After organizing and preparing the data, I asked "What are the general ideas participants are saying?" During the conduct of the study, four main questions were asked of the participants. Generally, the participants spoke about their path to leadership, how they identify themselves as leaders, what makes a good leader, overall thoughts about women in educational leadership, and recommendations as to how women could be encouraged to go into educational leadership. Everyone was able to speak to very specific instances and provide personal examples in each area. Generally, women were very aware of their gender and how it influenced interactions in regards to educational leadership.

When asked how they travelled to this point in their leadership or how they characterize their paths to leadership, women described a variety of experiences ranging from childhood encounters to pivotal moments in their careers. 
As they spoke to how they identify themselves as leaders, they pointed out some common adjectives. At times, the ways they identified did not necessarily match how they defined a good leader.

When it came to explaining what makes a good leader, all focused on what came to their minds as leaders in a positive way. Very rarely did they highlight anyone or any quality in a negative way. Occasionally, it would come up as a notion of what not to do, but overall, they identified good leaders in positive ways and as ones to which to aspire.

Overall, all of the women expressed detailed thoughts or observations about women in educational leadership. They were able to draw easily on personal experiences or those that others had gone through and describe them as ones unique to being female in leadership.

As they were asked to make recommendations, generally, the women were quick to give answers, but also quick to point out the challenges that come along with implementing those recommendations. None claimed to have all the "right" answers to the problem, or even ones that worked.

Next, I asked, "What is the tone of the ideas?" The tone of the ideas shared by the women was that of determination, awareness, and curiosity as evidenced by their use of words like "pursue", "goal", and "wonder". The tone was often matter-of-fact and often led to other questions. I never got the impression that the tone was overly emotional. They were able to relate factual stories that conveyed truthful, personal experiences that answered the questions. At times, the women would speak passionately about different topics and I believed the women were frank in their communications with me, as they appeared to trust me.

Finally, to conclude this reflection phase, I asked, what is the impression of the overall depth, credibility, and use of the information? The impression I left with after completing and re- 
reading the interviews is that female educational leaders were aware of their low numbers in educational leadership and were aware of their gender and its impact on their identity as leaders, but did not let it discourage them from completing their duties. They did not seem to view it as an obstacle. There was a sense of acceptance amongst them; they were rather matter-of-fact about it.

\section{Reflection about Positionality}

In Chapter III, I explained how I thought my positionality would play a role in this study. After the study was completed, I reflected about it and came to a few conclusions. First, since I engaged in backyard research, I recognized that personal bias could present itself, and I did my best to eliminate it in my work. I tried very hard and with intention to be flexible and open to changing my point of view if I felt it inhibited the process of study and the results. Glesne (2011) advised researchers to not "evaluate, preach, or compete" and I tried to live with that advice throughout the interviewing and in the work beyond (p. 67). I know that I succeeded to the best of my ability because the amount of data collected is overwhelmingly in the words of the participants, not mine. I had to ask myself to analyze with the questions, "What is going on here? Am I seeing what I hope to see and nothing else?"

Before conducting the study, I presupposed that it would be hard to obtain the cooperation of many participants, mainly due to lack of time. In reality, I found that it was very easy to get the participation I needed because of the timing; I conducted the study during the summer months of June, July, and August. While educational leaders are still working in that period, the pace is laid back, there are fewer distractions, and the seasonal break seems to help to put people at ease. I had little trouble trying to schedule women to sit for an hour or more with me. Their schedules were more flexible and open in the summertime. 
Choosing to complete a study in a field of which I have some knowledge was beneficial to the study and, personally, to me. I was able to gain insight into how people think and how they work. I see them in a different light now and it has been eye opening in the sense that I recognize more about their depth and their thinking.

As I interviewed each woman, I realized some behaviors from myself. Often, I had to refrain from trying to explain a question further or expound with my own anecdotes in order to help the interviewee answer the question. In a few instances, I tried very hard not to expose my personal bias when discussing issues of which I had first-hand knowledge. In order to elicit more in-depth responses, I did utilize pausing often after asking a question and after getting an initial answer. I affirmed many answers, helping the women to understand that whatever they had to say was valid and thought provoking. I took on the role of researcher as learner as much as possible, explaining as much to the study participants (Glesne, 2011, p. 60).

The women were comfortable sharing their thoughts with me and a couple even shared that they felt at ease talking with me because I am a woman and one that works in the same field. Based upon the length of answers I collected from all the women, I also had a sense that I explained the purpose of the study well. I was able to ease their minds about how they would answer and a couple shared that they were less nervous once they knew they were able to answer the questions with ease.

I never had an impression that the women were concerned about confidentiality in the study because they easily consented and signed off on the informed consent form. I attributed this feeling of comfort to the fact that educational leaders must constantly maintain confidentiality and protect the identities of the people they work with and are around often. 


\section{Coding the Data}

As part of a third step in Creswell's (2014) data analysis guidance, I proceeded to code the data. I also referenced Glesne's (2011) coding advice for qualitative researchers that suggested coding data in order "...discern themes, patterns, processes...make comparisons and build theoretical explanations" (p. 194). I was careful to index and categorize, not count (Glesne, 2011, p. 194). I gathered grouping of words and categorized them with labels and terms. In this way, I engaged in descriptive coding. I assigned labels to the pieces of data and summarized in a word or short phrase, such as "Purpose" and "Mentoring". As I formed the codes, I took into account Tesch's (1990) Eight Steps in the Coding Process (Figure 2).

I read each interview again and began to get a sense of the whole. My field notes and analytic memos helped me get this sense as well. They helped me remember statements and major ideas pointed out through the conversations. I wrote down ideas as I read the field notes, memos, and transcriptions. I found that as I read each interview, I was able to get a general sense of each one. Along the way, I made connection between the stories I was told, asking what had been illuminated and what themes and patterns existed (Glesne, 2011, p. 194). A lot of them maintained similar themes. There were a few outliers: ones that did not follow any particular theme and ones that did not run parallel with any of the others. I also tried to pay attention to what was not said in the interviews and was successful in writing analytic memos that addressed that area specifically (Glesne, 2011, p. 195).

After I read the transcripts with the purpose of gathering a general sense of the material, I compiled a list of the major topics covered in codebook (Glesne, 2011, p. 197). I organized the list into five main categories, keeping those categories aligned with the topics of the interview questions: "Path to leadership", "Women in educational leadership", "Definition of good 
leaders", "Identification as a leader", and "Recommendations". In addition, a sixth area was added, "Other", for topics/content that did not fit into the original five categories. I did experience what Glesne (2011) calls "definitional drift" and had to re-align my later codes with earlier ones (p. 196).

Once I was able to structure the coding around the five areas, I took that list of topics back to the data. As I re-read each interview transcript, I began to code the data using sub-area titles (labels) and wrote them next to relevant segments of text. Often, I created labels as I read and assigned them to the appropriate places. The list of labels ended up being very extensive, compiled to an average of fifty-five topics over the five areas. I used descriptive wording for the labels, such as "Encouragement to lead" (assigned under "Path to leadership") and "Gender influence on interactions" (assigned under "Women in educational leadership").

Next, I tried to reduce the total list of two-hundred fifty-eight labels by grouping ones that related to the others. For example, I combined "Urge to lead" and "Urge to stay the course to lead" into one title: "Urge to lead" (assigned under "Path to leadership"). I used an Excel spreadsheet to keep track of the topics and labels. I alphabetized the labels within each of the five major areas. This step made it easier to find occurrences of each as I referred back to the data for various reasons. Essentially, I counted in order to draw and verify conclusions about the information. Miles et al. (2014) endorsed counting as a good way “(1) to see rapidly what you have in a large batch of data (2) to verify a hunch or hypothesis, and (3) to keep yourself analytically honest, protecting against bias" (p. 282). I kept track of how many times "Urge to lead" was mentioned and by whom. Counting made it easier to see which categories and themes had been cited by the women. Noting the frequency of some helped me tease out a number of major, main themes and build connections (see Table 2). 
Table 2

Path to Leadership: Mentoring

\begin{tabular}{lc}
\hline Mentoring & Number of Participants Mentioning Items \\
\hline Discouraged by male leader & 4 \\
Encouragement by professors to lead & 1 \\
Encouragement by colleagues to lead & 6 \\
Encouragement by female mentor to lead & 10 \\
Encouragement by male mentor to lead & 9 \\
Encouragement by supervisors to lead & 2 \\
Encouraging other women & 1 \\
Bad female mentor vs. good female mentor & 2 \\
Support to lead & 4 \\
Peer influence & 1 \\
Observation of leaders & 1 \\
Learning from negative model & 1 \\
\hline
\end{tabular}

Eventually, I began the process of pulling out the text that I labeled so I could see the patterns and themes even more clearly.

As I more closely examined the bits of text, I was reminded of the Creswell's (2014) explanation that codes could fall into three categories:

1. Codes on topics that readers would expect to find, based on the past literature and common sense,

2. Surprising codes (ones that were not anticipated at the beginning of the study),

3. Unusual codes that may be interesting to readers. (p. 248)

It was true in my experience with the data that the codes did keep in step with those three categories. For example, "Encouragement by other females" was a code for a topic that others and I would expect to find in asking questions about any woman's path to leadership. Encouraging others and helping others is a common behavior that occurs as people work through opportunities to lead. A code on a topic I did not expect to come up through the questioning was "Dress". A few of the women cited times when they had been critiqued about their choice in how 
they dressed as a woman and that it was an occurrence they viewed as a problem for women, not men. It was surprising because I assumed dress was a non-issue or that every professional (male or female) had to consider it as he/she interacted in the workplace. An unusual code that came up was "Crying". A quarter of the women brought up crying in the workplace and talked about how they viewed it and how others viewed it.

I was careful to "... develop codes only on the basis of the emerging information collected from participants" (Creswell, 2014, p. 248). I did not formulate codes as a precursor to the interviews or the coding. Some participants helped in coding by offering suggestions about topics, titles, possible avenues to explore, questions, historical context, etc. Most often, though, the interviewees, through their answers, helped in the formation of themes and patterns that came about through coding.

As I continued to analyze the data, I asked a question Creswell (2014) suggested, "What were the lessons learned?” (p. 249). I left the interviews with a sense of that learning as I personally reflected on the intent and meaning of how gender identity affects women in educational leadership roles. I had a personal interpretation of the data, held in the understanding I possessed from my own experiences, but I hesitated to put all the effort into that pathway, as I wanted to avoid inserting some possible bias. I relied on the literature and the theories to guide my interpretation as well. Because my goal was to discuss recommendations to address the research problem and nudge reform, it was necessary to draw on other research, the data, and theory.

Keeping field notes, analytic memos, and transcripts helped make me aware of details, moments, and subtle clues before, during, and after interviews. From those resources, I was able 
to draw out particular strands I knew I would be able to examine more closely, including ones that I had not anticipated and ones that I had anticipated.

\section{Description of Participants}

Throughout the process of coding and afterwards, I formed a description of the participants and the themes. I drew information from the answers to the first question, "What was your path to leadership?" The women were able to convey specific details about experiences all the way back in their youth and throughout their careers. Since the women could give details about any points in time, some chose to recall further back in their memories, while others began as they entered college.

\section{Leadership roles.}

Generally, the interviewees were all educational leaders in that they held positions and are/were currently employed in school districts fulfilling the roles of building administrators, principals, directors, and assistant superintendents (see Table 3).

Table 3

Leadership Roles

\begin{tabular}{llll}
\hline Building-level Administrator & Principal & Director & Assistant Superintendent \\
\hline BP & KH & BT & DC \\
KD & NM & MB & DI \\
ML & TU & MI & EX \\
MT & & & MP \\
ON & & & \\
\hline
\end{tabular}

\section{Demographic data.}

Their demographic information as a group ranged as follows: twelve of the fifteen interviewees are white. The remaining three consist of one African-American woman, one Asian woman (Indian descent), and one biracial woman (African-American and white descent). Five 
of the women are in their 30s; six of them are in their 40s; three are in their 50s; and one woman is in her early 60s. Only three of the women are single (one divorced); the other twelve are married. Three of the women do not have children of their own (See Table 4).

Table 4

Participant Demographic Data

\begin{tabular}{lllll}
\hline Participant & Ethnicity & Age & Marital Status & Have children? \\
\hline BP & White & $30 \mathrm{~s}$ & Single & Yes \\
BT & White & $50 \mathrm{~s}$ & Married & Yes \\
DC & White & $40 \mathrm{~s}$ & Married & Yes \\
DI & White & $60 \mathrm{~s}$ & Married & Yes \\
EX & White & $50 \mathrm{~s}$ & Married & Yes \\
KH & White & $30 \mathrm{~s}$ & Married & Yes \\
KD & White & $40 \mathrm{~s}$ & Married & Yes \\
MB & Indian/Asian & $30 \mathrm{~s}$ & Single & No \\
MI & White & $50 \mathrm{~s}$ & Married & Yes \\
ML & White & $30 \mathrm{~s}$ & Married & Yes \\
MP & White & $40 \mathrm{~s}$ & Married & Yes \\
MT & White & $40 \mathrm{~s}$ & Married & Yes \\
NM & Biracial & $30 \mathrm{~s}$ & Divorced & No \\
ON & White & $40 \mathrm{~s}$ & Married & Yes \\
TU & Black & $40 \mathrm{~s}$ & Married & No \\
\hline
\end{tabular}

The demographic data will be informative for this study in that it may give the audience a fuller picture of the participants. As they read the quotes from the women and think about the insight provided, the demographic data gives some context.

\section{Career history.}

All of the women taught in schools at some point in their careers in education, which is typical practice and is usually required for licensing to become an administrator or higher. While most began their professional lives as teachers, a few women started in other fields, and then followed a calling to pursue an interest to work with students. (See Table 5)

Funny enough, right out of college I actually did not teach straight out of college. I worked at a theater in the Chicago area. (ON, personal communication, June 25, 2018) 
So I went to [college]. My first degree's in...public relations...So my first professional job was at [local college]. I was in charge of campus safety. And I walked in, and there was a Post-it [note]. It was just a piece of paper that said, "Good luck." That was it. And I was hired through the student life office, through a commission from the president's office, and I worked part-time in the student life office and part-time in the police department. I knew absolutely nothing about police anything, and I had to learn. (EX, personal communication, June 4, 2018)

I decided that I wanted to take a break from that [other career]. And I had my teaching degree. Actually, my certification I had never applied for it, because I never used it. I made the application, transferred it from [state] to [state], and started teaching here in the community. (MT, personal communication, June 5, 2018)

My original, when I went through college the first time, my degree was in Food, Nutrition, and Dietetics, and followed that path right out of college. Worked in the food service industry, restaurant industry, for about six years, and then I worked at the university level in campus dining services for about 10 years as an associate director there as well. So I kind of went up through, started as a dining center administrator. (BT, personal communication, June 7, 2018)

Table 5

Participants: Career Starts

\begin{tabular}{ll}
\hline Career Start & Participant \\
\hline Started in education & BP \\
& DC \\
DI \\
KD \\
KH \\
MB \\
MI \\
ML \\
MP \\
NM \\
TU \\
BT \\
EX \\
Did not start in education \\
\end{tabular}

It made sense that most of the women began their adult lives in the teaching profession; one of the requirements to be an administrator is teaching experience. Education is described a 
"calling", a profession that people are drawn to and stay in. As far as the women who did not start through teaching, it appears as though they still were involved in working with people (theater, public relations, coaching, and food service).

\section{Key Themes}

As I planned how to present the data analysis, I thought about Belenky et al. (1986) and their work in the book, Women's Ways of Knowing. That text used quotes and examples directly from the women to explain the ways of knowing. Often, Belenky et al. (1986) presented a claim about a way of knowing, and then supported it with quotes from their interviews. Lastly, they would comment about the claim and the quote in order to tie everything together and make connections for readers. I use that format here in Chapter V as I shared the key themes in the data analysis. Since the women had to respond to questions that allowed them to draw upon their own experiences, none had issues in coming up with answers. There was plenty of data to sift through. Of course, some women talked more and longer than others did, but that depended upon personality. Some women were more outgoing and talkative, while others were more reserved.

\section{Path to Leadership}

When women talked about their paths to leadership, they most often spoke to four key areas: personal experiences, mentoring, purpose, and negative experiences.

\section{Personal experiences.}

Within the realm of personal experiences, most could cite details about times they were presented with or created opportunities to lead prior to their service as administrators. They spoke about situations in which they were placed, asked, or pursued leadership, usually as teachers. In addition, they conveyed fondness for sharing memories about childhood experiences and their family backgrounds. 


\section{Opportunities to lead.}

The most related, common experience among the women in their paths to leadership is that they were presented with opportunities to lead, which they took. That decision often spurred them on to seek out more occasions in which they could further their education, exercise their knowledge within meaningful administrative/leadership work, accepting the lifestyle of a leader as a change, and build their confidence in the field.

And I thought it'd be good to do that [get administrative degree] early because I knew eventually I would want to do something leadership-wise in education. And I worked at [local school district] for two years before getting the job here. And after a couple years of teaching here I became the department chair for English and then into this role from there. (ON, personal communication, June 25, 2018)

So once I found myself in, at that time it was [teaching] fourth grade, then once you get comfortable with your curriculum, with the students that you work with, then it was easier to seek out some leadership opportunities...And she [NM's principal] had had a situation with the one that had been [the administrative aide] for years, and so she called me one afternoon and asked me if I would be willing to cover the office for her for the next two days when she was going-- or for two days later that week when she was going to be gone. And she didn't know at the time, but I had student taught under the person who was the administrative aide and so I knew that was, "Oh, okay." I, of course, accepted and I was flattered that she asked me to do that. And then she asked me to-- she said she'd like to relieve that person and then have me do that permanently...So I did that and then just kind of really enjoyed being more of a leader, more of a visual, go-to person, and just being in front of the kids and the teachers, and doing all sorts of things, and just kind of being her second person on a lot of things whether she told me to do it or it was just made sense for the building and the kids or just naturally people would just assume things. So it just really kind of transformed very organically...But [my new principal's] invited me in to being part of those kinds of things, and to sit on interview committees and so I've had experience with that already and that kind of stuff so there really is-- and we problem solve together a lot so there's really so many things that I've already been exposed to just because of my interest, and then her desire to help mold me too. That's been really awesome so. (NM, personal communication, June 1, 2018)

So I was in the classroom for eleven years, and then my first administration position I was an assistant principal...for two years. And I learned more in that job than I learned in any-- than I've learned in any other administrative position I've been in. But about February of that year, second year I was there, the elementary principal job at [a nearby school district] came open. And I knew that I would never be even considered for an 
elementary principalship in [my school district] because there are too many elementary people. And I really thought that I wanted to look at some other age levels. So I applied for that and I got that job. So I was the principal [in the nearby school district at an elementary school] for three years. That third year, in about October, I got a phone call from [my previous school district] asking me to come talk to them about [a new] junior high being built. And they wanted to talk to me about being a principal [there]. So I did that, interviewed, and then got that job. So I was at [that junior high] for two years. Loved it. Starting a new school was an amazing experience. To get to handpick your staff- I mean, it was amazing. I wouldn't trade it for anything. And I thought that I would be there for a very long time. However, the director of secondary ed job came open and I was encouraged to apply for that because those positions, as you know, don't come open very often. So I applied for that, and I'd been there for five years. And then this job [assistant superintendent] came open in December of this year. (MP, personal communication, July 2, 2018)

And the special ed coordinator in my building was resigning from the position, which was an administrative position. So as soon as I finished my Master's, the following school year I decided to just give it a shot. And then I was in that position for five years. (ML, personal communication, June 26, 2018)

I wanted to see a different area more so than kind of specializing in teaching altogether. So I think my-- I was looking at either special ed or educational administration and that's the route that I ended up choosing. And so I kind of did a fast-track course of going to school full-time. I really enjoyed it. (MB, personal communication, June 11, 2018)

And so I kind of thought where do I go from here? What do I do? So I started looking at well what do I want to do? What do I really like? And I kept going back to that instructional coaching. And so I thought why not? Why not me? And that's what got me on the path. And then I got into the principal prep program and went from there. (KD, personal communication, June 27, 2018)

I mean I got some great opportunities. So then I was coaching. I was teaching part-time. I was coaching in the district because we had to implement it. So I was in at all elementary and junior high, and I had teams that I coached, instructionally coached. Did that for three years. And then the regional office asked me if I-- them and [a local superintendent] started talking, and he said, "Sure, you can borrow her." They paid for part of my time. And then pretty soon it was time for me to go. And I wanted to stay home with my kids more. And I was given that opportunity to do that. And so I took a pay cut, and I coached for the regional office. And then a grant came in, and [another superintendent] called me, and he said - I'll never forget; it was January - and he goes, "I need somebody to do this grant." And I'm like, "All right. I know how to do grant work." And he's like, "Okay." And I did that grant. And I got doing that, and I said, "We need more PD." And he goes, "All right, fine." I said, "I need more money." "Okay, fine." And so then I became the professional development coordinator. And then his assistant resigned, and he offered me the job, and I said no. That was the best decision I ever made. And then two years later, I 
said yes. And so I've done that. Now I've been the assistant now for the last eight years. (EX, personal communication, June 4, 2018)

And so, then that was when I started with [current school district]. And [my principal] offered me the opportunity to work on some different committees and be in charge of some PLC-kind-- we didn't call them PLCs then. But they basically were PLCs at that point. And some leadership things in some writing some grants, and doing some things in the department, and stuff like that, which I enjoyed in addition to the teaching part of it. (DI, personal communication, June 1, 2018)

Yes. Small rural elementary. I was at [an elementary school] for a year, and then more of an urban setting, which sounds kind of weird to say that about [another elementary school] but we had, at the time, had a lot of the flight from [a larger city] down to the Section 8 housing. I mean, that was a very big eye-opener for me because I taught at [an affluent elementary school]. So it was my first real experience with children in poverty, deep poverty. (DC, personal communication, July 2, 2018)

After I left the first district I worked in, I went to a much smaller district where leadership opportunities were almost required because our staff was so small that almost everyone had to be involved in something outside of the classroom for the school to function and provide extracurricular opportunities for students beyond the classroom walls. But even there, at that rural location with a small, small staff, I did building-wide leadership things including providing professional development for teachers, and initiating and starting new state initiatives like MTSS, at the time, which was PBIS and RTI services at that building. But, again, because I enjoyed the creation of systems, and practices, and protocols that all teachers could use for the betterment of students. (BP, personal communication, June 5, 2018)

The opportunities to lead were abundant and varied, despite being in the same field. Many of the women were able to practice leadership in a variety of settings. Their gender did not seem to be an element that held them from these opportunities. In fact, they seldom mentioned gender as being a factor. The experiences were mainly positive and they remembered them fondly. Many were in awe of how the steps in the journey had played out.

\section{Childhood experiences.}

Many women recalled childhood experiences that may have influenced their gravitation

toward service as leaders.

It's probably part of my DNA because I've always, even when I was little, I've always liked organizing things and sort of making sure that everything was happening and going, 
whether it be groups that I was working with or clubs, things like that. (ON, personal communication, June 25, 2018)

So I was either going to be a teacher or a nurse, and special ed-- if I was going to go into teaching, it was going to be special ed because I grew up with my brother who had a learning disability. And so I just saw a bunch of things that worked out well as far as teachers he had and a bunch of things that didn't work out well as far as teachers he had...And I was always very independent. I was always very just organized and on top of things. And I think that's because of just being the oldest. I think that when you are raising children, depending upon if you have multiple kids, sometimes you expect more out of that oldest because they just kind of help in some different regards. And I think it's that more so than gender that kind of lead me to, "Okay, I kind of want to do something that I can kinda be in charge of," right? Because even as a teacher, I was in charge of my classroom. (ML, personal communication, June 26, 2018)

I mean, I wasn't raised in a very traditional home. My dad went to work. He did his things; my mom did everything else. Cooked. My mom went to work to get away from doing everything else when I was in first grade. Traumatized me. But when I stayed home with my kids she said, "You're doing the hardest job you'll ever do in your life. Going to work is so much easier." She is so right. (MI, personal communication, June 8, 2018)

I think my experience in high school, just working with my guidance counselor, I liked the people aspect of it. I liked helping people as they were navigating some of those longterm life decisions and what they wanted to do. I wanted to be part of that. (MB, personal communication, June 11, 2018)

Well I think that I've always been a leader. I mean I can go back to third grade getting Girl Scout of the Year award kind of thing. But people have told me that I was a leader for most of life, so I don't know if it was a self-fulfilling prophecy or whatever. (EX, personal communication, June 4, 2018)

I've known since I was eight years old that I wanted to be in education, and I never really wavered from that...I mean, honestly any of my traits as an educator, as a leader, I completely attribute to my upbringing. To the fact that I was an athlete. I mean, to all the things that have contributed to my life. (DC, personal communication, July 2, 2018)

I was very involved in FHA [Future Homemakers of America], and that was where my leadership started was with that, which was very female-oriented. (BT, personal communication, June 7, 2018)

These childhood experiences were prominent as influential forces in the lives of the women and their path to leadership. Most seemed to acknowledge their willingness to follow an area of interest that involved working with people and described having a personality built to lead. As 
the women talked, it appeared they had not really thought much about how those moments in their youth had influenced their lives up to that point.

\section{Family background.}

Most had positive childhood experiences with education and many had families (mainly

parents) who were supportive in many ways.

I grew up in a family that was very centered on education. My dad was a professor at [college]. I had a lot of aunt and uncles who were teachers and a cousin who also went into teaching. And my mom worked for the schools so I was really surrounded by it a lot...So I really liked to support people and help people...it was really more that when I saw somebody that was struggling with something I wanted to help them. But as an 8-, 9, 10-year-old I didn't really know how to do that besides telling them what to do. But that altruistic-- that has always been very much a part of me, and my mom was very much that way, my dad was very much that way. And so I mean, that's where a lot of it has come from - wanting to help people. (DC, personal communication, July 7, 2018)

It goes back to my parents. It was always just instilled in us from a very young age about doing well in school. I mean, that was just a-- there were no opportunities to not do well. It was not going to happen in the [TU] household. And, I mean, just even with the-everyday for us, we ate dinner as a family. And there was no TV. There weren't devices at that time. But if there were, my dad sure wasn't having it. But it was an opportunity. You sat down at the table and my father literally asked us what we learned in school that day. And this, I mean, happened as long as I can remember. And so education was always part of a discussion in our household. It was just, you talked about school. You talked about teachers. You talked about what went well. You just talked about everything. (TU, personal communication, May 31, 2018)

The women were surrounded by family members who valued education and made it a priority;

that attitude and habit influenced the women as they grew into leaders. Their families, especially,

may have had an impact on them as they began their journeys.

And that was just part of what we did. And if you were a friend who happened to come over and you were at the house at that time with dinner, and we used to tell them, "You better get ready. You better have something you're going to talk about." Because for my dad, it was a big deal. Don't say nothing - that just was not acceptable. He refused to believe you were at school all day, and there was nothing. And so our friends just knew that wasn't going to fly. And so there was always an emphasis on education, from the very beginning. It was just kind of what you did. And when I think about even our kids now who don't even think about college as an opportunity for them. Like that was always a "You're going to school. Period." There was never a "Well, I don't know." It was a 
"Where am I going to go?" And not even knowing how he was going to pay for it...And I know not everyone has the family dynamic that we do. And I was very fortunate to have [it]...I remember all those things. And it just, it clearly shaped who I became. (TU, personal communication, May 31, 2018)

My parents were always very supportive. Part of it is probably-- I'm an only child, which I don't know, some people think that that's a reason that-- because I've always been very independent and self-sufficient and my parents were willing to support anything I really wanted to do. So that helped because I could explore a lot of different avenues. (ON, personal communication, June 25, 2018)

I talked to my husband and said, what do you think about this [taking a job in administration]? The biggest discussion was centered around, we had during this time started a conversation and a process of adopting my son. And so we were in the adoption phase with the birth mother, and not knowing for certain if this is going to happen or it's not going to happen. You don't know until the very, very end. So he was going to be born in August. We had to really talk about, are we going to be able to manage all of this? Me in the job, a potential new baby, all of this. And we kind of decided, let's go for it. Let's do it. So that's how I landed here. (MT, personal communication, June 5, 2018)

...but I also think it's part of my family and the way that you're raised. I mean, there was tons of sitting around and just talking about stuff. So I don't know that that's a female characteristic or that's just part of who I am as a result of being raised in my family. (MP, personal communication, July 2, 2018)

Yeah. Well, I mean, I grew up in an extremely supportive household. My dad, like I said, was a professor. My mom worked in the school district. And pretty much anything that I decided that was important to me, that I wanted to do, they would get behind me and support me in that. I never heard any limitations growing up. Oh, like, "You might not be able to do that because we can't afford it, or because we don't have time, or because you don't have the skills, or because you're a girl." I mean, none of that. I just never heard that. But I also grew up in a household with extremely high expectations. So the citizenship thing in school. When I was in sixth grade I got poor marks on citizenship because I was passing notes in class and I wasn't paying attention and everything. I got straight As but I was grounded for an entire nine weeks. So I mean, the whole high principles, high expectations, that was driven into me at a very young age. And so I very much attribute it to that, but then I also-- I just had an extreme amount of support through everything that I've ever done. I've always had coaches in my life who have helped. (DC, personal communication, July 2, 2018)

In my own home, my mother made all the decisions, but she sometimes deferred to my father, rarely though. Publicly, a lot of times, she would pretend to defer to my father, but never privately. My mother ruled the roost utterly and completely. But it was very traditional values. You know what I mean?... She completely relied on my dad for anything physical, "The yard work needs to be done. There's a spider on the ceiling. There's a scary person outside; go deal with that." All of those types of-- I mean, it was a 
very traditional upbringing, except for the fact that my mother, for most of my life, was the financial breadwinner and the ultimate decision-maker over major household decisions. But on that, it was very traditional roles. My mother's a nurse, again, a femaledominated profession, and my dad was a security guard......my parents raised me to believe that I could do anything I wanted. I had no reason to doubt that. Literally, I mean, they told me that, and then everything that I ever did, provided reinforcement for that. (BP, personal communication, June 5, 2018)

Well, I come from-- my family background, both my parents were educators, my sister's an educator. My father was an industrial arts teacher and was only in that probably for about 10 years, and then he started his own business. But my mother continued in education for many years to kind of help support that business. You know what I mean? ...she [my mother] was a principal in a prison system. So she worked in K-12 for many years but then, eventually, that's where her career led her. So she has always been in that kind of leadership role as well. And then my sister is special education-- she works with [a large university] doing a lot of grant work and running grant programs. And so she's very much in a leadership role but kind of in a different way than you would-- like you said, not a professor. She doesn't do classes but she does that other piece. (BT, personal communication, June 7, 2018)

Some of what drove the women to enter the field of education depended upon how their families steered them and how those family members set examples for them to follow and look to for guidance. It may have been parents, siblings, or husbands that helped the women navigate their choices and decide what was best for their careers. The women spent time thinking and talking about how a mother or a father would act within their families, depending upon gender and status. They also questioned what they would do if they were in the same position, but as the husband. They wondered if their husbands would think and act the same way they have up to a point.

\section{Pivotal moments.}

One described a pivotal moment in her childhood which she claimed drove her to understand her path and choose it the way she did.

I was kind of thinking about this [path to leadership] because you talked to me about the topic itself, women in leadership. And I was thinking about when was that pivotal moment - because I think we all have that pivotal moment - where we have an experience that kind of speaks to us or something. And it's probably going to sound very corny and 
everything, but I remember as a young girl-- and there was a time where, in the small town that I lived, there was what they called a soapbox derby. And I heard that they were going to have this soapbox derby in my town and everything, and was all excited about it. I was probably all of maybe 10 years old or so. And my dad and I, immediately, we went to the garage. And we got out the wagon, took the wheels off, and we started building this soapbox derby. And it was getting better and better. And then a few days later, my mom and dad sat me down. And they said, "We have some bad news for you. The soapbox derby is only for boys" And I was so upset with that. I mean, I had my heart set on this, being a part of this thing that the guys in the neighborhood-- I mean, I grew up in a neighborhood of guys. And we all did cops and robbers, and all of those kind of things. Kicked the can and all the things. And here I was being excluded from participating just based on the fact that I was female. And I look back to that oftentimes as one of those pivotal moments where you either go one way or the other after that. And so I think because of that, I have always felt that I wasn't any different than any of the guys, so why should I have different experiences, or not be able to do something or not do something-do something or not do something based on being a female. (DI, personal communication, June 1, 2018)

Although the pivotal moment occurred in her childhood, she attributes her choice to become a

leader with how she dealt with that moment as a female. It was a moment that helped her define her identity and how her gender would play into that identity.

DC remembered an incident that altered her entire trajectory;

I should say the traits that I choose to emulate the most have to do with relationships and with how you treat people. I went through like a life-changing event. When I was in sixth grade, I was kind of that nasty-- I started to go down that road of being a nasty teenager and saw somebody that I considered a friend spit on another girl in the hallway. And it was like a switch. And I mean, literally that moment, I changed who I was, and I abandoned a whole group of friends that I had. You know what I mean? (DC, personal communication, July 2, 2018)

Both of these women understood that one encounter would shape how they viewed themselves for the rest of their lives and certainly in their careers. Fortunately, they did not allow the discriminatory practice or the bad influence of peers discourage them in their life journeys; instead, those moments reinforced their views that they could do anything they wished. 


\section{Mentoring.}

The participants spoke highly and in detail about their connections with mentors. The

interactions were varied and most often positive. There were specific people and groups who

helped these women along the way, as they rose through the ranks.

\section{Encouragement by others.}

All of them encountered positive mentors in their lives who encouraged them to pursue

leadership.

And so I just happened to be in a conversation in this office with [my principal], and that was enough. So she was really the catalyst. And it was, "You need to go into leadership. You absolutely need to do educational administration." And was very upfront about-- at that time, twenty years ago, there weren't lots of female administrators and certainly not minority female administrators. And so she felt like, "This could be a good path for you. If you're even a little bit interested, I'm going to suggest you go this route." And so it was really because of [her] that I was like, "Alright. I'm going to do this." And then even within that, opportunities within the building, she was very much about, "How about this committee? How about that committee? What are your thoughts about being a team leader?" I became an interim administrator in the office after I finished my Master's [degree] She was just very much a strong part of it. And so when there was an opening in this building, after four years of teaching, she approached me about it. (TU, personal communication, May 31, 2018)

[After consideration of going into educational administration] I talked to [a female principal] and I said, "What do you think? Do you think that--" and she said,

"Absolutely." She said, "I've spoken of you as somebody who's in the building, who is a team player, who's a leader, who is someone I can trust and go to, and I absolutely think you should do this and that you'd be good." And so just from there on, she's been kind of, I don't want to say promoting but she-- I've learned so much from her, and she's been very intentional about talking to me about things, and telling me things just in confidence about some procedures or hey, when you're a principal, look out for this kind of stuff, or this is what this is, or things like that which I've appreciated. So I feel like I've really had some on-the-job training for a couple of years. She's given me some opportunities. I'm calling it an opportunity but helping with the schedule's not really an opportunity. (NM, personal communication, June 1, 2018)

So while they were building [a new elementary school], all these other people, as they start talking about principal candidates, people that know me are like telling [my mentor] her, "You really need to talk to MP." So finally she just called, "Can we meet [for coffee] or something? I just want to have some conversations with you about [the new elementary school]." But she is a very strong leader and visionary, so she encouraged me 
to do that. And then she told me up front. She then moved into the assistant superintendent job eventually...but she told me up front that she would love to get me over to the central office. So I knew that at some point I would be over there. (MP, personal communication, July 2, 2018)

I was paired with her [female mentor], and she was retired director of special education from [school district]. And I worked with her, side by side, for two years. And she became a mentor to me. At that time, I was finishing up my degree in [educational administration] and had finished it [while] with her, and got the role as an assistant principal. And she always knew my desire was to stay in special education. And she encouraged me, and told me some very wise things, and was very influential to me. And she told me that in order to be a good director, you needed to be a principal. (MI, personal communication, June 8,2018 )

I think that she [my principal] has been one that has...seen something in me, or seen that potential or the growth that's happened that I had her kind of as a mentor to push me and maybe put me in some positions that I wasn't ready for. When she had asked about the position open, as far as assistant principal, "Is that something you're interested in?" And I said, "No, I don't really think I'm ready for that. I hadn't really taught all that long. I kind of jumped around from two years in the classroom...to now I've been subbing. I don't know that I'm really ready for this." She's like, "I think you'll be fine. It'll be okay. We'd really like you to be part of this team." (MB, personal communication, June 11, 2018)

Within that first year, [my female principal] started asking me, "Okay, you've gone back and got your masters in reading. Have you ever thought about being a principal?" And I was like, "No [laughter]. I have not." And she was like, "You're really good at looking at the whole picture." (KH, personal communication, June 5, 2018)

What is striking about these descriptions is that, typically, a mentor made it a point to seek out these women and often saw something in them they claimed not to see in themselves. The mentors also made it known to the women by placing them into opportunities to act as leaders or by saying something encouraging that compelled the mentees to progress.

\section{Discouragement by others.}

The mentors were male and female. In most cases, the mentor was a superior to the woman, but in a few situations, the mentors were colleagues or peers. Interestingly, though, some of the women dispatched stories about how they spent time observing or listening to poor 
leaders and learned what not to do, which, in turn, inspired them to move into a leadership role.

These pseudo-mentors unofficially provided motivation for these budding leaders.

I asked him [my principal]. I said, "Well, I'm just kind of exploring options for myself". There had been talk of teacher leadership becoming a program at [the local university] but it wasn't there yet and it was years off. And I said, "What do you think about administration? About me going into administration?" And I just asked him. And his response just let the air out of me. He said, "I wouldn't recommend anybody go into administration." I was like, "Oh, okay then." And we just left it at that and there was never any-- I just felt like obviously he doesn't think I'm fit for it so that's his way of saying it. Is there so much red tape, and paperwork, and all that stuff? And there is, of course, but I was kind of like, "Oh, alright. Well thanks for putting it to me in a nice way." So I just really didn't consider it and was still thinking hmmm, what's my end game here? I'm getting to the point where thirteen years in-- what am I going to do? Am I going to be a teacher in this classroom for the duration of my career or do I want to do something bigger? (NM, personal communication, June 1, 2018)

And what was weird was [a male principal], who was here, he told [my husband]--[he] was a floating custodian at that point-- and he told [my husband], he said, "I see that your wife put in for this job. There's no way she's going to get it." He said, "You never get your first job opportunity." And I know that was one of those, "You're probably right." In my head I'm thinking that because I am thinking I don't have experience. My only experience is covering in this district. Then [a female principal] came to me and said, "Most likely, you're not going to get it, but this interview is going to be great for you. You're going to have that opportunity." So I was going into the interview feeling really crappy. (KH, personal communication, June 5, 2018)

[One of the mentors] was a male. And I will say that one of the things that really spurred me at the end was I had a really awful principal later. And I really kind of felt like well-I'm going to say it, "If he can do it, I can do it." (KD, personal communication, June 27, 2018)

And just really learning how to navigate some things and just to watch her [female principal] and you would always-- whenever we were in any sort of meeting, anything-just picking up on her. And you would learn things that I would want to do, things that I knew, like, "Okay. I'm not going to do that." But either way, I always felt like I learned something. I grew as a result of just being a part of that administrative team with her. So it's been good. It's been very good. (TU, personal communication, May 31, 2018)

So when I started teaching here the principal here was the exact opposite of what you would want in a school leader, and so that kind of lit a fire as far as wanting to help make things different. (ON, personal communication, June 25, 2018) 
Honestly, the only reason that I tried for it is because it was in a building that I had been in and, honestly, I thought I could a better job. I mean, it's really the genuine, honest answer. I had no desire to look for a new job. When I finished my masters, I had no desire to leave the classroom right away. That was not my intention. I had only been teaching for six years and I was perfectly fine. But I thought that-- I watched my predecessor as a...coordinator do some things that I thought weren't great and I thought that I could try it. (ML, personal communication, June 26, 2018)

I did not expect to hear the participants speak about people in their careers who motivated them by not leading effectively or through displaying discouraging behaviors. Instead of focusing on the damage wrought by these people, the women chose to make the interaction a learning opportunity and to hone their skills.

\section{Observations of leaders.}

Most of the women could cite one or more influential people in their lives, ones who encouraged them to pursue leadership. Males and females at equivalent rates mentored the women. Within that context, their colleagues and their supervisors propped them up. There were also instances of being discouraged and/or negativity in the field, but those encounters usually served as inspiration despite possible detriment. One woman was informally mentored through their observations of other leaders she encountered:

I was able to see the things that I liked in some of the coaches and some of the things that I didn't like, and it really helped kind of shape some of my leadership tendencies and how I wanted to be and how I wanted to lead, and so forth. (MT, personal communication, June 5, 2018)

The combination of the formal and informal mentoring was a great help to the aspiring leaders. The ways the mentoring was delivered did not appear to matter, whether it was through one-onone conversations or observation. A variety of methods was effective and impactful to the women. Through these interactions and inspections, they learned about leadership and how they would identify themselves as leaders. 


\section{Purpose.}

An important theme that revealed itself when the participants spoke about their paths to leadership was that of purpose and their reason for choosing to lead. Many acknowledged they had an urge to lead for various reasons and that drove them to pursue the path further. A few described moments of self-realization and how it influenced their direction. One woman cited that she did not know that teaching and educational leadership would be in her future, but that the "helping professions" were definitely ones she was interested in - nursing, special education, etc. (ML, personal communication, June 26, 2018). Some decided to take the leap because of an interest and/or inspiration to do so.

As the women entertained the thoughts of how they came to this place in leadership, they were quick to give credence to their thoughts about intending to lead, the urge they began to feel to lead, learning more, being inspired, and the self-realization that eventually came as they built their confidence in leadership.

And in taking the classes of the principalship, I started to realize that it was the kind of thing that I liked to do. I just hadn't really thought about it before and it wasn't in my long-term plans. (DC, personal communication, July 2, 2018)

By the time I started the Master's degree in administration, I was intent on getting an administrative job immediately. There was no question in my mind at that point. (BP, personal communication, June 5, 2018)

And I really liked the instructional coaching side of [work]. So I got done with that and I- a position opened up in my district. It was my dream position. It was a little bit more-- it was kind of that balance of being a teacher/leader but I didn't need an administrative-well I got denied that position. And so I kind of thought where do I go from here? What do I do? So I started looking at well what do I want to do? What do I really like? And I kept going back to that instructional coaching. And so I thought why not? Why not me? And that's what got me on the path. And then I got into the principal prep program and went from there. (KD, personal communication, June 27, 2018)

And then what, I guess, led me to continue in an admin position versus going back to the classroom after that is I really just liked having an impact on a larger scope. Trying to 
guide teachers to work with students versus just working with students. (ML, personal communication, June 26, 2018)

In a large district, never wanted to be the sole director. Wanted to be one of those support people underneath. I didn't like that executive role, which really did a lot of fiscal management, and visionary stuff, and not so much hands on. I wanted to stay in contact with teachers. I wanted to stay in contact with students at some level and parents. And be involved in that type of direct support. (MI, personal communication, June 8, 2018)

And what I really wanted to do was I wanted to deliberately know, deliberately, intentionally build up the next group of administrators. And I knew that I couldn't have as much influence from [a different] office. Although I have coached and trained every single superintendent and principal [in an area] it's different. (EX, personal communication, June 4, 2018)

But I think what I liked the most about leadership was empowerment. Getting the opportunity to empower other people to do the things that they are good at or could be good at. I like seeing the potential in people and giving them opportunities for them to build their capacity and grow, for the benefit of the whole district or for the benefit of lots of students. But I think that's an area where I feel dedicated to it. I don't know that it's specifically because I'm a woman. But I feel like that's something, or a gift, that we can give back is empowering other women to follow that path. Opening up some doors, not being afraid to do that for other people...I think because I want better for other people. I want better for our kids. I want better or best for our staff, for our kids, for people who follow. I want to build-- I see the potential in people. And I see these good things in people. And maybe they don't even see it themselves. But I want to push them kind of thing. And I want to push us, as a district, to do that, too. Or as a building. So that we're offering the best that we can for our kids, and for our staff, and everybody...I think we take it very seriously, too. There's a real passion that women bring to leadership that I've seen over and over again with different people. I like that because I think through passion comes some really fruitful developments. And I like to think that that's kind of, oftentimes, the fuel for women in leadership, is that they really have a passion for it. It's not just like, "Well, okay. I've been a teacher for five--" I'm a guy, "I've been teacher for five years, so now it's time for me to become an administrator." I think women really want to do it. And I think they really have a passion for it. (DI, personal communication, June 1, 2018)

In speaking of purpose, the women were often very determined about their directions and were clear about what they enjoyed as part of leadership. The tasks often revolved around helping others, working with people. The older, more experienced contributors had more detail to give about their will to lead and how it had benefited them and others. They were thoughtful about what made them want to enter into unknown territory, especially since they had not considered it 
prior to teaching, which many thought was their end game. The urges they experienced were strong in some cases, subtle in others. The process of self-realization took some inward reflection. They asked themselves tough questions about the direction they were headed. They began to get to know themselves and figure out what they enjoyed and inspired them. The inspiration revolved around helping others (making an impact on a larger scale, empowering others, instructional coaching with teachers, etc.).

\section{Negative experiences.}

Often, the women would bring up negative experiences as they recalled the routes they travelled to become leaders. Mostly, they were reluctant to leave teaching or be "in charge" and the self-doubt that accompanied their decision to pursue a different role in education was something they recognized as not ideal. That self-doubt made them feel uncertain about the direction they should go and made them question their passion for the trek to educational administration. An interesting side effect of persistence was that a few women felt a strong sense of separation from colleagues and students; they remembered that effect was not a pleasant one.

A quarter of the women did not start out in education and had some different experiences in their journeys to educational administration. Often, when negative ordeals occurred in those other fields, it stimulated the women to pursue other avenues. For example, BT discovered over time that she lacked the passion to stay in her original career path. This discovery was disheartening:

Then [the original career] kind of went back to more of that supervision piece, and I supervised large staffs, large budgets, all those kinds of things. So there was a change in leadership, a difference in opinion. Not that his opinion was wrong and mine was right, it's just different way of looking at things and I just wanted something a bit more meaningful.... I think he knew that we didn't always agree on things but I don't think he knew exactly what my real issue was, probably. And the other piece was I was-- so that was part of it. The other piece was because I had been kind of that special project person and then done a lot with developing a purchasing system, and renovations, and those 
kinds of things, and when they were restructuring then I went back into that supervision and back into that union piece that I didn't love. So that was the other part. (BT, personal communication, June 7, 2018)

Getting a degree in education helped to reignite her interests and she was able to integrate her beginning career experiences into leadership as well.

\section{Reluctance to leave teaching.}

Many of the participants expressed most their reluctance to leave teaching. A majority gushed about the joys of teaching: how rewarding it was for them, how they truly felt they had mastered the art and craft of it, and how incomprehensible it seemed for them to leave it.

When I started it, I had no intention of going back to school for an admin degree. I had a Master's in reading that I graduated with in 2009 and I was kind of good with that, had taken some other graduate-level coursework, had done some stuff on technology, and I had done some academic things and wasn't quite sure what my path was going to be. (NM, personal communication, June 1, 2018)

But I started on my Master's the first summer, after I just taught one year, in curriculum and instruction because I had no desire at all to be an administrator. (MP, personal communication, July 2, 2018)

Never desired to be an administrator. Never. Never. Thought I would teach, loved the classroom, loved everything about it...Never ever wanting to be a building principal, always staying in my lane of special education, being an advocate for those marginalized kids being included. I was all about that. Never wanted to be a building principal. (MI, personal communication, June 8, 2018)

But I also never really saw myself down the road as building principal. (MB, personal communication, June 6, 2018)

Within that first year, [my principal] started asking me, "Okay, you've gone back and got your Master's in reading. Have you ever thought about being a principal?" And I was like, "No [laughter]. I have not." And she was like, "You're really good at looking at the whole picture." And I said, "Eh, no, I'm fine right where I'm at." (KH, personal communication, June 5, 2018)

But then, [my principal] came to me and asked me if I would be interested in an assistant principal role or something like that because of some of the committee work and stuff...And I said, "Maybe. But I really, really like teaching [laughter]. Could I do a parttime and part-time? Could I teach and do that?" And he goes, "No, no, no, no, no.". (DI, personal communication, June 1, 2018) 
And it was really tough because my teaching partner at the time -- it was the most amazing teaching partnership. It was very hard for me to think about leaving that because it was hardly a job. We did everything together. It flowed really well. I had phenomenal kids, great families. Teaching was really fun for me, but I just really felt like I needed to go into that next journey. (DC, personal communication, July 2, 2018)

As the women reflected about how much they loved teaching, it was apparent in their words and on their faces that they may have never considered pursuing a leadership position because they were so highly satisfied. It took the work of others and their determination to get enough courage together to leave a profession in which they were so successful.

\section{Self-doubt.}

Because of their misgivings about leaving teaching, many were riddled with self-doubt, unsure about their direction, and, therefore, hesitated to take the leap into educational administration.

So I have some of those going towards me possibly being an elementary principal. And in the back of my mind there is always that self-doubt. And I had this conversation with my husband about, is this something that we want to explore? If I take over an elementary building, whatever that building is, my first year would be a lot of time again, first couple years getting things set. And I said, what happens if I don't like being the principal, the person of a building? What happens if I don't like it or I'm not good at it? I can't come back to something right now that I really like and I enjoy. I've kind of got my groove. (MT, personal communication, June 5, 2018)

...because I think it goes to that self-doubt too. Does everybody hate me? Do I suck at this job? And so when someone does affirm you in that way, I tend to really respond to that. (BT, personal communication, June 7, 2018)

I remember the couple nights before the first day of you're the principal thinking, "Okay, what did I get myself into [laughter]?”. (DI, personal communication, June 1, 2018)

Absolutely shocked [when she was offered the first job she interviewed for] because I didn't-- I mean, I have all these people saying to me, "No one gets their first job. No one.”. (KH, personal communication, June 5, 2018)

Self-doubt was a problem for many of the women as they struggled to come to terms with their leadership and their confidence. Despite others telling them they were capable, earning the 
proper education and credentials, and getting hired in an administrative position (some for many

years), that sense of skepticism still pervaded. A few of the women wondered if men felt the

same way or if men dealt with self-doubt in the ways they did.

\section{Isolation/separation.}

Sometimes, the delay to take charge came from fear of being separated from students and separated from colleagues.

I always felt like there was kind of a separation [from colleagues]. I never really felt like I fit in. Even though I had got along very well with them. But I never was the one that they were like, "Oh, let's go hang out. Let's do this." I was always kind of treated a little bit differently. Probably because I was doing so much professional development with them. From my second year in that district, I was leading professional development. (KD, personal communication, June 27,2018 )

[While teaching] You're like in the safe spot. You are loved, and adored, and practically walk on water. It's like, "Oh, Miss U, you're the best thing ever." And then you go to administration. And it's like, "You are the devil. You are the reason everything is wrong. I hate you. You're punishing my kid." You know? And so it was like, "Oh, okay. All right. Let me try not to take this personally, but, boy, you sure are saying a lot of things that make me take this personally.”. (TU, personal communication, May 31, 2018)

The women concurred that being a leader is hard work. At times, as they forged ahead in their journeys, other unanticipated side effects became known. It was a shock to some when they realized they were isolated from others, especially as they set out to work in a field whose participants value and need people. The sense given was that they had to come to terms with it or they would not survive in the role of a leader.

They also expressed an uncertainty about their roles as women in such positions.

When I feel like we climb, do we get to the point where it's like, I don't really need to climb anymore. I'm okay where I'm at. You know. I don't know. That uncertainty is not comfortable. I don't like it [laughter]. (MT, personal communication, June 5, 2018)

When I started teaching in the building, I knew I wanted to get my Master's degree. And I wasn't really sure about which direction I wanted to go. (TU, personal communication, May 31, 2018) 
I started at [local university], and again not knowing for certain what I wanted to do. I felt like curriculum and instruction wasn't necessarily the path. I felt like that was just kind of a continuation of my undergrad. I wanted to see a different area more so than kind of specializing in teaching altogether. (MB, personal communication, June 25,2018 )

I don't know what else is leadership other than collaboration, and building those relationships, and trying to develop other people. I'm trying to do more of that because I think that's what people have done for me, so I'm trying to be more of a mentor to other people. But sometimes not always sure what I have to offer is what other people want or need, so. (BT, personal communication, June 7, 2018)

The uncertainty they experienced was part of their identities in many ways; they recalled it to be a factor in their later decisions, good or bad. At times, a questioning tone emanated from their wondering about their paths, as if they were still not sure that they made the right decisions along the way.

\section{Good Leaders}

The themes that came through in the rest of the data were quite clearly empirical as far as the women were concerned; they had plenty of experience and examples on which to draw as I asked the questions related to what makes a good leader, how they identify themselves as leaders, and women in educational leadership, in general.

Based on the flow of the interviews and the questioning, it became logical to examine the two closely related categories of what the women defined a good leader to be and how they saw themselves as leaders. In order to understand the data that reflected their views, I created a roleordered matrix that “...groups, summarizes, and compares different people's role perceptions about selected topics or issues that enable the researcher to compare and contrast those perceptions" (Miles et al. 2014, p. 162). 
Table 6

Role-Ordered Matrix: Good Leaders

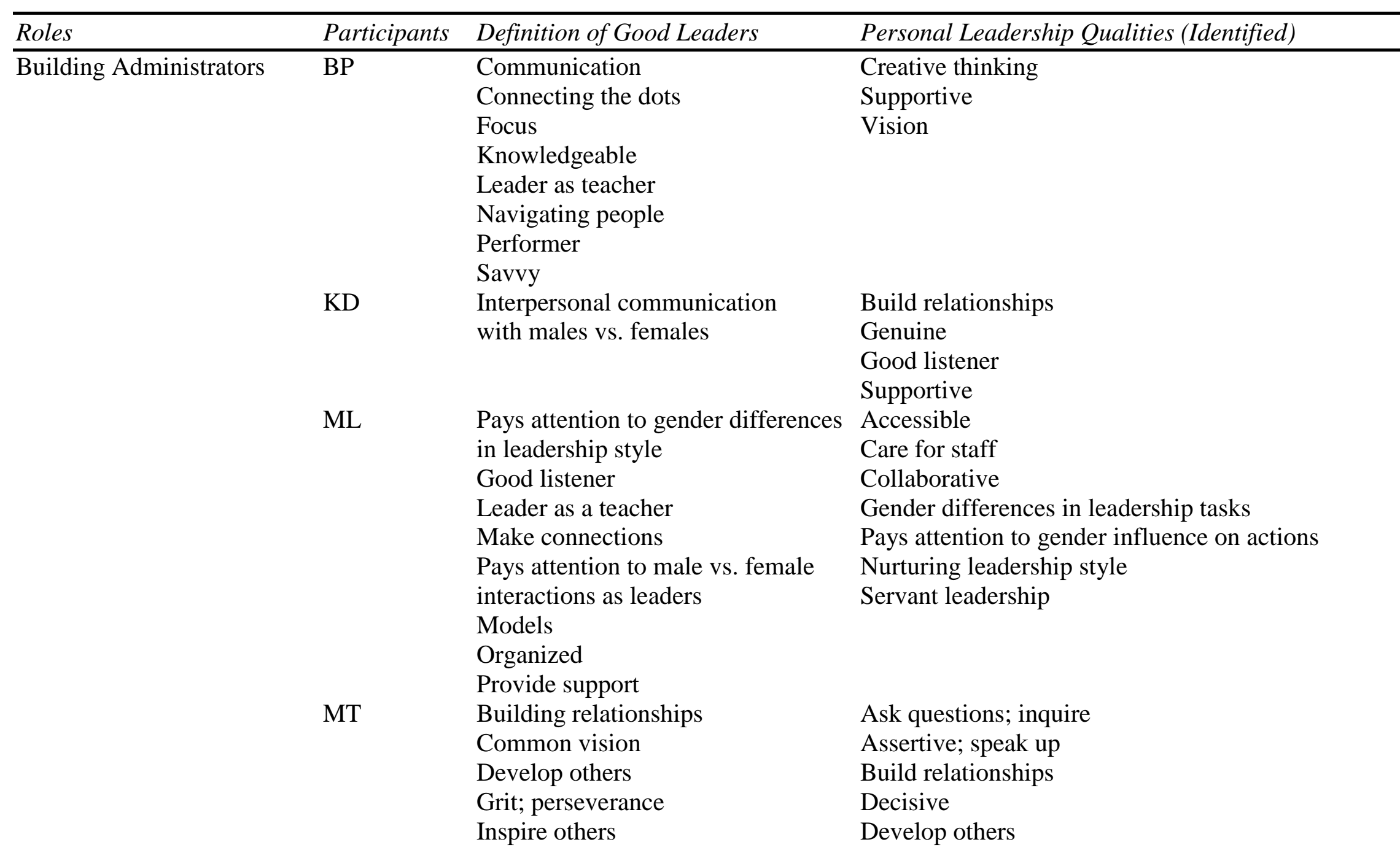

(Table Continues) 


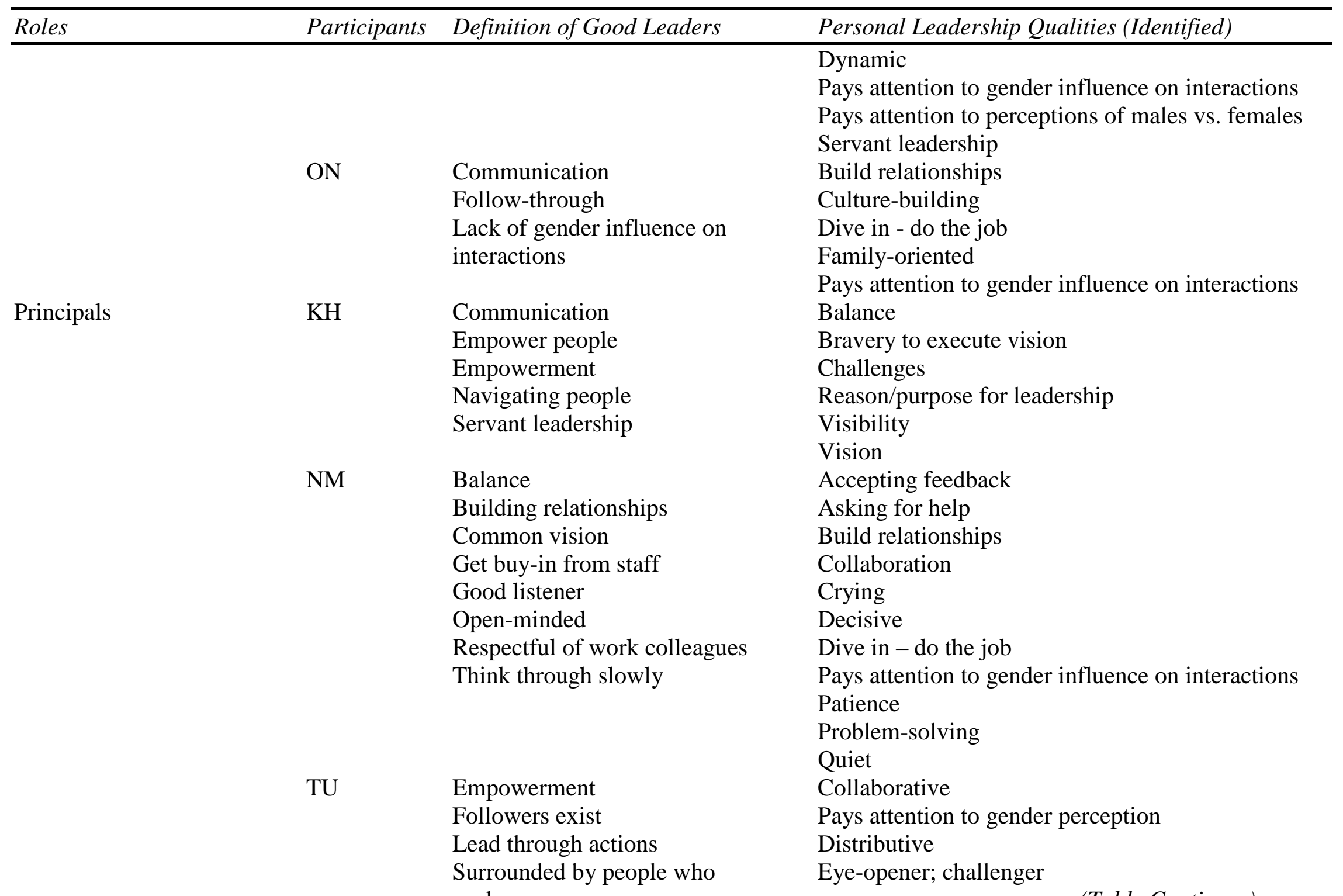

push

(Table Continues) 


\begin{tabular}{|c|c|c|c|}
\hline Roles & Participants & Definition of Good Leaders & Personal Leadership Qualities (Identified) \\
\hline Directors & $\mathrm{MB}$ & $\begin{array}{l}\text { Attention to detail } \\
\text { Decide for the whole } \\
\text { Establish boundaries } \\
\text { Pays attention to gender differences } \\
\text { in leadership styles } \\
\text { Good listener } \\
\text { Use resources and empower people }\end{array}$ & $\begin{array}{l}\text { Open-expressive } \\
\text { Pays attention to perceptions of males } \\
\text { Self-reflective; aware } \\
\text { Servant leadership } \\
\text { Build relationships } \\
\text { Collaboration } \\
\text { Family background influence } \\
\text { Self-reflective; self-aware } \\
\text { Vision } \\
\text { Creative thinking } \\
\text { Differences in ways of leading } \\
\text { Do right by kids } \\
\text { Efficiency } \\
\text { Goal-oriented } \\
\text { Open-mindedness } \\
\text { Reliable } \\
\text { Blurred lines in role } \\
\text { Collaboration } \\
\text { Pays attention to consequences for different } \\
\text { treatment based on gender } \\
\text { Crying } \\
\text { Decisive } \\
\text { Pays attention to differences in gender self- } \\
\text { perception } \\
\text { Facilitation; collaboration } \\
\text { Family background influence } \\
\text { Pays attention to perceptions of males vs. females } \\
\text { Play the game } \\
\text { Treatment from others based on gender } \\
\text { Work in progress }\end{array}$ \\
\hline
\end{tabular}

(Table Continues) 


\begin{tabular}{|c|c|c|c|}
\hline Roles & Participants & Definition of Good Leaders & Personal Leadership Qualities (Identified) \\
\hline \multirow[t]{27}{*}{ Assistant Superintendents } & $\mathrm{DC}$ & $\begin{array}{l}\text { Building relationships } \\
\text { Vision }\end{array}$ & \\
\hline & DI & Balance & Build relationships \\
\hline & & Collaborative & Developing others \\
\hline & & Pay attention to lack of gender & Dive in - do the job \\
\hline & & influence & Multi-tasking \\
\hline & & Pays attention to gender influence & Reason/purpose for leading \\
\hline & & $\begin{array}{l}\text { on expectations/perceptions of } \\
\text { females }\end{array}$ & Work towards leadership \\
\hline & & Handling change & \\
\hline & & Implementing with leadership & \\
\hline & & Leadership capacity/potential & \\
\hline & & Natural leader & \\
\hline & & Navigating people & \\
\hline & & Pays attention to perceptions of & \\
\hline & & males vs. females in interactions & \\
\hline & & Reason/Purpose for leading & \\
\hline & & Self-expectations & \\
\hline & & Task assignments for females & \\
\hline & & Trust & \\
\hline & & Transparency & \\
\hline & EX & Acting on core beliefs & Articulate \\
\hline & & Building leadership capacity & Build relationships \\
\hline & & Pays attention to gender influence & Crying \\
\hline & & on expectations/perceptions of & Family-oriented \\
\hline & & females & Pays attention to gender influence on interactions \\
\hline & & Knowledgeable & Give right information \\
\hline & & Navigating people & Impactful \\
\hline & & Networking in leadership & Support (or lack of) \\
\hline
\end{tabular}

Providing support

Self-expectations

Values

(Table Continues) 


\begin{tabular}{|c|c|c|c|}
\hline Roles & Participants & Definition of Good Leaders & Personal Leadership Qualities (Identified) \\
\hline & MP & $\begin{array}{l}\text { Build relationships } \\
\text { Common vision } \\
\text { Communication } \\
\text { Connection } \\
\text { Empower people } \\
\text { Humility } \\
\text { Reflective } \\
\text { Navigating people } \\
\text { Recognizing others } \\
\text { Transparency } \\
\text { Trust } \\
\text { Values }\end{array}$ & $\begin{array}{l}\text { Collaborative } \\
\text { Pays attention to gender influence on interactions } \\
\text { Lay foundation } \\
\text { Participating in like tasks } \\
\text { Task-oriented; task-based } \\
\text { Transparency } \\
\text { Vision }\end{array}$ \\
\hline
\end{tabular}




\section{Defining good leaders.}

Interestingly, the women only shared a few qualities between what they assigned to good leaders and how they see themselves as leaders. Building relationships, collaboration, focus/vision, support, and transparency were the main commonalities between qualities the women thought good leaders should have and qualities they have. The analysis of this particular data was surprising as I anticipated that women would cross-reference those attributes between others and themselves and that did not necessarily happen all the time.

All of the women could list many attributes that define a good leader. They presented a wide range of tasks, descriptors, and behaviors that good leaders should be able to complete and embody. Ones that were mentioned most often included building relationships, effective communication, empowerment of others, navigating with and through people, being a good listener, and trust. In many instances, as the women thought and spoke about what they perceived to be good leadership, they brought to light descriptions about males and females, pointing out differences and similarities. In such, they described the interactions, communication styles, influences, and perceptions they observed about good male and female leaders. The interviewees often engaged in comparing and contrasting leaders of both genders.

\section{Building relationships.}

The participants determined that the ability to build relationships is one of the best qualities of a good leader. They spoke of the importance of following the "Golden Rule" (the biblical tenet, "Do unto others as you would have them do unto you.") and that good relationships serve leaders well, underscoring that a good leader is only as good as the people surrounding him/her. A few noted that having a following was key to successful leadership and they told specific stories about such situations. I should say the traits that I choose to emulate the 
most have to do with relationships and with how you treat people...And that's very consistent with the lifestyle that I'd grown up with my parents and what they expected in a Christian household and that the most important thing is how you treat people. I mean, nothing else. Even if you can't even read the words on a page, if you treat people right, you're going to be successful. I mean, that was very much ingrained in my head. So I would say that for me, a good leader is someone who does keep the people in mind, can build relationships, and uses those relationships as a way to help those people grow. (DC, personal communication, July 2, 2018)

There's three ways that you can be a leader...One is you get a title, and people will respect you because of the title...I think the other one is position. That you can have a title but a different position, power position. And the third is relationships. (EX, personal communication, June 4, 2018)

I think, for me, good leadership starts with building the kind of relationships that can move an organization or move a part of an organization... (DI, personal communication, June 1, 2018)

I also think it's someone that has to be-- you have to be able to get the buy in from staff, either through the relationships that you develop, or just that your stuff is that good that they want to follow you. (NM, personal communication, June 1, 2018)

And when I think of some really effective leaders, they're really good at relationshipbuilding and then leveraging those relationships to move an organization forward. (MP, personal communication, July 2, 2018)

Out of the several skills the women attributed to good leadership, building relationships between those who lead and those who follow was one of the first mentioned, which indicated its importance. They noted its benefits and the evidence that its impact is critical to how a leader can make progress with people. 


\section{Effective communication.}

The women also highly ranked utilizing effective communication as a leader. They

stressed the importance of this skill by speaking of how important communication is in educational administration.

And then communication is always the number one issue. If you have good lines of communication with your people, you can accomplish anything...But I don't think males are necessarily any more capable or vice versa of being good communicators...I think that just comes down to personality. (ON, personal communication, June 25, 2018)

Communication is huge, and I think, to some degree, there has to be-- I don't want to necessarily say personality because I don't think all great leaders have the same personality, but there has to be a way for those leaders to connect to their stakeholders...I think the one that I'm going to keep coming back to, that seems to be more natural for women, is the communication piece. That seems to be something that-- when I think of female leaders that I've worked with, or been exposed to, they're really good at that. And it's something, from my experience, that a lot of male leaders struggle with. Or those that are, it's taken them time to get that way. And it's something that's been very deliberate on their part. It seems to me like that is something that comes a little more natural for most females. And written, verbal. I mean, all of the above. The whole communication piece is a challenge for a lot of male administrators that I've [laughter] worked with. (MP, personal communication, July 2, 2018)

I mean, regardless of education----or any other field I've been in----communication has always been number one in any field, I think. That's probably the biggest one...because if it's bad, then lots of things are bad. If it's good, then lots of things are good. (BT, personal communication, June 7, 2018)

I think women are much more communicative. I think they are more communicative than men. I think they're much more systematic. And I think they're much more transparent. They put that list out there, they wear it on their sleeves, they share that so that everybody knows. It's my opinion that men, they might share that, but not in a systematic way, where it's really transparent for everybody. And what I mean by transparent, that everybody can see it and mull it over, even just visually. (MI, personal communication, June 8, 2018)

In their exploration of the importance of communication in good leadership, these women

thought about if being a male or a female made a difference in how communication happens. As noted in the prior quotes, there were differences in their viewpoints. MP who thought males and females communicate differently is more experienced and is higher up in educational 
administration. ON had a background in theater, which may have influenced her perceptions.

Perhaps males she worked with were most likely hyper-communicative due to being active in theater, which demands effective communication at a very high rate and standard. Regardless, these women, along with others, thought that good communication was a useful skill in a good leader.

\section{Empowerment of others.}

Quite a few subjects in this study cited empowering others, especially women, as being a valued quality in a good leader. They had first-hand knowledge of such empowerment at the behest of leaders, as they were often the beneficiaries of such effort. The interviewees gave examples of situations where others had experienced the benefit of mentoring that prodded and pushed.

But I feel strongly about making sure that everybody knows what's going on. And I, at times, may have been more transparent, especially when I was a building leader, than I should've been. But that whole information piece makes people feel empowered. And if there's stuff that doesn't have to be confidential, then why are we not sharing it? I mean, a lot of times if you explain the why behind your decisions, things go a lot smoother. (MP, personal communication, July 2, 2018)

I always thought I had to know everything. And you don't have to know everything. But you have to know your resources. And you have to empower people. And if they are an expert, that's where you want-- you have to empower that right person... But you have to allow that person to hone their craft and bring that gift to the table to share with everybody, so to speak. (MI, personal communication, June 8, 2018)

So empowering [staff] to try this or take the lead on this because ultimately, they're going to most likely get more support than even us as leaders, the building leaders, the established building leaders. Sometimes they can get more buy-in. I mean, there are people who have already identified themselves as leaders and want to try things, and they come to you and say, "I want to try this." "Absolutely, let's do that." I think when you see sparks of that creativity, when you see sparks of that innovation, just encouraging them to do that. (KH, personal communication, June 5, 2018)

These participants understood the value of empowering others. They did not specify a preference for males or females as the ones to empower; that difference did not matter to them. What 
mattered was the act of intentionally setting up the situation so that others could lead and

perform.

\section{Navigating with and through people.}

One of the harder skills all leaders must activate is the act of navigating with and through

people. Educational administrators have to learn this way of getting things done early in their

careers. If they do not learn it quickly, they tend to fail. The women I talked with referred to this

way of being in leadership as one of the more important, active ways of enacting initiative.

But one of the things that [a mentor] -- his number one response or number one item [of advice] was, "You need to become friends with the superintendent, and you need to figure out how big his or her ego is, so you know how to work around that when you're trying to make decisions for your staff." And that is very, very true [laughter]. (MP, personal communication, July 2, 2018)

My secretaries never have somebody talk nasty to them because as soon as somebody gets nasty, they're to transfer them to me. And that's never a good thing for that person on the other line. My people work really hard. And I think that's a female trait. I think the other part of my gender is that I really-- I think teaching is-- I think the profession of teaching is giving hope. You'll hear me say this sometimes. It is that belief that if you get educated you can have a better whatever it is, life, day, education, I don't know. And I think women have to be hopeful people because we bear children. Right? I mean we bear children, and I think that's it. (EX, personal communication, June 4, 2018)

It seems to be a common thread that when you look at those individuals, it's very evident that they have worked their way up, or they have worked hard at, or they have a strong work ethic. They also seem to have built strong social capital, as well. And I think, but I don't-- I mean, this is just a theory. But I think because they've had to navigate around roadblocks that have been put sometimes in front of them. Where sometimes there hasn't been the same amount of roadblocks that have been put in place for males. (DI, Personal communication, June 1, 2018)

And so we need people who are in leadership who understand the job itself but also know the political workings of legislature, and city boards, and things like that. They need to know which organizations to belong to and when to talk to the press. And they need to be able to navigate that public sphere adeptly. (BP, personal communication, June 5, 2018)

As they explained the navigation with/through people that educational leadership requires, these interviewees mentioned gender as a factor that influenced that navigation, but not necessarily 
halted it. They were aware that how that navigation happens can vary, but that it is an act that is necessary and bittersweet.

\section{Good listening.}

As leaders work to navigate with and through people, one of the duties they must perform is to listen well.

Well. First of all, I think it's someone that has to be able to listen without necessarily reacting right away, and consider all views of whatever the issue is. (NM, personal communication, June 1, 2018)

And I think that being a good listener and really hearing the needs of your faculty in order to be able to assist with what they need to be doing for the needs of the students is really important. (ML, personal communication, June 26, 2018)

I think an effective leader, a good leader, is a good listener. Can make those decisions from an educated standpoint, looks at the whole, has presence, is approachable yet professional. Do you know what I mean? You don't cross that line. (MI, personal communication, June 8, 2018)

The women claimed that good listening makes a difference in how followers view a leader and

how a leader views followers. Without it, the kind of progress needed in education cannot happen.

\section{Trust.}

Lastly, in regards to defining good leadership, a major theme was that of trust. Trust was valued as a trait good leaders must plan for, practice, and maintain in order to be effective.

I think that the people that you are leading, you have to trust them, and that's hard. It's hard for me as a very type A. I like to be in control. If something were to go wrong, I like to know that, hey, it falls back on me, and it wasn't because of something that I delegated to somebody else. That's hard for me even 10, 12 years into working, however long I've been working. But yeah, that trust, I think, is really important. And I've been fortunate that I have had three bosses in my lifetime, as far as being an adult in the career, that have trusted me. (MB, personal communication, June 5, 2018)

And we had-- I think another thread in there was trust. We had trust in each other that we could give our best, and our best from whatever standpoint we came from, and our knowledge, and our thoughts on something, without any fear of anything. Any fear of 
reprisal, or any fear of anything. That we could just be totally transparent and honest. And that whatever we developed was going to be better than any one of us could have on our own because of that. (DI, personal communication, June 1, 2018)

These two women conveyed their belief that trust was important to leadership in a way specifically tied to their own experiences with being trusted or being in a trustful situation. They were certain that good leaders with trust are valuable because they had positive and long-lasting interactions with trust themselves.

\section{Identity as leaders.}

The participants answered assuredly when asked how they identified themselves as leaders. Interestingly, though, they often answered using adjectives that were different from the ones they used to describe good leaders. More than one mentioned situations that exposed negative experiences or weaknesses (i.e., crying on the job). In this portion of the study, too, they delved into exploration about gender differences and whether or not their gender influenced their identification as leaders. They reflected about the descriptors and whether or not the same would be said about a man. As the contributors examined their identities as leaders, they considered one of my follow up questions: Thinking about all the qualities you listed in identifying yourself as a leader, how much at all does your gender have a role in that identity? Many times, as they thought about the answer to this question, the women talked through about how they were perceived differently than males. They cited specific situations and examples they had personally experienced.

\section{Building relationships.}

Members of this study cited building relationships the most as they distinguished their identities as leaders. 
Making relationships with the kids and the teachers and being out there and getting involved with them and watching what they're doing and being in the classroom. Those are the things I care about. (ON, personal communication, June 25, 2018)

One of the best things I think, having been in this district a long time, is having relationships. I knew every principal before, every elementary principal. I had many conversations with all of them prior to being announced [as a new principal]. Just over the years from different things, whether I was teaching summer school with [an elementary principal] or [another elementary principal] knows my mom and so that's all. That kind of stuff. So just having all those but I-- the number of emails I received afterwards that were just congratulatory and thankful and if you need any help let me know. If you need [help]-- was amazing and so I know that support is there already and so I won't have any problems reaching out for that...And yet distinguish myself as different enough from the [previous] principal, too...So that was hard initially. It started with relationships, getting to know people. (NM, personal communication, June 1, 2018)

I feel like building a relationship is important, and I've kind of always thought that if you're leading, and you turn around and nobody is following you, you're not really leading. So you could have all these great ideas and so forth, but if you haven't built the relationships that make people want to walk along with you, then you're not going to be successful as a leader. I think that it's also about, as you're building those relationships, figuring out who are the ones that are critical relationships that you have to build to be able to get the other people to come with you, too. I know on my seventh grade floor, some people were really easy to just, you're my principal, whatever. And then there were other ones that I was like, oh boy, they are onions, and I had to peel them a little layer at a time and not come in too hard, but just slowly, slowly, and over time I have been able to see those relationships build and realize that they see me as a leader. But that took three years for some of them, where others not so much. So I think that relationship piece is huge. (MT, personal communication, June 5, 2018)

Well, I think his perception is-- I mean, a male perception-- the perception is if you are someone that can remove emotions from some of your decision making, then you're stronger. That's definitely a male characteristic. And in my most recent past, I've had some board members say things to me like, "Basically, you need to make decisions. Take the emotion out of it." And in my mind, that was a slam against what we were trying to do. We were advocating very strongly for something we thought would make the teachers lives easier. And yes, we may have gotten emotional, but we have the relationship with them. The board members, they don't know who they are. I could say our superintendent at this point doesn't know the staff. So it's really easy to make these decisions when you have no personal connection to your stakeholders. (MP, personal communication, July 2, 2018)

One is you get a title, and people will respect you because of the title. One is because of-I got to think-- I always forget this one. It must not mean anything to me. Title, I think the other one is position. That you can have a title but a different position, power position. And the third is relationships. And I'll never forget, I was very early in my career, very 
early, year three. And he [a mentor] told me that. He goes, "Why don't you decide right now how you want to be seen." And I don't care about titles, and I don't care about positions because I've always been able to do what I wanted to do anyways. So for me, I identify myself as a leader on if people are inspired after being with me or a project, or something I've exposed them to, or something like that. If they're willing to take a chance. ...I'm about "We are professional colleagues". That's the beginning of a relationship, right? So I've got to take care of you as a professional colleague first. And then if that relationship develops - and one out of ten will - into a friendship, cool. That's great. But my job, and I think any leader's job, is to take care of the people that work with them in that environment first. I believe the same about teachers. Your job is to take care of the kid in your classroom. The family life, the dean's office, that might come later, but take care of your sphere of influence. You start closest to you, number one. Number two, they have family values that they're not afraid to talk about. And I know those two seem to contradict each other in a way, but I find that good leaders have a good foundation at home and when that foundation is rocky, they make bad decisions at work. Now in saying that, everybody has rocky relationships at home. It's not perfect. I'm talking about like when they don't have support at home, or friendships, or stuff like that...So this is where having a title helps me because the title got me in the door, but the relationships got me authority. (EX, personal communication, June 4, 2018)

I know that in leadership you've got to build relationships, and I think I'm good at building relationships but only when they are like in close proximity to me. Building a relationship with teachers in another building that I don't know and I see infrequently, that's hard for me. I'm not one of those people that I'm just-- I don't draw people to me and vice versa. So I think that part's a challenge for me. (BT, personal communication, June 7, 2018)

And I really try to build strong relationships, especially with staff. But when I said with being genuine, to me if I were to go out and be all goofy and to try to be this gregarious person, that's not me, and that would come off as fake, and I would feel fake. So I try to be consistent in who I am, whether it's dealing with kids, or staff, or anything like that. And that's a little bit of a hurdle at times because it takes a little while for the people to get to know me and-- but I try to just make that personal contact with them. So instead of trying to be the big personality in front of the whole staff, I'm much more-- I'll go to the classroom and have a conversation one-on-one with them or if I have a question or if they want me to follow up with discipline or something that I'm working on, I'm much more likely to go and talk to them in person. And then trying to make those personal connections. Asking about their kids, and their projects that they're working on, offering to help. (KD, personal communication, June 27, 2018)

Just as the women placed building relationships high on their list when asked to define a good leader, they answered in similar ways when it came to looking inward about themselves as leaders. What is noticeable in these answers is how the women described the very personal ways 
and style they use to go about that task. Building relationships was handled differently, depending upon the personality of the woman and their philosophies about leadership. Personal, emotional connections with people were of utmost importance and they described those interactions as a valuable tool.

\section{Servant leadership.}

Connecting their leadership to the importance of building relationships, the women spoke about how they considered themselves servant leaders.

So I think it's really important to not only talk but walk the walk. So listening and being approachable, and I really think that servant leadership is really huge. I mean, I feel as though I'm here to assist my teachers to help the kids, not that my teachers are here to assist me. (ML, personal communication, June 26, 2018)

So when I think about myself, I really think about that servant leadership role, and that's really I feel like the main course that I take within leadership. I don't know. I mean, that visibility is huge when I think of leadership and when I think of the contributions that-- I mean, you can make all the contributions that you want, but if other people don't view you as that either-- but there's definitely a balance between being part of a team versus leading a team. And you try to do both because you need to lead that team, but you also want to be included as part of that team. I don't want it to seem like I am the only person who matters on this team. (KH, personal communication, June 5, 2018)

I am definitely a servant leader. I am really about serving others. I am one of those people-- I think about even when I meet new people. I don't tell them what I do. I may say that I work for [school district] or I work at [school name]. Because I think there's always this perception that comes when you tell somebody that you're a principal. And to me, the title is the least important thing on the planet. And so I don't care that people know that because that is not what I'm about. I am really here to serve the students and then the staff of [school name]. It's all about them because [this locale] is not this booming metropolis for minority women. Let's just start with that. And so there are kinder, gentler principalships. There are more diverse communities that I think I could be in. But I've often thought about, I'm here for a reason. And I feel like the students and staff need me to open their eyes to some things. (TU, personal communication, May 31, 2018)

And the other thing to leadership, I think, is being a servant leader. So not only do we have to be able to formulate the direction and be able to help push along, but to be able to get the input from the people around you of where do we want to go, and then I'm going to do the things to help us move there. And in that is serving them to be able to help them do their job better. (MT, personal communication, June 5, 2018) 
Greenleaf (1970) defined the servant-leader as, “...[a] servant first... It begins with the natural

feeling that one wants to serve, to serve first. Then conscious choice brings one to aspire to lead"

(p. 6). As the women explained their role as a servant-leader, they were able to accurately define

it as one that helps the leader and the people being led. They are able to get to a place in their

leadership that allows for progress, a place in which they feel valued and their staff feels valued.

Feeling valued helps students.

\section{Decisiveness.}

The participants were very certain about how decisiveness was a critical attribute they

tried very hard to hold onto when leading others.

I think that decisiveness can come off when women are that way, as being a bitch, as being a power freak. Well, it's nothing like that. It's just like I know we have a laundry list of things to get done, and when you give me these options, I can tell you which one aligns with my vision very quickly. And I feel like if you have to think about it, then there is a problem. I'm talking about curriculum or policy-types decisions. There should be a clear answer based on your values, your vision, and if you're student-centered, the answer should present itself. So I typically decide things very quickly. But I know that, again, sometimes women get thrown under the bus for following their values or their visions, or making decisions very quickly and can be seen as being inflexible and/or being a [expletive]...But I'm very conscious of that, of how I make decisions, how quickly I make decisions, the way that I message it. (MP, personal communication, July 2, 2018)

I think I can be decisive. I am decisive. So if there's a decision that needs to be made, I'll make it...So I will make a decision. I'm not indecisive, I'm decisive. I like to hope that most of my decisions are right and good and move us along. I'm sure there are times that it's not [laughter]. (MT, personal communication, June 5, 2018)

And even when I was a building principal, ultimately, I'm the one that's on the line, and I'm the one that's got to make-- can I draw that line? You bet I can. If I have to make that decision, I have to make that decision...I can be decisive. I have to be decisive. I know that when I am decisive-- it's not a popularity contest. I know that. I'm very much not a popular person many times in the district. And that's okay because I know where my decision is made from. It's made from gathering information and it's always with the best interest of the student and also the law. (MI, personal communication, June 8, 2018) 
I try not to be a dictator. I definitely know that that's not my style at all. I think though finding that balance between, hey you got to make a decision you got a-- it's got to be made regardless of who you're upsetting versus being collaborative and making those decisions. So I'm going to-- I've tried to do both. (NM, personal communication, June 1, 2018)

As the women who discussed decisiveness shared its importance, they also explored how that decisiveness is perceived. The tone that they used was one of conviction about being decisive. They were aware that decisiveness in women could be perceived in certain ways, differently than it is in a male. They seemed afraid that having the quality of decisiveness would make them out to be perceived as unforgiving or rigid, which they defended was not the case. They also implied they are proud of the fact they perceive themselves as decisive. This tone was evident as they repeated the same kinds of words in their answers and in explaining the purpose behind the value of that quality.

\section{Focus and vision.}

The women contributed that diving into the job of leadership and actually doing it with focus and vision was important to their success and effectiveness.

So by keeping that very large picture in focus and then working our way through all these other issues, whether it be grading practices or school improvement planning, with all these things that go into creating the ultimate outcome, keeping that main focus in mind. (BP, personal communication, June 5, 2018)

I would say that I'm very vision-driven. I like to know what the endpoint is, either defined by the board, defined by the superintendent, and then that tends to drive everything that I do...So I would say someone also who has really clearly defined vision and values, and whose actions align with that vision and values. (MP, personal communication, July 2, 2018)

...there were so many things that I could see, or have this vision of where I wanted the school to go, and where I wanted the teachers to go, and what kind of opportunities we could open up for kids. (DI, personal communication, June 1, 2018)

I see myself, hopefully, moving into a [principalship] at some point because I think my strength is big vision stuff. I'm very organized person, but I think my strength is seeing 
the big vision and having other people help me achieve that. (BP, personal communication, June 5, 2018)

I'm always looking at that aspect of, "Okay, I'm going to do what's in the best interest of children." That doesn't always make people happy, but I'm not here to make them happy. I'm here to provide that supportive environment, but yet-- I mean, I feel like I'm an outlier sometimes, in the sense of, "This is our goal. This is what we're reaching for." But sometimes I don't have the backing behind it just due to perspectives maybe. (KH, personal communication, June 6, 2018)

...but I guess I've always known that it was, it just wasn't at the tip of my tongue - is the importance of having a vision and staying with that vision and being very intentional about aligning everything that you do with that vision. So I guess that would be another leadership trait. Respecting the history of an organization, I think, is also important. But again, that comes through the people [laughter] to me. (DC, personal communication, July 2, 2018)

Vision and focus is defined by these women as important and purposeful. Many tied it back to students and how it can affect them, which shows a lack of self-centeredness. They believed that vision and focus has a strong meaning in human lives. They stressed the requirement that vision and focus takes organization. It is the job of leaders to remember it and to keep it in the forefront. They must communicate it and motivate others to see and support it.

\section{Support (or lack of).}

At times, the interviewees would talk about how support was something they tried to give frequently and that they did so even when they were not feeling supported.

I've had the experience where a female basically took one of my ideas and called it her own and I had to call her out on it. So I think some of that goes on. Now, I haven't had a guy do that. Yet...And I also feel like sometimes it depends on the-- for example, the ones above, our bosses, whether they advocate for us and encourage us to. I feel like some of the women who've gotten ahead have had good advocates that have celebrated and promoted-- hey, this is what this person has done. (KD, personal communication, June 27, 2018)

I've had very few situations that women have not helped me. You know like how sometimes you'll hear that the backstabbing or the-- I've not had a lot of that. I've had a little, not a lot. (EX, personal communication, June 4, 2018). 
I was very fortunate to have a female administrator who really pushed me to be in opportunities within this building. And so I feel some level of responsibility, like, "You got to pay it forward and create opportunities for other women." I think, unfortunately, as women, we, maybe, don't always do enough to help each other versus I think it's a more common practice with men...I hate to say it, but there's some cattiness or something. I don't know what it is with some women. If it's a sense of insecurity or what it is to kind of pull each other along. I don't see that with men. I think men are way more comfortable reaching out to each other. I don't know if it's a fear that we don't want to look like we don't know what we're doing or what the case is. But as I think about, just even in my years as principal, I can't say I've necessarily reached out to other women either. But I know as assistant principal and associate principal, I had a lot more contact just even with our colleagues across and communicating with each other and getting together. It's kind of funny. We did a lot more often than I did as building principal. I don't know if it's just I'm just too busy or whatever the case is. (TU, personal communication, May 31, 2018)

So some acknowledgment that you were not the end-all be-all, that you can't be expected to have all the answers, and making sure that you're recognizing and valuing, giving credit, to those people that may be able to support and assist you. And I think really good leaders recognize what their areas of strength and weakness are. And then they build a team that is complementary to them. But in order to get there, you have to be reflective enough to be able to admit you do have some weak areas, and then try to find some leaders that kind of fill in those gaps...And again, being confident in what it is you do and surround yourself with supporters. Find your group and just utilize each other. Again, that's one of the greatest things. And you know this, being part of a pretty large district and team, that you become better as a result of who surrounds you and the conversations that they pull you into, and all of those kinds of things. I think knowing also when to ask for help, when you feel like you're-- when you're drowning or when you don't have enough information to make a decision, not being afraid to ask for help. (MP, personal communication, July 2, 2018)

So I think just having those various people to talk to that would lend support. And it wasn't always the pat on the back, "Hey, you can do this." It was truly, "I don't have a lot of expertise or background in this, so I'm going to need to pick your brain." I think that's one of the things that was most helpful to me...And not to say that my current boss doesn't do this, but I will say that I felt it was very much from working with [former principal] and working with [former principal] that they wanted to see, specifically, women and leadership positions excel. So what we do-- or how can I best support you so that you do that? (MB, personal communication, June 11, 2018)

... [a former principal] was an awesome principal to work for, and she was awesome because she was thoughtful, she provided that feedback, she was purposeful, but she also knew you could do your job, so she'd let you do your job. [Another former principal], and maybe it's just because of where she was at in her career, and [then she was sick] on top of it, it was, "If you're doing your job, I'm going to leave you alone, but if you're not doing your job, your team's going to help you out." She didn't want to make waves. She wanted to provide the support but she kind of did it in a non-supportive way and put it on 
others' plates. And so quickly it was like, "Okay, we've got to figure out how to survive here." Because it's a tough [elementary] school, too, the demographics and the behavior. So we quickly learned to rely on each other... Take advantage of [support] and utilize those talents and move forward because this job isn't easy. But I don't think that it's one that you can just do by yourself either. What's nice is having supportive networks. I mean, we all know each other now, and we've been together long enough where I know I can call on you because you've had this experience, you've done this. So that collaborative approach, it's just huge. (KH, personal communication, June 5, 2018)

I think the one thing that I am struggling with, not just in work but in society right now, I don't think it's man versus woman. I don't want us to get into that culture because I know a lot of men that support women as leaders. And I know a lot of women that support men as leaders. And I think that we'll really know we get rid of the gender issues when we can't even remember. And I've been given a really great gift in my job now that I really can't tell the difference between the people I work with. I don't think about the men and women very differently. Nor do I think I'm perceived very differently either, so. I struggle with that because I think that right now we're really-- is supporting women leadership against men? And I say no. But I think we should be supporting good male leadership. And I don't see that as against a man, or a woman. Do you know what I mean? (EX, personal communication, June 4, 2018)

Former United States Secretary of State Madeleine Albright (2016) once said, “There's a special place in hell for women who don't help each other" (para. 2). When the topic of support from others came up, some of the women pointed out they didn't necessarily get support from other women. I did not expect this information to be revealed at the rate that it did. I did not prompt the women to speak about the kinds of support by women specifically; I only asked them if gender mattered when it did come to support. Again, surprisingly, they shared stories about how support from women could be contentious and lacking, or perceived as such, or even expected. The women expressed confusion about those incidents and it made them wonder about the cause. It made them think about how lack of support can hinder the progression of women in educational leadership.

\section{Crying.}

All of the women brought up examples of how their gender influenced interactions they had on the job. Some of them mentioned one that surprised me in what they qualified as a female 
reaction they said happens from time to time: crying. A quarter of the women presented their experiences with crying on the job, but it was not necessarily what one would expect. Naturally, some had actually done it; they expressed regret and explained how it was perceived as typical for their gender. Others, though, shared their frustration that it was assumed they would cry on the job. Still, the women took time to analyze the experiences with crying (or not crying). One defined herself as someone who does not cry, based on the feedback of a male colleague who was encouraging her to go into administration.

So the joke at [my former school] was always, first-floor people were humanities people [laughter], and second-floor people were math-science. So [my former principal] would always say-- I remember my first year, as an [assistant principal], by November, saying something like, "If I would've known all of the adult counseling that goes on in an administrator's office, I would've gotten a counseling degree, for the love of Pete. I feel like that's all I'm doing." And part of it was that those people knew me. I taught with those people for forever, but still, it was different. And one lady was in my office one day crying. And she was crying. I'm like, "There's no crying at work." I was being stupid. [My male mentor weighed in], "Well, you think that because you're a second-floor person." I said, "What do you mean by that?" He's like, "Second-floor people don't cry." And he starts laughing. Evidently, that had been a joke in the office that the second-floor people were much easier to deal with because [laughter] they're very black and white. We're math and science teachers. And the first-floor people are a little more difficult to deal with at times because their world is gray...It was very interesting. So that became the joke. And him and I still joke about that. Whenever I get emotional, moving jobs, whatever, we had conversations. I will always say, "Why am I crying? I'm a second-floor person. I should not be crying.". (MP, personal communication, July 2, 2018)

Therefore, she is still often surprised when it actually happens. Another woman described a time when, as she began a new job, a man asked her when they (colleagues) would see her cry for the first time. She was taken aback by this question and the assumption by him (and possibly others) that it would happen. Though the man did not press the issue, the woman deduced that he had asked the question of her because of her gender and was making assumptions on that basis as well.

I had somebody ask me what makes me cry. Now, this was a colleague. "EX, I need to know what makes you cry." I go, "Onions make me cry and really sappy movies."...I 
knew what he was getting at. I go, "What makes you cry?" He goes, "No. That's not what I mean. I mean like on the job? When am I going to see you cry?" And I said, "Probably about five minutes after you do." And he goes, "You're not a crier?" I said, "No. I'm not a crier." I go, "Where are you going with this?" And he goes, "I was just wondering if you're going to cry or not." And I said, "No. I'm going to go back to what are you talking about?" Like now I start playing dumb because it's so asininely stupid to ask me this question. And I don't think it was meant that way. And I just kind of left it there. I don't have to fight those fights. I mean I don't have to fight those fights. But you do go tsk. Like that. I just thought it was a really interesting-- did he think I was going to go into this new job and start crying? This is somebody who's known me for a long time. And it wasn't anybody in the central office...But it was just so interesting that I would be asked that because would you ask a male colleague that? No. (EX, personal communication, June 4, 2018)

NM went into great depth about how she reacts in work situations and if the situation

ever warrants crying as a reaction. She postulated that men do not have the same thoughts or reaction. She even went as far as to say others may perceive her as insensitive or less feminine

because she does not cry.

I tend to be an emotional person and so I fear that it gets in the way. It never has. I haven't just broken down and cried but and I tend to get a little more tough when I'm in those situations but I just hope that that's not something that's going to-- I don't think it will. It hasn't yet.... I can cry on a dime. I haven't and I intend to get a little more tough and firmer when faced with kind of that adversity sometimes and I'm, "Oh well, I'm not going to fight with you but I will tell you no." That kind of stuff, but I don't know that that's gender necessarily, it's just who I am...in some ways I feel like, yeah there's that gender identity but sometimes I feel too, there's some qualities about myself that I feel like, well it's kind of masculine - just - I don't know. I mean, I can't really identify any of those but just with so many of the topics, so many of the conversations in the world right now about identity, about gender so you just kind of-- I'm starting to think oh well, is it really feminine, is it masculine? What does it matter? It's just who people are but I'm not super cuddly and I mean, I like touch but I don't go out and seek, I'm not going to be hugging every kid that's comes to the door. Little kids, kindergartners especially, they're going to come hug you anyway but I'm not that person. I'm not super touchy-feely but yet I have a heart and I still care and I express that. (NM, personal communication, June 1, 2018)

Lastly, MI proposed that crying should not happen under any circumstances because the side

effects could be damaging to a woman or a career.

I don't cry. I don't cry. I hate crying in the workplace. I'm a very emotional person. Because I think it makes us look weak. Especially to them so I make sure I don't cry. 
Believe me, I wanted to...I mean, how many times have you been upset, or something's happened, and you want to. And I'm a crier at home. I mean, I'm an emotional person. Don't you do that professionally because they're going to see you as being that woman, that crier, that emotional person, that you can't handle it. Do you know what I mean? I mean, that's gender. I think it's gender...And then the minute you cry they look at you differently. (MI, personal communication, June 8, 2018)

The topic of crying on the job was not one that I promoted or suggested to the women. I found it interesting that they conjured up their experiences with it on their own, especially to highlight how gender plays a role in their interactions. Because the women felt it was important enough to mention, on more than one occasion, I believe that their study of this emotional response was one of mixed reflection and judgement. (See Table 7). 
Table 7

Conceptually Clustered Matrix: Crying

\begin{tabular}{|c|c|c|c|}
\hline Participant & Acceptable to Cry & Fear of Crying & Unique to Females \\
\hline NM & $\begin{array}{l}\text { Yes } \\
\text { I can cry on a dime }\end{array}$ & $\begin{array}{l}\text { Yes } \\
\text { I hope it's not } \\
\text { something that's } \\
\text { going to [happen]... } \\
\text { I've never cried when } \\
\text { I've been in that } \\
\text { leadership role }\end{array}$ & $\begin{array}{l}\text { Yes } \\
\text {...but I don't know that that's } \\
\text { gender necessarily; it's just } \\
\text { who I am }\end{array}$ \\
\hline MP & $\begin{array}{l}\text { No } \\
\text { And one lady was in my } \\
\text { office one day crying, } \\
\text { I'm like, 'There's no crying } \\
\text { at work.' }\end{array}$ & $\begin{array}{l}\text { Yes } \\
\text { I'm a second floor } \\
\text { person, I shouldn't } \\
\text { be crying }\end{array}$ & $\begin{array}{l}\text { Yes } \\
\text { the perception is if you are } \\
\text { someone that can remove } \\
\text { emotions from some of your } \\
\text { decision-making, then you're } \\
\text { stronger }\end{array}$ \\
\hline MI & $\begin{array}{l}\text { No } \\
\text { I don't cry. I hate crying in } \\
\text { the workplace. I'm a very } \\
\text { emotional person. Because } \\
\text { I think it makes us look weak. } \\
\text { Especially to them so I make } \\
\text { sure I don't cry. }\end{array}$ & $\begin{array}{l}\text { Yes } \\
\text { Believe me, I've } \\
\text { wanted to [cry] }\end{array}$ & $\begin{array}{l}\text { Yes } \\
\text { Don't you do that } \\
\text { professionally because } \\
\text { they're going to see you as } \\
\text { being that woman, that cryer, } \\
\text { that emotional person, that } \\
\text { you can't handle it. }\end{array}$ \\
\hline $\mathrm{EX}$ & $\begin{array}{l}\text { No } \\
\text { I said, 'No, I'm not a cryer.' I } \\
\text { go 'Where are you going with } \\
\text { this?' And he goes, 'I was just } \\
\text { wondering if you're going to } \\
\text { cry or not." And I said, "No. } \\
\text { I'm going to go back to what } \\
\text { are you talking about?" Like } \\
\text { now I start playing dumb } \\
\text { because it's so asininely stupid } \\
\text { to ask me this question }\end{array}$ & & $\begin{array}{l}\text { Yes } \\
\text { it was just so interesting that I } \\
\text { would be asked that because } \\
\text { would you ask a male } \\
\text { colleague that? No. }\end{array}$ \\
\hline
\end{tabular}

Table 7 shows the understanding four different women in this study have when it comes to crying on the job. All of them spoke to whether or not it is acceptable to cry on the job, their fears about crying, and whether or not it is unique to females. Most agreed it is not acceptable to 
cry and that it makes them look bad as leaders. This position engendered a fear that crying would happen because they knew it was possible or that it had happened. All of them understood that crying is perceived as unique to females in the workplace, even those in positions of leadership. Though it cannot be conveyed in Table 7, I can attest from listening that there was a sense of frustration, denial, self-loathing, and resignation from the women as they spoke about crying and the impact it had on them and others in their leadership.

\section{Women in Leadership}

The subjects of this study were asked to think about and offer general thoughts about women in educational leadership. Often, the interview answers would come out interwoven within the answers to other questions. If that was the case, I asked the women to circle back to something they said in passing or as part of another answer. This prompting would often lead the women to expound upon different topics and lead into others. Of course, gender was a central factor in the conversation. The question I posed was intentionally broad, as I was not entirely certain what women would have to say. Prior, I suspected in my own mind that they would share in my observations and experiences, but I knew it was possible that each person may have different insights. Ultimately, reflection surfaced about five central areas: expectations of women, compared to men; gender influence on interactions; perceptions of females, compared to males; support (or lack of) from other females, and negative experiences. I created a conceptually clustered matrix so I could see relations between variables, make contrasts/comparisons, and find intervening variables, if any existed (See Figure 3) (Miles et al., 2014, p. 173-78). For this area of the study, I found “...that participants [were] giving very similar or vastly different responses to questions or that unexpected variables, concepts, and themes [were] emerging" (Miles et al., 2014, p. 173). Because the thoughts women mentioned 
about women in leadership seemed spread out in the interviews, I needed to bring together "key data from key participants into a single matrix. The goal [was] to summarize how things stand with regard to selected variables, concepts of themes of interest”' (Miles et al., 2014, p. 178). 
Figure 3

\begin{tabular}{|c|c|c|c|c|c|c|}
\hline Title & Participant & $\begin{array}{l}\text { Expectations } \\
\text { of women }\end{array}$ & $\begin{array}{l}\text { Gender influence on } \\
\text { interactions }\end{array}$ & Perceptions of females & $\begin{array}{l}\text { Support (or lack } \\
\text { of) from females }\end{array}$ & $\begin{array}{l}\text { Negative } \\
\text { experiences }\end{array}$ \\
\hline \multirow[t]{2}{*}{$\begin{array}{l}\text { Building } \\
\text { Administrators }\end{array}$} & $\mathrm{BP}$ & $\begin{array}{l}\text { Tighter; loss } \\
\text { of flexibility }\end{array}$ & $\begin{array}{l}\text { Restraining male or } \\
\text { female students }\end{array}$ & $\begin{array}{l}\text { they argued against the } \\
\text { education to a high } \\
\text { degree of women }\end{array}$ & $\begin{array}{l}\text {...all of the staff } \\
\text { that I spoke to } \\
\text { seemed really } \\
\text { supportive of me }\end{array}$ & $\begin{array}{l}\text { Or they've } \\
\text { lost some } \\
\text { sort of their } \\
\text { femininity }\end{array}$ \\
\hline & KD & $\begin{array}{l}\text { So that was } \\
\text { reinforced, to } \\
\text { sit and behave } \\
\text { and act like a } \\
\text { lady and that } \\
\text { sort of thing. }\end{array}$ & $\begin{array}{l}\text {...get to the nuts } \\
\text { and bolts of what } \\
\text { your question is, } \\
\text { don't worry about } \\
\text { phrasing it a certain } \\
\text { way, or hurting } \\
\text { anyone's feelings }\end{array}$ & $\begin{array}{l}\text { And they wouldn't be } \\
\text { satisfied with it so they } \\
\text { would call back and } \\
\text { they would ask to } \\
\text { speak to him. }\end{array}$ & $\begin{array}{l}\text {...those of us in } \\
\text { this role are we } \\
\text { supporting each } \\
\text { other? }\end{array}$ & $\begin{array}{l}\text {...the } \\
\text { principal } \\
\text { said... } \\
\text { "Well, } \\
\text { there } \\
\text { would be if } \\
\text { you want to } \\
\text { go element } \\
\text { ary." ... } \\
\text { But I was } \\
\text { really } \\
\text { insulted by } \\
\text { that }\end{array}$ \\
\hline
\end{tabular}




\begin{tabular}{|c|c|c|c|c|c|c|}
\hline Title & Participant & $\begin{array}{l}\text { Expectations } \\
\text { of women }\end{array}$ & $\begin{array}{l}\text { Gender influence on } \\
\text { interactions }\end{array}$ & Perceptions of females & $\begin{array}{l}\text { Support (or lack } \\
\text { of) from females }\end{array}$ & $\begin{array}{l}\text { Negative } \\
\text { experiences }\end{array}$ \\
\hline & ML & $\begin{array}{l}\text {...good ol' } \\
\text { boys could be } \\
\text { administrators } \\
\text { as well as } \\
\text { teachers }\end{array}$ & $\begin{array}{l}\text { I think that it's just } \\
\text { as important, } \\
\text { though, to have } \\
\text { females as it is to } \\
\text { have males in } \\
\text { leadership roles. }\end{array}$ & $\begin{array}{l}\text { But I also think that } \\
\text { there's a good ol' } \\
\text { boys club in a variety } \\
\text { of different places and } \\
\text { women aren't in a } \\
\text { good ol' boys club. }\end{array}$ & $\begin{array}{l}\text {...I think that it's } \\
\text { really good to have } \\
\text { that male } \\
\text { perspective in a } \\
\text { variety of different } \\
\text { situations also. }\end{array}$ & $\begin{array}{l}\text { I don't } \\
\text { know that } \\
\text { they're } \\
\text { going to } \\
\text { look at me } \\
\text { differently } \\
\text { in what I } \\
\text { say or don't } \\
\text { say } \\
\text { because I'm } \\
\text { a female... }\end{array}$ \\
\hline & MT & $\begin{array}{l}\text { And to be } \\
\text { honest, that's } \\
\text { a challenge } \\
\text { that we face } \\
\text { as women that } \\
\text { men don't } \\
\text { have to face. }\end{array}$ & $\begin{array}{l}\text { And I'm putting } \\
\text { myself in there and } \\
\text { doing the things } \\
\text { that I see him } \\
\text { doing, and I should } \\
\text { be able to do those } \\
\text { things, too. But the } \\
\text { reality is, there is a } \\
\text { difference between } \\
\text { you and me. }\end{array}$ & $\begin{array}{l}\text { Because my coworker, } \\
\text { being a male and very } \\
\text { "get in there", and } \\
\text { whatever. }\end{array}$ & $\begin{array}{l}\text {...things were } \\
\text { going to be okay, } \\
\text { and my support } \\
\text { was going to be } \\
\text { here. }\end{array}$ & $\begin{array}{l}\text { And in the } \\
\text { back of my } \\
\text { mind there } \\
\text { is always } \\
\text { that self- } \\
\text { doubt. }\end{array}$ \\
\hline
\end{tabular}




\begin{tabular}{|c|c|c|c|c|c|c|}
\hline Title & Participant & $\begin{array}{l}\text { Expectations } \\
\text { of women }\end{array}$ & $\begin{array}{l}\text { Gender influence on } \\
\text { interactions }\end{array}$ & Perceptions of females & $\begin{array}{l}\text { Support (or lack } \\
\text { of) from females }\end{array}$ & $\begin{array}{l}\text { Negative } \\
\text { experiences }\end{array}$ \\
\hline & $\mathrm{ON}$ & $\begin{array}{l}\text {...it's really } \\
\text { hard to get } \\
\text { into } \\
\text { leadership } \\
\text { early because } \\
\text { you're } \\
\text { expected to } \\
\text { take care of } \\
\text { all the wife } \\
\text { and motherly } \\
\text { duties which } \\
\text { doesn't leave } \\
\text { you a lot of } \\
\text { time to do } \\
\text { some of those } \\
\text { things... }\end{array}$ & $\begin{array}{l}\text { So I still always feel } \\
\text { like females have } \\
\text { difficulty working } \\
\text { with other } \\
\text { females... And } \\
\text { especially when } \\
\text { you're dealing with } \\
\text { multiple strong } \\
\text { women, I think that } \\
\text { tends to be an issue. }\end{array}$ & $\begin{array}{l}\text {...I'm perceived as } \\
\text { being a bitch, that I'm } \\
\text { being a nag...I think } \\
\text { females are viewed } \\
\text { much more negatively } \\
\text { than when men make } \\
\text { decisions that way... }\end{array}$ & $\begin{array}{l}\text { I hate to say it, but } \\
\text { there's some } \\
\text { cattiness or } \\
\text { something. }\end{array}$ & $\begin{array}{l}\text {...there is a } \\
\text { major pay } \\
\text { discrepanc } \\
\text { y in our } \\
\text { district-- } \\
\text {...between } \\
\text { the } \\
\text { genders. }\end{array}$ \\
\hline Principals & $\mathrm{KH}$ & $\begin{array}{l}\text {...I feel like } \\
\text { you're the } \\
\text { mom of this } \\
\text { school. They } \\
\text { come to you } \\
\text { essentially for } \\
\text { discipline and } \\
\text { punishment, } \\
\text { right? }\end{array}$ & $\begin{array}{l}\text { I mean, how often } \\
\text { do you see [the } \\
\text { male } \\
\text { administrators] } \\
\text { presenting on } \\
\text { material or doing } \\
\text { PD for others? }\end{array}$ & $\begin{array}{l}\text { So he behaved very } \\
\text { differently with me } \\
\text { than he did the male } \\
\text { police officer who } \\
\text { brought him back. }\end{array}$ & $\begin{array}{l}\text {...instead of } \\
\text { tearing down, why } \\
\text { don't women } \\
\text { support each other } \\
\text { more? Because this } \\
\text { isn't an easy field, } \\
\text { right? }\end{array}$ & $\begin{array}{l}\text { Again, we } \\
\text { could have } \\
\text { empowered } \\
\text { each other } \\
\text { instead of } \\
\text { breaking } \\
\text { each other } \\
\text { down. }\end{array}$ \\
\hline
\end{tabular}




\begin{tabular}{|c|c|c|c|c|c|c|}
\hline Title & Participant & $\begin{array}{l}\text { Expectations } \\
\text { of women }\end{array}$ & $\begin{array}{l}\text { Gender influence on } \\
\text { interactions }\end{array}$ & Perceptions of females & $\begin{array}{l}\text { Support (or lack } \\
\text { of) from females }\end{array}$ & $\begin{array}{l}\text { Negative } \\
\text { experiences }\end{array}$ \\
\hline & NM & $\begin{array}{l}\text { trying to find } \\
\text { that balance } \\
\text { of, nope this } \\
\text { is the way it's } \\
\text { going to be, } \\
\text { without just } \\
\text { turning into a } \\
\text { total bitch, for } \\
\text { a lack of a } \\
\text { better word, } \\
\text { and still be } \\
\text { respectful and } \\
\text { professional. }\end{array}$ & $\begin{array}{l}\text { sometimes I feel } \\
\text { too, there's some } \\
\text { qualities about } \\
\text { myself that I feel } \\
\text { like, well it's kind } \\
\text { of masculine just I } \\
\text { don't know. }\end{array}$ & $\begin{array}{l}\text { I think there's a little } \\
\text { bit of fear maybe from, } \\
\text { I mean if we just } \\
\text { think-- if I think about } \\
\text { my own perceptions } \\
\text { like the different } \\
\text { genders, I can see that } \\
\text { fear. }\end{array}$ & $\begin{array}{l}\text { the number of } \\
\text { emails I received } \\
\text { afterwards that } \\
\text { were just } \\
\text { congratulatory and } \\
\text { thankful and if you } \\
\text { need any help let } \\
\text { me know. }\end{array}$ & $\begin{array}{l}\text { I think } \\
\text { there's a } \\
\text { little bit of } \\
\text { fear }\end{array}$ \\
\hline & TU & $\begin{array}{l}\text { And as a } \\
\text { woman of } \\
\text { color and } \\
\text { leadership in } \\
\text { this building, } \\
\text { I am expected } \\
\text { to give } \\
\text { community } \\
\text { perspective }\end{array}$ & $\begin{array}{l}\text { I don't know if it } \\
\text { comes from being } \\
\text { minority or a } \\
\text { female or whatever } \\
\text { it is, but there has } \\
\text { always been a } \\
\text { feeling of having to } \\
\text { work a little harder, } \\
\text { do a little more. }\end{array}$ & $\begin{array}{l}\text { But I think there are } \\
\text { also time in different } \\
\text { situations where you } \\
\text { are absolutely judged. }\end{array}$ & $\begin{array}{l}\text { And I wonder, just } \\
\text { thinking about } \\
\text { leadership-- As } \\
\text { women, are we } \\
\text { quicker to } \\
\text { recognize that in } \\
\text { other women? I } \\
\text { think so. I think so. } \\
\text { Not to say that men } \\
\text { can't. }\end{array}$ & $\begin{array}{l}\text { women just } \\
\text { tend to give } \\
\text { a lot of } \\
\text { themselves, } \\
\text { I think. } \\
\text { And so we } \\
\text { don't } \\
\text { reserve the } \\
\text { time to, } \\
\text { kind of, } \\
\text { build } \\
\text { ourselves } \\
\text { up }\end{array}$ \\
\hline
\end{tabular}




\begin{tabular}{|c|c|c|c|c|c|c|}
\hline 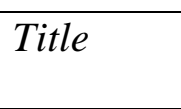 & Participant & $\begin{array}{l}\text { Expectations } \\
\text { of women }\end{array}$ & $\begin{array}{l}\text { Gender influence on } \\
\text { interactions }\end{array}$ & Perceptions of females & $\begin{array}{l}\text { Support (or lack } \\
\text { of) from females }\end{array}$ & $\begin{array}{l}\text { Negative } \\
\text { experiences }\end{array}$ \\
\hline Directors & BT & $\begin{array}{l}\text {-- it was just } \\
\text { an } \\
\text { expectation. } \\
\text { And it wasn't } \\
\text { even if you go } \\
\text { to college. It's, } \\
\text { no, when you } \\
\text { go to } \\
\text { college... }\end{array}$ & $\begin{array}{l}\text { [if I'd been an male } \\
\text { I] probably would } \\
\text { not have felt the } \\
\text { need to leave a job } \\
\text { to go do something } \\
\text { else. }\end{array}$ & $\begin{array}{l}\text { I think if I had turned } \\
\text { it and it was my } \\
\text { husband doing it, I } \\
\text { would have supported } \\
\text { him }\end{array}$ & $\begin{array}{l}\text { If a male took this } \\
\text { role, would they } \\
\text { say, "You know, I } \\
\text { need to have a } \\
\text { support person." }\end{array}$ & $\begin{array}{l}\text { Well, } \\
\text { probably if } \\
\text { I had been } \\
\text { a male, I } \\
\text { would } \\
\text { have-- } \\
\text { yeah, I } \\
\text { would say } \\
\text { it probably } \\
\text { would have } \\
\text { been } \\
\text { different. I } \\
\text { probably } \\
\text { would not } \\
\text { have felt } \\
\text { the need to } \\
\text { leave a job } \\
\text { to go do } \\
\text { something } \\
\text { else }\end{array}$ \\
\hline
\end{tabular}




\begin{tabular}{|c|c|c|c|c|c|c|}
\hline 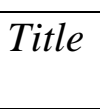 & Participant & $\begin{array}{l}\text { Expectations } \\
\text { of women }\end{array}$ & $\begin{array}{l}\text { Gender influence on } \\
\text { interactions }\end{array}$ & Perceptions of females & $\begin{array}{l}\text { Support (or lack } \\
\text { of) from females }\end{array}$ & $\begin{array}{l}\text { Negative } \\
\text { experiences }\end{array}$ \\
\hline & MB & $\begin{array}{l}\text { I don't know } \\
\text { that I attribute } \\
\text { that to being } \\
\text { female either, } \\
\text { though, I } \\
\text { think that's } \\
\text { just human } \\
\text { nature. }\end{array}$ & $\begin{array}{l}\text { But I like to think } \\
\text { that sometimes we } \\
\text { as females can just } \\
\text { be a little bit more } \\
\text { creative, outside of } \\
\text { the box thinking. } \\
\text { Not always, but... }\end{array}$ & $\begin{array}{l}\text {-- I think that my } \\
\text { experience in the } \\
\text { school has certainly } \\
\text { been an attribute, or an } \\
\text { asset, to what I'm } \\
\text { doing now. }\end{array}$ & $\begin{array}{l}\text { And she said, } \\
\text { "You'll learn. } \\
\text { You'll figure it out } \\
\text { and we're all here } \\
\text { to help you." }\end{array}$ & $\begin{array}{l}\text { We } \\
\text { brought on } \\
\text { a new } \\
\text { administrat } \\
\text { or at my } \\
\text { current job. } \\
\text { And I did } \\
\text { wonder a } \\
\text { couple of } \\
\text { times like, } \\
\text { 'Really, are } \\
\text { we just } \\
\text { hearing } \\
\text { this?' } \\
\text { Because } \\
\text { I've said } \\
\text { this for two } \\
\text { years...bec } \\
\text { ause he's a } \\
\text { guy }\end{array}$ \\
\hline
\end{tabular}




\begin{tabular}{|c|c|c|c|c|c|c|}
\hline Title & Participant & $\begin{array}{l}\text { Expectations } \\
\text { of women }\end{array}$ & $\begin{array}{l}\text { Gender influence on } \\
\text { interactions }\end{array}$ & Perceptions of females & $\begin{array}{l}\text { Support (or lack } \\
\text { of) from females }\end{array}$ & $\begin{array}{l}\text { Negative } \\
\text { experiences }\end{array}$ \\
\hline & MI & $\begin{array}{l}\text { There weren't } \\
\text { hardly any } \\
\text { women in } \\
\text { leadership at } \\
\text { that time. And } \\
\text { I think it was } \\
\text { our mindset } \\
\text { that we were } \\
\text { the teachers, } \\
\text { and the men } \\
\text { PE teachers, } \\
\text { sorry, became } \\
\text { the } \\
\text { administrators }\end{array}$ & $\begin{array}{l}\text { if they want } \\
\text { something they } \\
\text { wouldn't bypass the } \\
\text { director and go } \\
\text { right to HR, or right } \\
\text { to the assistant } \\
\text { superintendent. }\end{array}$ & $\begin{array}{l}\text { I do think some } \\
\text { principals would treat } \\
\text { me differently if I was } \\
\text { a male. I do, I'm sorry, } \\
\text { I do }\end{array}$ & $\begin{array}{l}\text { In a large district, } \\
\text { never wanted to be } \\
\text { the sole director. } \\
\text { Wanted to be one } \\
\text { of those support } \\
\text { people underneath. } \\
\text { I didn't like that } \\
\text { executive role }\end{array}$ & $\begin{array}{l}\text { 'Oh, the } \\
\text { boys' club } \\
\text { is going to } \\
\text { lunch, and } \\
\text { we're not } \\
\text { invited.' }\end{array}$ \\
\hline $\begin{array}{l}\text { Assistant } \\
\text { Superintendents }\end{array}$ & $\mathrm{DC}$ & $\begin{array}{l}\text { I, to this day, } \\
\text { remember that } \\
\text { even though } \\
\text { my teachers } \\
\text { would get on } \\
\text { my case about } \\
\text { being bossy } \\
\text { and } \\
\text { everything, [a } \\
\text { male mentor] } \\
\text { cultivated that }\end{array}$ & $\begin{array}{l}\text { I was bossy and that } \\
\text { I [laughter]-- so I } \\
\text { think I always sort } \\
\text { of had that when I } \\
\text { was younger. It was } \\
\text { termed "bossy" } \\
\text { [laughter]. And now } \\
\text { as an adult, it's } \\
\text { termed "leader" }\end{array}$ & $\begin{array}{l}\text { We were really } \\
\text { advocating for a } \\
\text { man...But you know } \\
\text { what? We now realize } \\
\text { that we're fine with } \\
\text { you because you don't } \\
\text { lead like a woman. }\end{array}$ & $\begin{array}{l}\text { And it was just at } \\
\text { the very end and } \\
\text { really looking at } \\
\text { my classroom and } \\
\text { thinking about the } \\
\text { impact I could } \\
\text { have and how I } \\
\text { could support } \\
\text { teachers. }\end{array}$ & $\begin{array}{l}\text { I found out } \\
\text { ahead of } \\
\text { time that a } \\
\text { few of the } \\
\text { teachers } \\
\text { had been } \\
\text { making } \\
\text { comments } \\
\text { that they } \\
\text { felt like } \\
\text { they } \\
\text { needed a } \\
\text { male there. } \\
\text { They'd } \\
\text { always had } \\
\text { a male }\end{array}$ \\
\hline
\end{tabular}




\begin{tabular}{|c|c|c|c|c|c|c|}
\hline Title & Participant & $\begin{array}{l}\text { Expectations } \\
\text { of women }\end{array}$ & $\begin{array}{l}\text { Gender influence on } \\
\text { interactions }\end{array}$ & Perceptions of females & $\begin{array}{l}\text { Support (or lack } \\
\text { of) from females }\end{array}$ & $\begin{array}{l}\text { Negative } \\
\text { experiences }\end{array}$ \\
\hline & DI & $\begin{array}{l}\text { Back in the } \\
\text { day, you } \\
\text { became a } \\
\text { teacher or a } \\
\text { nurse. That } \\
\text { was sort of } \\
\text { the } \\
\text { expectation. If } \\
\text { you were } \\
\text { going to go to } \\
\text { college, that's } \\
\text { what you } \\
\text { were going to } \\
\text { become. }\end{array}$ & $\begin{array}{l}\text { I think, as a woman, } \\
\text { fortunately or } \\
\text { unfortunately, } \\
\text { sometimes you } \\
\text { straddle this line of } \\
\text { you can be a certain } \\
\text { amount of assertive. }\end{array}$ & $\begin{array}{l}\text { Things like balancing } \\
\text { home and work } \\
\text { responsibilities. Or } \\
\text { balancing education } \\
\text { with home and work } \\
\text { responsibilities. Even } \\
\text { just navigating around } \\
\text { the perceptions by } \\
\text { some people }\end{array}$ & $\begin{array}{l}\text { it was my dad, at } \\
\text { that point, who was } \\
\text { the supportive } \\
\text { person }\end{array}$ & $\begin{array}{l}\text { I remember } \\
\text { the couple } \\
\text { nights } \\
\text { before the } \\
\text { first day of } \\
\text { you're the } \\
\text { principal } \\
\text { thinking, } \\
\text { "Okay, } \\
\text { what did I } \\
\text { get myself } \\
\text { into } \\
\text { [laughter]? } \\
\text { " }\end{array}$ \\
\hline
\end{tabular}




\begin{tabular}{|c|c|c|c|c|c|c|}
\hline Title & Participant & $\begin{array}{l}\text { Expectations } \\
\text { of women }\end{array}$ & $\begin{array}{l}\text { Gender influence on } \\
\text { interactions }\end{array}$ & Perceptions of females & $\begin{array}{l}\text { Support (or lack } \\
\text { of) from females }\end{array}$ & $\begin{array}{l}\text { Negative } \\
\text { experiences }\end{array}$ \\
\hline & EX & $\begin{array}{l}\text { I think that } \\
\text { you have to } \\
\text { make a } \\
\text { decision, and } \\
\text { it is more } \\
\text { socially } \\
\text { acceptable for } \\
\text { a woman to } \\
\text { be the } \\
\text { caregiver in a } \\
\text { home than it } \\
\text { is a man. }\end{array}$ & $\begin{array}{l}\text { Women are allowed } \\
\text { to-- I am just } \\
\text { allowed to be me. } \\
\text { It's fine. I can talk } \\
\text { about my kids. } \\
\text { Nobody thinks a } \\
\text { thing about it. I can } \\
\text { take time off to go } \\
\text { to a ballerina } \\
\text { recital. Nobody } \\
\text { thinks twice about } \\
\text { it. In fact, they say, } \\
\text { "Of course you } \\
\text { will." Men that do } \\
\text { that, "Oh, my gosh, } \\
\text { really. He took off } \\
\text { again?" }\end{array}$ & $\begin{array}{l}\text { I remember when we } \\
\text { had a guy at the high } \\
\text { school took a } \\
\text { maternity leave, he } \\
\text { stayed home with the } \\
\text { kids. It was like } \\
\text { unbelievable that he } \\
\text { would do that. We } \\
\text { have a building } \\
\text { principal that is a } \\
\text { caregiver for a sick } \\
\text { wife and has to take } \\
\text { care of, and that has }\end{array}$ & $\begin{array}{l}\text { I've had very few } \\
\text { situations that } \\
\text { women have not } \\
\text { helped me. }\end{array}$ & $\begin{array}{l}\text { But I did } \\
\text { have one } \\
\text { and it } \\
\text { happened } \\
\text { last year. It } \\
\text { was } \\
\text { probably } \\
\text { the most } \\
\text { significant } \\
\text { one...And } \\
\text { this one } \\
\text { guy, } \\
\text { whenever I } \\
\text { would } \\
\text { bring up } \\
\text { anything, } \\
\text { he would } \\
\text { interrupt } \\
\text { me. }\end{array}$ \\
\hline
\end{tabular}




\begin{tabular}{|c|c|c|c|c|c|c|}
\hline Title & Participant & $\begin{array}{l}\text { Expectations } \\
\text { of women }\end{array}$ & $\begin{array}{l}\text { Gender influence on } \\
\text { interactions }\end{array}$ & Perceptions of females & $\begin{array}{l}\text { Support (or lack } \\
\text { of) from females }\end{array}$ & $\begin{array}{l}\text { Negative } \\
\text { experiences }\end{array}$ \\
\hline & MP & & & $\begin{array}{l}\text { And so to them being } \\
\text { professional and being } \\
\text { a woman meant that } \\
\text { you didn't have a } \\
\text { personality or that you } \\
\text { weren't fun. And I } \\
\text { don't know that I've } \\
\text { ever heard anyone } \\
\text { really talk about men } \\
\text { in that way. }\end{array}$ & $\begin{array}{l}\text { So some } \\
\text { acknowledgment } \\
\text { that you were not } \\
\text { the end-all be-all, } \\
\text { that you can't be } \\
\text { expected to have } \\
\text { all the answers, and } \\
\text { making sure that } \\
\text { you're recognizing } \\
\text { and valuing, giving } \\
\text { credit, to those } \\
\text { people that may be } \\
\text { able to support and } \\
\text { assist you. }\end{array}$ & $\begin{array}{l}\text { 'Well, what } \\
\text { is up with } \\
\text { all the } \\
\text { women } \\
\text { being } \\
\text { removed } \\
\text { and } \\
\text { everything? } \\
\text {....And } \\
\text { then there } \\
\text { were just a } \\
\text { number of } \\
\text { things } \\
\text { where we } \\
\text { were being } \\
\text { left out and } \\
\text { conversatio } \\
\text { ns were } \\
\text { being had } \\
\text { about } \\
\text { things that } \\
\text { were my } \\
\text { job by } \\
\text { someone } \\
\text { else. }\end{array}$ \\
\hline
\end{tabular}

Figure 3: Conceptually clustered matrix: Thoughts about women in leadership. This figure summarizes thoughts in different areas from the interviewed women. The matrix format helps display relations between variables, make contrasts/comparisons, and find intervening variables, if any existed. 


\section{Expectations of women.}

The interviewees described several instances where they sensed that there are particular expectations of women. The consensus was that every woman contemplated its existence; only one was not entirely sure being female had anything to do with her specific situation. The expectations centered on acquisition of education, being motherly, and behaviors. If women pursued educational opportunities, they were limited in their choices, which may have later affected their path to leadership by inhibiting it. Women are also expected to be motherly, to care for and tend to others, which may have confined them in that type of role, as leaders are often not viewed as nurturing. Most considered was how women are expected to behave. Again, the women felt restricted and regulated by others. They spoke of how others expected them not to be a certain way in different situations, which is something the women struggled with as they tried to fit in with others as leaders.

\section{Gender influence on interactions.}

The participants came to understand that their gender influenced their actions and interactions with others. They spoke of this observation in uncertain tones: "I don't know...", "I still always feel like...", "I probably would not have...", "I like to think that...". Those answers communicated a sense of doubt about their abilities as leaders. Some accepted their fate, counting it as an advantage.

\section{Perceptions of females versus males.}

The contributors knew that others perceived them as different from men in similar situations. The perceptions were not positive. A sense of comparison seemed to be always at work. The women felt judged, inferior, misconstrued, and treated differently. Their leadership was always questioned and misunderstood in many instances. 


\section{Support (or lack of) from other women.}

The women in this study often garnered support from others, but, at times, suffered from a lack of it. They shared stories about much benevolence from mentors, formally and informally, and disclosed their appreciation for that care. They also shared information about times when support was lacking, especially from women to women. It appeared that principals struggled the most with lack of support and questioned why they or others did not do more. On the contrary, the assistant superintendents seemed to be the most positive about support they had encountered over time. All of them recognized that support is critical to the success of all leaders.

\section{Negative experiences.}

Lastly, often, the women I talked with were able to relate negative experiences they had while being women in educational leadership that did not necessarily fall into the previous categories of expectations, gender influence, perceptions, and support. They spoke of self-doubt, fear, rejection, disrespect, and loss. Some of the stories were sad because the incidents that took place were so unnecessary and the women knew that to be true.

\section{Other}

When asked if they had anything to add at the end of the interviews, the participants would often bring up issues they had questions about and expressed wonder at some of them.

\section{Awareness of gender roles.}

In a few instances, the women articulated an awareness that gender roles were present and assumed in situations. For example, one building administrator wondered if men thought about the same things that women had to think about. Early in her interview, she cited choosing to stay at home after a baby is born as a choice that women really do not have; they are expected to do it. She wondered if men even considered it. At the end of the interview, she wondered 
again if men thought about the same considerations women did. She cited insecurity and trying

to self-coach to build confidence as issues she was not sure if men thought about as much as

women:

If I take over an elementary building, whatever that building is, my first year would be a lot of time again, first couple years getting things set. And I said [to my husband], what happens if I don't like being the principal, the person of a building? What happens if I don't like it or I'm not good at it? I can't come back to something right now that I really like and I enjoy. I've kind of got my groove. He's like, that sounds like the same conversation we had when you were leaving [previous school] to come here. So I think what he was trying to do is build that confidence that says, you've been down this road before, and you will make of it what you want to make of it. So I question, do men go through that same-- and I don't know if it's insecurity, because I would never describe anything about me as insecure. But it feels like what insecurity feels like. Can I do it? Will I like it? And what happens if I don't? Because I've got a good thing going right here. I know my job, I know what's expected, I have a great team that I'm working with. Do I really want to be that leader that-- you know? I keep going back and forth to where-and then my fear is, if I'm not ready to pull the trigger and say yes when the district says, what about this, then will I be no longer considered? Do you get to say, right now the timing isn't good. But you know. I don't know. So I'm always curious, do men go through that same process and never articulate it? Or that is just climb, climb, climb. You know what I mean? (MT, personal communication, June 5, 2018)

Another woman, MB, shared an observation she kept to herself in her job, but was aware of, in regards to gender roles. In her current role, she brought insight as a former building administrator. While still in the field of education with that team, she was able to reference her former experiences and share lessons with her current team. However, she perceived that little movement or decision-making was made based on her advice. Then, the team obtained a male who had been in an administrative position like MB's. Naturally, as the team worked together, he began saying some of the same things MB had previously pointed out. It began to appear as though the team listened and heeded his advice, making decisions based upon it. Obviously, these encounters left her bewildered and questioning:

I'll go back to the example of when we brought on a new administrator at my current job. And I did wonder a couple of times like, "Really, are we just hearing this?" Because I've 
said this for two years...because he's a guy? I don't know. I don't know. (MB, personal communication, June 11, 2018)

MB was certainly perplexed as to why this was happening and she could not ignore that it was happening. However, she could not explain why it was happening. She noticed it, but never said anything to her colleagues. That awareness pervaded her interactions and put her gender at the forefront.

\section{Dress.}

More than a couple of the women mentioned how the way they dress as women in their

jobs is considered and even critiqued.

I think there's things are absolutely acceptable for males that aren't for females...I'll even talk about dress. How we dress in our work. And I had a male make a comment, at somebody from my district office [about her choice in dress]. It was like, "Really? Oh, okay." Just interesting that there would be some feedback. And it wasn't even related to me, but another female administrator. And it's like, "Have you not seen--?" But, okay. Duly noted. And so there are just certain things. And it's so silly. That it's like, "All right. Note to self. Do not wear--" And it's so silly. It's like, "Really?"...And it's so silly because I refuse to believe [a male colleague] is thinking about what he wears when gets up and comes to work. I refuse. But as a female? Oh, heck yeah. It's like, "Is that too tight? Is that too low? Is it too--?" It's all those thoughts as you're pulling the outfit together. And it's ridiculous.... What am I implying with this outfit?...And I am telling you I refuse to believe that a guy is choosing his outfits in the morning based on any of that. But as a woman at the head of this building, I always do. What am I doing today? What's on my agenda? Who do I have to meet with?...That's part of it...I know I'm going to be perceived a certain way. (TU, personal communication, May 31, 2018)

But the eyes are always on you of whether or not you're being appropriate. And as a woman, it's like, "Am I dressed appropriately enough? Am I being a positive role model for the girls in the school?" Things like that. (ON, personal communication, June 25, 2018)

[The other office assistants told my assistant] that I always seem very put together and professional, and they just didn't know if I had a personality and if I was going to be fun, and [my assistant] was like, "Yes, she is [laughter]. And you just need to know her." So I think like, "What?" They've only interacted with me as a parent. My kids go here. So I had some interactions with them from that kind of lens, but I don't know them other than that...So [my assistant] said that they specifically mentioned how you dress, and all that kind of stuff. And so to them being professional and being a woman meant that you didn't have a personality or that you weren't fun. And I don't know that I've ever heard anyone 
really talk about men in that way. If it's a professional man, it's a professional man. That doesn't mean that they don't have a personality. So I thought that that was interesting. (MP, personal communication, July 2, 2018)

I would say one thing would be don't try and be a man. Don't dress like them. Don't talk like them. You're not a man. Everybody knows you're not a man. Don't try and be. Now in saying that I think that women administrators have to dress the part. I think all administrators should dress the part. Right? And you have to know your audience. Like just the other day, I was going to visit [an outdoor student activity]. So I dressed more casually. I knew they were going to be in shorts. I didn't want to show up in a suit. I don't really wear suits, but I wouldn't-- a jacket and pants? (EX, personal communication, June $4,2018)$

Like MB at her job, these women are often perplexed as to why dress matters, but also acknowledge the reality that they must consider it. Silently, they continue to allow for daily time to deal with clothing choices, mainly out of fear about how others will perceive them and if they will be taken seriously as educational leaders. They know there is real commentary from others about women and the way they dress. They must keep that reality in view.

\section{Ethnicity.}

Three of the women interviewed are not white. I did make a point to ask them about how their ethnicity plays a part in their leadership, as I did not want to overlook the fact that it may do so. All three were able to recall situations in which they understood that their ethnicity was a factor that other considered when dealing with them.

It's hard because I find that I've got to make sure that sometimes if there's initiative or if there's something that I want to do, it's not perceived as it's because I'm black. It's because, "Oh, you want to do this for the black kids because you're black." Forget the fact that data might show that this is something that we need to do. That we've got this discrepancy. That you look at the achievement levels. You look at the makeup even of our staff in this building. And there are minimal opportunities for our students of color to interact with other people of color. Let's just keep it real, people of authority in this building who look like them. There's a mentoring program we're looking at right now. I have to be so thoughtful about how this is presented to our staff. Because I can't come off as, "Here's TU, trying to alienate all of the other students. And only cares about the students of color." ...It's very subtle...But even when I initially took the position, there were people who struggled with, "Oh my God. It's about to be a black woman leading the charge." And so it was just kind of ironic when some of those people then would make 
some comments or say different things later. I know what you said. I know what you said. And so, but, I'm going to be professional. I'm going to be professional...Because there was some perception that this job was just handed to me. And it's like, "Are you kidding me? I worked my butt off to be here. I worked my butt off." But somehow I'm lesser than somebody else?...And as a woman of color and leadership in this building, I am expected to give community perspective-- there better not be any "You're suspending a student of color based on what somebody else--" You know? And it's like "Um." That is not the reality until you are. There's this fine line that you're kind of having to dance. (TU, personal communication, May 31, 2018)

And so I'm biracial but I was raised by my mother who's Caucasian so more of my tendencies lean toward that so I probably, I'm using air quotes here, "fit in a little better" or didn't have to prove myself as much because I don't have a dialogue. Well, I mean I'm sure I do if I went somewhere [else]...I certainly have never tried to pretend to be more one or the other that I'm not comfortable with but I think it's helped me to be able to bridge kind of the gap between students especially. Maybe not so much with staff but it's never come up as an issue. (NM, personal communication, June 1, 2018)

And I'll tell you, an Indian in education is not common, unless you are going the professor route...We are the lawyers, the doctors, the engineers...At the end of the day, I think any Indian parent is going to be happy when their kid finishes their bachelor's degree and gets a job that pays the bills. They're going to be happy with that. I think it is-and I've seen it just in our own family, not necessarily our immediate family, but extended family, where the cousin hasn't finished their undergrad or hasn't finished their associate's, it's almost like there's this little black cloud over them...And so it was fine that I chose to go into education. I think for a period of time, it was always the, well, what are you going to do next? Like this can't be the endpoint that you're going to retire in 35 years with just having taught. My personal perspective with my parents is that there was definitely more of a pep in their step when they could tell people, "Oh, she's an assistant principal."...because now it kind of equated me to more of a beginning doctor level in their minds, which I just think is funny, that's not why I did it, and nothing to it...So whatever path that was, I think honestly, if my parents were ever surprised or disappointed that I went into education, at the end of the day, they could always hang their hat. "And MB hasn't asked us for anything. She's able to support herself. And she doesn't rely on us." And I think Indians talk. And they love to boast, for lack of better words, about how successful their kids are. And so if anybody wants to talk about the MB kids, "Oh, look at those MBs. All of them have their-- they've got their four-year degree. They all have their masters." My brother and sister both have their Ph.Ds. And they're all working and independent. So we are the family-- we are the success story...In a true serious nature, do I think about [being the only Indian in the room]? No. I will joke around about it, that I'm this bonus minority here. (MB, personal communication, June $11,2018)$

All of these women had different perspectives about how ethnicity factors into their leadership.

While they were aware of the possible misconceptions or the expectations from others, they did 
not let it stop them from leading. I left the conversations with the sense that it was an annoyance that had to be managed, an unfair acknowledgement that had the potential to stop them from achieving their goals. I never made the connection that race/ethnicity was amplified because of gender.

\section{Having children.}

Twelve of the women have children of their own. Only three of those twelve did not mention them during our interview. When the topic of having children came about, the women typically discussed the significance that choice made on their careers and their leadership.

I taught for two years. And then I was home with babies for a few years, four or five years. And during that time that I was home with babies, so to speak, I was on the school board there. (DI, personal communication, June 1, 2018)

...I just wanted something a bit more meaningful. And at the same time, my son had been diagnosed with autism so I was trying to navigate that and figure out what that meant and how I could best support him and know what that was. And he was diagnosed in third grade, I believe. I knew he had some developmental delays and disabilities prior to that but, really, the autism was in third grade. So about sixth grade, I decided that's about the time I started to take classes at ISU, and just fell in love with the special education program. (BT, personal communication, June 7, 2018)

The other position was from the town I grew up in, and it had its own pros and cons too, but would require a life upheaval. Moving my children out of district and selling the house that I owned here in this district. And ultimately, I decided to stay at the district that I had interned in because it would have less of an impact on my personal life, and it was a known quantity to me...It's hard to say in my own personal experience because I was a mother at a very young age and everybody knew it. So everybody always wanted to know where my kid was [laughter]--because I had to take him with me to college. Yeah. I had to take him to volleyball games on the way buses. My kid was always everywhere with me. And I've been lucky enough to work with people and in districts that were okay with that, that I could bring my child with me when I was coaching to make ends meet. And he rode the volleyball bus with me and things like that. And we could take our kids here, and it was a family-friendly type of atmosphere. But I know that women in professional-- that'd be a whole different situation than the coach bringing her kid versus the superintendent bringing her kid to work. I think that the perception of that would be very different. I think the perception of the principal of the building having to bring their young infant to school that day because the sitter fell through would be perceived as not professional. So I think, again, that the expectations for administrators and higher-ups for females in education, those become tighter and requires them to lose 
some of that flexibility to also be a family person. It's almost like that's the cost of doing business. If you want to have this upper echelon position, then you get to sacrifice your family. That's ridiculous. (BP, personal communication, June 5, 2018)

I think that with having children, I-- not that we aren't both caretakers, because we are. But I'm going to be more primary as far as if they're sick, or if this needs to happen, or keeping track of what permission slips need to go back to school, or all of that kind of mom stuff. And I don't know if that's just me or if that's typical of most moms. I don't necessarily know, I guess. I would say as I look to my friends and relatives and whatnot, that's pretty typical of moms. Female versus male. And so there are things that I'm going to consider differently than what my husband's going to consider. If there were to be a job that might pop up that I thought, you know what, I could maybe try a building principal of a small elementary school or something. I could maybe-- okay. I have a lot of different considerations than what my husband would. Not that he wouldn't consider his family, but it would be very different. And so I think that that has a lot to do with-- as you ask me about recommendations or advice or whatnot, I think that where you are in life might be your mindset for one point in time, but that-- maybe not let that necessarily hinder you for other facets of your life. Whether or not I take that advice I have no idea [laughter]. But I do think, again because I'm somebody with where I am in my own life, personally and professionally, that I see a difference between males and females in that regard. (ML, personal communication, June 26, 2018)

I had been in education, a teacher, not very long, and then decided to stay home with my children. Came back to work after being home with my children for 13 years into the world of special education as a paraprofessional...But when I stayed home with my kids she said, "You're doing the hardest job you'll ever do in your life. Going to work is so much easier." She is so right....I think that's just how we're made. We bear children. We have children. We raise children. Part of raising children then also is creating the household and making sure the basic needs are met, right. That's our role in women. And if we want to have more, we still have to do this. So we do it so much-- we do so much. So I think that's why it kind of attracts us....-- I don't want to say our genetic makeup because that's a cop-out. It's not genetics, but it is. We bear the children. We raise the children. We're the primary caregiver for the children...I always tell them, and again, when we're around young teachers, no time is the right time. "Oh, my kids are too little." No time is the right time. My kids are teenagers, and I missed how many soccer games? My son still shoves it in my face [laughter]. Still, he does, and he's 24..."Well, you missed it because you were in class [laughter]." You know what I mean? No time is the right time. So do it. Just do it. (MI, personal communication, June 8, 2018)

So when I did the first two years, [in] the superintendent program, one of the main-- well, there are a couple of main reasons. But one of the reasons I didn't want to continue on and do the doctorate is because-- the time. It's just they're involved in all sorts of other things and so to give up that time with them to do that for myself is just not where I'm at right now...I hate to use the whole in our society catchphrase, but if you are a typical female, right? You get married, you're going to have some kids, it's really hard to get into leadership early because you're expected to take care of all the wife and motherly duties 
which doesn't leave you a lot of time to do some of those things. I was fortunate enough to be able to quit my job in [a large city], move here, go to grad school full-time...I mean, that was just a luxury I randomly had and did early but most people don't have that. And so to be able to stop and give up all that time with your family is really difficult and that's why I know a lot of people don't do it, a lot of women I should say, not people. Because it's much more acceptable for the man in the household to not be home or not be carting kids from activity to activity and doing all those things. And those gender roles just still exist...So it's very rare that you get a female that doesn't have to focus on those priorities and can take those steps because the farther you are in your career the harder it is to jump into something like this. (ON, personal communication, June 25, 2018)

And so my first husband was a building principal, and our kids were young. Now we got divorced when [my daughter] was four. But for those first few years, I wanted to stay home. Let me say it this way. I felt I was putting my career on hold. I was not. I didn't stop learning. I was not $100 \%$ out of the workforce. That's really when I became really good at instructional coaching because I had to concentrate on it because it was my bread and butter. And so in the rearview mirror, I can say those three years that I felt like at first I was taking off actually were the foundation of me being able to go where I've gone. (EX, personal communication, June 4, 2018)

I talked to my husband and said, what do you think about this? The biggest discussion was centered around, we had during this time started a conversation and a process of adopting my [child]. And so we were in the adoption phase with the birth mother, and not knowing for certain if this is going to happen or it's not going to happen. You don't know until the very, very end. So he was going to be born in August. We had to really talk about, are we going to be able to manage all of this? Me in the job, a potential new baby, all of this. And we kind of decided, let's go for it. Let's do it...and I think it was scary because at the time our administrative team, [a male building administrator] was divorced and his kids predominantly lived with his ex-wife. [A female building administrator] didn't have kids, and [the female principal] didn't have kids. And when they hired me, it wasn't with this idea that come August I'm going to be with child. You know? It's not even like, I'm going to tell you in August that I'm pregnant or anything like that. It was like, no, he's here...And I have no sick time [laughter]. And so I didn't know how that was going to go over with this particular staff. I met with [the female principal] when I started to feel like more than likely that this is going to happen, and her response couldn't have been better. She had said to me that look, if I walk across the street and get hit by a bus, they're going to have a warm body in my seat by the end of the week. And our family and who we deem as our family is the most important. Everything that she shared with me at that point told me I was in a good place and things were going to be okay, and my support was going to be here...Because whether we like it or not, as women, that maternity leave poses a problem. When we look at somebody coming in and we know they're going to spend the first six to eight weeks of the school year out, and we have a building to run and positions to fill, that's a challenge. And to be honest, that's a challenge that we face as women that men don't have to face...It is very unique to women. Knowing kind of the idea behind this, I think that that is something that can play a role, and very much an unspoken role, in our work environment. And the reason why I say it's unspoken 
is because oftentimes even women to women. You know what I mean? It's like, oh crap, she's pregnant [laughter]. She's going to be gone. Now we have to get a long term sub. And they're not good. Long term subs are not good. Because we want to support one another, but at the same time it's like, ugh. (MT, personal communication, June 5, 2018)

The general thread the women commented on regarding children in their personal lives is how it influenced their decision-making about their paths to leadership. When asked about details of those paths, typically, family and children did not initially come up. However, the subject was discussed when the women gave thoughts about educational leadership and the struggles associated with maintaining a position as a leader. Typically, they agreed that having children impeded their abilities to be more effective as leaders. They seemed to understand that women have different choices to make about their careers than men do, especially if they have a family.

\section{Chapter V Summary}

Chapter V explained the types of analysis that I practiced as I examined the data, specifically thematic and contextual. I reflected about the data as a whole and my positionality after conducting the study. I coded the data, which led to describing overall aspects about the participants and analyzing key themes. Some key themes were discussed within the major topics of paths to leadership, good leaders, women in leadership, and other topics of interest. Chapter VI will discuss the findings of this study. References are provided. 


\section{CHAPTER VI: FINDINGS}

Glesne (2011) reminded researchers: "Remember that your purpose is that of elucidating the range of possibilities and of transforming your data into a useful form that communicates the promise of your findings" (p. 210). With that reminder, and much as Belenky et al. (1997) did, based on the data I gathered from the interviews and with the theoretical framework of Gender Identity Theory in mind, I present my findings. I used a variety of different analysis tools. Miles et al. (2014) and Glesne (2011) offered many different ways to interpret data.

\section{Thematic Approach}

Glesne (2011) suggested that researchers might present their findings in various, organized ways (p. 229). I chose to use the more common way by approaching the information thematically. I used a thematic approach as I wrote up the qualitative data and offered my interpretation: "By analyzing the data, the researcher generates a typology of concepts, gives them names or uses "native" labels, and then discusses them one by one, illustrating with descriptive detail" (Glesne, 2011, p. 229). After analyzing the data in the ways previously explained in Chapters III, IV, and V, I was able to assign names to an arrangement of concepts. I will discuss them one by one and attempt to expound about them with descriptive detail.

I believe my interpretation of the data is accurate because, once prompted, every woman had plenty to say about situations interactions, perceptions, etc. regarding their gender and how they identified themselves or how others identified or perceived them. I also believe the interpretation of the data is authentic because the participants would often bring up gender and its influence without prompting. Lastly, I have had similar experiences, made similar observations, and reacted in similar ways as the participants; therefore, I believe them when they speak to those things. 
Based on the research gathered in this study, as far the low number of women in educational leadership are concerned, I found that there were two major areas in which gender played a role. Gender did influence how the women saw themselves as leaders and their gender identities were connected to their leadership styles, skills, and qualities. This influence has an impact on why women decide to go or not go into educational leadership. Stryker \& Burke (2003) professed "...the relation of social structures to identities influences the process of selfverification, while the process of self-verification creates and sustains social structures" (p. 284). Their professions about their identities proved true based on the examples provided by the women interviewed for this study. The women self-verified their gender identities before, during, and after their tenure as leaders. Because they did so, they reported the existence of gender influencing their leadership and provided details of instances where gender identity affected their leadership styles, skills, and qualities. In turn, the decision to go into educational leadership was influenced by gender identity.

\section{Gender Influence on Leadership}

The women discussed examples of situations where their gender may or may not have influenced their interactions, their reactions, or how others responded to them. Their observations were illuminating because they often experienced different situations firsthand.

I think a female teacher would in some cases trust a male leader more than trusting or confiding a female because of that. Yeah, but it has nothing to do with the person's actual ability to do those things [laughter]...It's just we have to be careful in different ways. So I think as a female we have to be careful with male students... Whereas I think as a male you would have to be careful with female staff members. Which may be a big stereotype in my opinion but I think when you look at things happening that are publicized or out in the media, things like that. I think that's where there's a lot of trouble, for lack of a better word. And it's only because of the handful of people that have done things they shouldn't. But the eyes are always on you of whether or not you're being appropriate. And as a woman, it's like, "Am I dressed appropriately enough? Am I being a positive role model for the girls in the school?" Things like that...There is the good ol' boys club. There still is. There is in this district. And because there are many times over the past six years that 
the men will all go to lunch together, or go golfing, or have these plans and the females are not invited. Which, I don't personally care, but when I'm thinking about what you're writing about with leadership-- I mean are there things happening at those meetings that are-- even though they're social meetings, but are there things work-related that happen? Absolutely. (ON, personal communication, June 25, 2018)

I have different thoughts now being a mom, because I was in leadership in an admin position before I had children and now, subsequently, since I've had. And I think that a mom, as far as gender and a female, I feel like if you're doing things right, you're really not being very selfish as far as how you lead your life in putting your kids first. And while you certainly need to take care of yourself, I think that I perform my role as a leader, as a female in the same manner that I do kind of as a mom in regard to what can I do to ensure that my kids' needs are met and that my teachers and students' needs are met. And I do think that that is a difference between a male and a female as far as just having that experience and that role. I don't know that I operated that much differently before I had kids, necessarily, because I do think a lot of those are just personality and traits that I have. And that might be that way because I'm a female versus a male, but I definitely think that there are just some things-- there's just some different-- you can have a different set of lenses that you're looking through, I think, with that additional lifealtering experience of being a mom and being in education and being an educational leader...So I think it's really important to have a good balance of individuals. And I do think that men and women bring different traits to the table, and so I do think that there is-- I do think gender influences some of that. I think that it's just as important, though, to have females as it is to have males in leadership roles. Our admin team right now, like I said, is all female. And it's been that way for two years, but prior to that, it wasn't. And I think that it's really good to have that male perspective in a variety of different situations also...So I think gender does influence the way that female leaders lead versus the way male leaders lead. I don't know if it trumps just personality traits and values though, if that makes sense. (ML, personal communication, June 26, 2018)

...in some ways I feel like, yeah there's that gender identity but sometimes I feel too, there's some qualities about myself that I feel like, well it's kind of masculine just I don't know. I mean, I can't really identify any of those but just with so many of the topics, so many of the conversations in the world right now about identity, about gender so you just kind of-- I'm starting to think oh well, is it really feminine, is it masculine? What does it matter?...And I remember a teacher coming into the teacher's lounge after talking to them and saying, "Oh, I said we need a man here. We got to have a man here." Why would you say-- okay, that's illegal. You really shouldn't go say that. It doesn't make you look very professional. "Well our kids, a lot of them don't have fathers and they need that male role model." And I'm like, "Uh, well your principal is not a replacement for your father." While, I would agree with you that many of our kids live in single parent homes and oftentimes their dads are not part of their lives but we can't say that we want a male and it was just-- so I think that those kinds of philosophies still exist. The beauty of [my current school] is that they haven't had a male principal for a long time and well nine years and so I'm not following up with that where I think that mindset would have to change. (NM, personal communication June 1, 2018) 
...my conversation with [a colleague] the other day about breaking up the fights and so forth, it was a little liberating for me to hear [her] say, yeah, I'm not going to do that. Because my coworker, being a male and very get in there, and whatever. I said, all right, do I need to do that, too? And I'm putting myself in there and doing the things that I see him doing, and I should be able to do those things, too. But the reality is, there is a difference between you and me. (MT, personal communication, June 5, 2018)

I think that's bullshit; I think gender does matter...I think if I was a male they wouldn't skip me. They would know that there would be repercussions. There would be different repercussions. I go up to my boss and I say, "I wasn't consulted on this." And my boss is great, I think I get a different-- I feel there's a different reaction than if there was a male, and the chain of command was broken. If the chain of command was broken for a male, I think it would be treated differently than it is for a female. I do. I agree. I think it is different. (MI, personal communication, June 8, 2018)

And again, I don't know that if a male had proposed that idea if it would have taken off differently if a male would have. I don't know if that was something that was approved and accepted because I am female? I don't know that I would say that. But I like to think that sometimes we as females can just be a little bit more creative, outside of the box thinking. Not always, but...I don't know if right off the bat I would say it's because this person's male and this person's female. Because I think there are probably even differences in females. How [female administrator] handles something versus how I handle something versus how [another female administrator] handles it are all probably very different. So even within a gender itself, it doesn't make it exclusively one way. (MB, personal communication, June 11, 2018)

And really it was down to the needs of the kids. It wasn't so much about for staff, but it was more, if we had kids that had issues or concerns, it was nice when it wasn't necessarily one of, let's say, [a male administrator's] kids, but-- and it was one of mine, but you know what, they would really benefit from talking to a male. Or same for him, if it was an eighth-grade girl that really had a better connection talking to a female than a male. (TU, personal communication, May 31, 2018)

In fact, I think that that good old boy network is absolutely still there. There is no doubt about it. But there's nothing wrong with that, in my opinion, because they need their friends, too.... I think the other part of my gender is that I really-- I think teaching is-- I think the profession of teaching is giving hope. You'll hear me say this sometimes. It is that belief that if you get educated you can have a better whatever it is, life, day, education, I don't know. And I think women have to be hopeful people because we bear children. Right? I mean we bear children, and I think that's it. (EX, personal communication, June 4, 2018)

I think at different times in my life, and I hopefully think it's because of my age of what I am now, that I've experienced some things that you guys will not have to ever experience. (DI, personal communication, June 1, 2018) 
To be a principal and to be a superintendent, you probably have to change school districts a couple of times and be willing to up your family roots and do that. And I think that's still more of a-- not always, but I think, for women, that's harder to do...If a male took this role, would they say, "You know, I need to have a support person." And that would probably make me much more effective in my job. But I'm not going to ask for it because that would be asking for something and admitting that I needed help. Or that I couldn't do it. But then other people have no problems asking for-- and just even in this building, I've seen-- this is commonplace...And I think sometimes I wait to be invited, and if I'm not invited, I don't. Whereas, other people would say, "Well, no, you don't have to wait to be invited. You make that opportunity." So I think sometimes that would be a difference too. I think women sometimes at least-- I don't know if it's a woman thing or an [BT] thing. I wait to be invited instead of making my place around the table. I want to be invited to the table. (BT, personal communication, June 7, 2018)

Those quotes are some of the commentary from the women about how gender influenced their leadership. Out of these thoughts together came the general sense of some of the following patterns:

- The participants did not identify themselves as non-leaders even while in situations that may prohibit their advancement or work in leadership. I thought all women would be hyper-aware of being women in this field and I noticed they are not necessarily so aware. They did not seem phased by the line of questioning and often did not venture into the impact of gender unless specifically asked about it. They did not go to a place of playing the victim very often.

- Even though most of the interviewees started out in their careers not identifying as leaders, they spoke as if they are now convinced of their status and speak/act as if they never understood otherwise. I was surprised to find that they exhibited a confidence in the leadership role, despite being female in that role.

- When it came to mentoring, I often asked if male or female mentors had a bigger effect on the study participants. There was no shortage of female mentors for 
these women. Therefore, they did not seem to notice that the shortage of females in educational leadership had any repercussions in their path.

- The subjects identified many attributes of a good leader, but of the ones they listed, they were different from the qualities they used to describe themselves as leaders. I asked the questions in a certain order: "What makes a good leader? How do identify yourself as a leader?" I anticipated that the women would make the connection between other leaders and themselves, however, most did not. Some of the women mentioned certain qualities across answers, but those were fewer in number than I predicted.

- One pattern that came to the forefront was that many of the women point out that gender does not play a role or influence their positions, yet all cited examples of situations in which cultural and gender-based decisions were made or expected. I questioned whether that outcome was a result of society conditioning them to think like that. Is it easier to rationalize that gender is a non-issue even though it is an issue? Perhaps, you cannot change gender so it is easier to ignore it.

\section{Gender Identity and Leadership Roles, Styles, Skills, and Qualities}

All of the women understood that gender affected how they viewed and defined themselves. When it comes to the role of a leader, their style, their skills, and their qualities, they all had thoughts about how being a woman transformed their identities.

\section{Staying comfortable.}

A pattern that emerged when the women described their reluctance to lead/leave teaching was that the rationale was to stay comfortable. They did not exhibit confidence; they expressed their lack of readiness, a lack of preparedness. They often did not see that everyone learns on job 
and failure is a reality and is a healthy part of learning. They seemed afraid to make mistakes and afraid to look incompetent. They feared critics. Based on how they answered and explained their journeys, I questioned whether they are women socialized to think that way.

\section{Lacking confidence.}

Lacking confidence appeared to be a common theme throughout the interviews. One of the major factors prohibiting movement into leadership for the women seemed to be that they did not have the confidence to do it. It took more than one try and often much convincing by others to persuade them to follow that path to educational leadership.

\section{Emotional leadership.}

Their leadership styles were often dictated by their gender roles. The women led with emotion, often feeling like they had to apologize for it, but not trying to do so:

And in my most recent past, I've had some board members say things to me like, "Basically, you need to make decisions. Take the emotion out of it." And in my mind, that was a slam against what we were trying to do. We were advocating very strongly for something we thought would make the teachers lives easier. And yes, we may have gotten emotional, but we have the relationship with them. The board members, they don't know who they are. I could say our superintendent at this point doesn't know the staff. So it's really easy to make these decisions when you have no personal connection to your stakeholders. (MP, personal communication, July 2, 2018)

The need to take care of staff was a strong one for many of the women. They spoke about how they took extra care to pay attention to the needs and meet people where they are, attempting to reap the benefits of better teaching if they did so:

We here at this building will often do things to just take care of our teachers, right? Whether it's slip little things into their mailbox, whether it's provide lunch or breakfast every now and then. We currently are an all-female admin team in this building, and we think about those kinds of things. (ML, personal communication, June 26, 2018)

I mean that was our only goal for the first year was to completely change the culture from the principal who had left. So we needed people to trust us and we needed to make this a fun place. And that's literally all we did for a year was make it fun to be here. So dressing up, acting crazy, doing funny things in the assemblies, making fools of ourselves, 
basically. Spending money to give the kids all free pop one day because they had had a great game and things like that. Because if we hadn't done that we wouldn't have gotten in a better place from where we had been which was not a good place. (ON, personal communication, June 25, 2018)

\section{Communication skills.}

Communication was mentioned as a top part of female leadership and the participants emphasized that women were better at it than their male counterparts, which they determined enhanced their leadership styles:

I think the one that I'm going to keep coming back to, that seems to be more natural for women, is the communication piece. That seems to be something that-- when I think of female leaders that I've worked with, or been exposed to, they're really good at that. And it's something, from my experience, that a lot of male leaders struggle with. Or those that are, it's taken them time to get that way. And it's something that's been very deliberate on their part. It seems to me like that is something that comes a little more natural for most females. And written, verbal. I mean, all of the above. The whole communication piece is a challenge for a lot of male administrators that I've [laughter] worked with. (MP, personal communication, July 2, 2018)

I think women are much more communicative. I think they are more communicative than men. I think they're much more systematic. And I think they're much more transparent. (MI, personal communication, June 8, 2018)

I feel like there's kind of a little bit of a different way you have to learn to interact with them [males], sometimes...you didn't have to worry so much about how you might phrase something. It was more just get kind of to the-- get to the nuts and bolts of what your question is, don't worry about phrasing it a certain way, or hurting anyone's [feelings]. (KD, personal communication, June 27, 2018)

The one thing that I've learned about working with men is you just quit talking. You just say it. (EX, personal communication, June 4, 2018)

They were proud of the fact they felt they were strong communicators; they excelled at it.

\section{Work ethic.}

Another way in which these leaders thought as women in their roles was through their

work ethic. They believed that they produced the best work by working harder than others, doing the job, and getting down to business: 
My strength is I'm a doer. So there are people who call themselves visionaries or whatever. That's not really my thing. I can do that if I have to but that's not my favorite thing to do. My favorite thing is to take problems and solve them or take things that have to be done and find the best, most efficient way to do it. (ON, personal communication, June 25, 2018)

I don't know if it comes from being minority or a female or whatever it is, but there has always been a feeling of having to work a little harder, do a little more. (TU, personal communication, May 31, 2018)

It is down and dirty, and women are in it down and dirty...Why are women doing the down-and-dirty work?...There's a lot to do. There's a lot to do. And you don't get a lot of glory for doing it. I didn't take this job to be the spokesperson...You don't get a lot of glory. You don't get a lot of recognition. It's a dirty job...Don't you think that's how we are? Women are very-- we're worker bees. (MI, personal communication, June 8, 2018)

And one of the common threads that I've noticed is [female leaders] all seem to have worked hard to either get there or have a strong work ethic in their positions. (DI, personal communication, June 1, 2018)

I do think that it has always from my seat appeared to be women often have to sort of prove themselves a little bit more. So I think in doing that sometimes, that's where some of those traits that we talk about come about. (MP, personal communication, July 2, 2018)

The urge to prove themselves and have pride in their work drove many of the contributors to say they thought female leaders often had to work harder than everyone else; this habit made itself known throughout their careers and was tied to their reputations as leaders. It made a difference in the quality of leadership shown by these women.

\section{Recommendations from the Women}

I asked many questions of the women about how they saw themselves and others in the leadership role, how gender influenced that, and the nature of their experiences. Afterwards, I asked the participants to think about what they would recommend as far as strategies in the effort to reduce the disparity in the number of males and females in educational leadership. The women had much to say and they said it easily. There was no hesitation and I did not have to prompt 
much to give clarity or to get worthwhile answers, which told me that the women had already thought about what would work, what must be done, and what would be helpful. The ease with which they answered told me that their gender identities had been developed by their experiences and those had shaped them. They knew what had worked for them in their journeys. They knew what may work for women if we are able to allow it. At this time in the interview, too, the women brought up questions themselves about what may work, pondering the possibilities. In addition, at times, they gave conflicting advice, which is worth analyzing.

\section{Pathways}

Many of the women shared that different pathways would enable women to pursue educational leadership. Gaining exposure to the different parts of the field of education was a step that seemed to be logical, yet not always encouraged. Not all women were guided toward that exposure. "When I started teaching in the building, I knew I wanted to get my Master's degree. And I wasn't really sure about which direction I wanted to go. I knew I didn't want to do another content area...But I was really just passionate about ELA. And I, kind of, got burned out on it though by the end. It was like, alright, I know I want to do either curriculum instruction or ed[ucational] administration" (TU, personal communication, May 31, 2018). To illustrate that misguidance, on one occasion, as I informally explained what my dissertation topic was about to an accountant, he asked me the question, "How are women trained to be educational leaders?" He pointed out that in the business world and in business education at the university level, all students are taught about and trained to pursue lower and upper level management positions, to move beyond the entry levels. I answered his question by explaining that teacher education at the undergraduate level rarely, if ever, mention or offer opportunities in educational leadership; the focus is simply on learning how to deliver instruction. If teacher leadership is addressed, it is 
done so as a sidebar or as a graduate class. After that conversation, I thought about that variance and about the recommendations made by the women in my study. At the beginning of their teaching careers, the women had no intention of going into educational administration. Was it because they were not encouraged or taught about the opportunity early enough? They reported being exposed to opportunities once in the career, of following their passions, tapping into their strengths, and setting goals.

\section{Exposure to leadership opportunities.}

All of the interviewees referenced some sort of opportunity to lead they had as a teacher, and it typically happened well into their careers. A participant, MB, offered advice:

I guess the only other thing that I would say is just giving them opportunities to practice leadership. And sometimes that's going to happen before they go into that leadership position. And I think kind of the mindset that I've been thinking of when we talk about leadership, I am automatically assuming school administrator. But even a teacher being a team leader, department chair could also be females in leadership. And I think it's going to go back to giving them that guidance and giving them the opportunity to learn. There's definitely some safer risks and safer settings that people can be exposed to, and knowing that they're supported in those situations is important. (MB, personal communication, June 11, 2018)

Without saying it, she was onto something when she suggested the experiences should happen earlier. Why not encourage teacher candidates during teacher education about the importance of teacher leadership? When asked how to increase the number of women in leadership positions, a participant, MT, presented: "You know, I guess just through encouraging and developing young people at the younger ages and supporting them and being in positions of decision-making. And kind of doing to them what mentors have done to me, and just encourage and pass on stuff that we've learned" (MT, personal communication, June 5, 2018). Both MB and MT have strong backgrounds in athletics, which also makes me wonder if their experiences with playing and coaching prompted them to answer in the way they did. Coaching is teaching and leadership is 
highly regarded in athletics. MP summed it up: "For one thing, I think you need to expose yourself to as many different parts of the education world as you possibly can. And you have to be confident in what it is that you possess and the skill set that you possess" (MP, personal communication, July 2, 2018). Since some of the women had backgrounds in these other fields, they saw it as an asset that they had been exposed to different experiences and it helped them later.

MI was direct about how she felt concerning involving women in leadership: "I always tell them [young teachers], no time is the right time. 'Oh, my kids are too little.' No time is the right time" (MI, personal communication, June 8, 2018). Her own experience of being a mother and finding balance with her leadership work induced her to advise in that way.

It is worth mentioning that I did encounter what I would classify as opposition to the advice mentioned prior about exposing teachers to opportunities early and often. One participant, EX, advised to not go into administration too early, in order to keep from burning out: "But I think that is one of the reasons we do not see as many women in superintendent positions. Now I will tell women now, 'Don't go into administration too early.' People are burning out, and it's hard. It's hard. If I could have a rule that you couldn't be an administrator until you were 40, I would. Maybe 35, same as the president of the United States. I'd be okay with that. Because at some point there's a ceiling" (EX, personal communication, June 4, 2018). ON lamented: "...the farther you are in your [teaching] career the harder it is to jump into something like this [administration]" (ON, personal communication, June 25, 2018). It seemed as though some of the contributors to this study may have been guessing about what could be the plan that would help get more women into the administrative realm. I believe the contradictory advice came from places of ignorance about what is and was available to educate women about the opportunities. 
The ignorance has been created due to what one woman explained was a lack of stability in the environment for women to achieve positions: "...but I think a part of the school district's mission and vision should be to recruit female leadership" (BT, personal communication, June 7, 2018). Not having the opportunities, nor being trained or taught about the opportunities, and not understanding the potential value in how or when to start in leadership are all obstacles.

\section{Find the passion.}

A few of the contributors recommended finding the passion as a helping mechanism that could spur women into considering the path to leadership. KH shared her story as an example: "You need to follow your heart. You need to follow what you're interested in doing. I mean, being able to have the practice of leading schools, and leading adults, and leading students led to my desire to continue that. You've got to find what makes you tick, you've got capitalize on your strengths, and then building that capacity where you think that you have areas to grow or weaknesses" (KH, personal communication, June 5, 2018).

\section{Mentoring}

Of all the recommendations the interviewees mentioned, mentoring in many formats was by far the most discussed. Engaging with others was the common thread. That engagement could happen through connecting with experienced people, collaboration with all sorts, paying attention to and providing modeling, and/or surrounding oneself with people in "like" roles. MB pointed out that having mentors who have "been there, done that" is critical to the success of women pursuing leadership and to retaining them in that field: "And so having somebody that you, as a person coming into a leadership position, being able to be connected with somebody that has experience, that's been in those trenches before, that gets it" (MB, personal communication, June 11, 2018). MP lived that experience: "I think the mentoring that I've had 
has been more a result of the role that I was in and who was around me at that time. So very informal mentoring, I would say. That's probably been the most effective. But someone who obviously shared a common language and was in the district. So there were common things we were working on together. That's the most authentic, I feel like" (MP, personal communication, July 2, 2018). BT recommended linking up in a more formalized way: "I think some mentoring and then some kind of professional organization like women in educational leadership, and I'm sure there's something out there" (BT, personal communication, June 7, 2018). BT's comment is interesting in that it points out that some of the women had ideas about mentoring that could work, even though they had never experienced those themselves. She felt that mentoring through a professional organization could be effective but she did not know what was out there in that capacity and she clarified later she was not a member of any organization.

EX stressed how important it is to surround oneself with a network of a variety of people: "I would say the other thing is get a tribe. Get a group of people that are not necessarily your friends. And you don't even actually have to identify them. But you have to watch them. Find people that you respect and watch them" (EX, personal communication, June 4, 2018).

Witnessing the modeling (the good and the bad) can be beneficial in growth as a leader.

\section{Personal Development}

The interviewees recommended several strategies in the area of personal development as an educational leader. They viewed them as ways to stay in it and ways to keep going.

\section{Building confidence.}

Building confidence was the one most cited. DI had a lot to say about how confidence works in women who are educational leaders. At first, she offered how to get that confidence empowerment from others is key: "I still think it goes back to empowerment. And building that 
confidence, or seeing that spark in someone, and then empowering them to act on it. Or helping them to build their capacity" (DI, personal communication, June 1, 2018). She believed that women and other leaders must help potential leaders. At the same time, however, she also acknowledged the reality of the research problem and how mentoring could play a role in changing it: "But I guess I wonder if sometimes there's still women who don't have the confidence in themselves to go to that next step or go to that next level. And so, it might be even more important for us to build that confidence in women that maybe guys have more of" (DI, personal communication, June 1, 2018). She goes to give an example of situations she saw in her work: "I have known some people who, once you put a roadblock in front of them, that's it. They shut down. They're done. And perhaps it's because they have not built the social capital kind of thing. But I think, for whatever reason, they fear that unknown, or they fear that they're not going to be good enough, or that they have a fear of that next step. Because it is risky sometimes. When you go from one position to another position, there's a certain amount of risk that you're taking. And some people are not comfortable with taking the risks that you need to take. Or think, 'Okay, I didn't get this job. I'm done. That's it. I'm not going to try to pursue it because that's over with"' (DI, personal communication, June 1, 2018). DI's thoughts about the important role of mentoring in developing female leaders are helpful because they work within the reality of the situation. Some women may lack the confidence they need to propel themselves into a position where they can feel supported and take risks. Mentors can help in combating that sense of futility. MI gave an excellent example of a time she was encouraged to apply for a position even though she believed she was not ready: "[My mentor told me] 'You do the work. You have the degrees. You do the work.' I'm all about doing the work and getting the experience in terms of, you go to school to do that. 'Don't doubt yourself, you can do it. Don't think that you're not ready. 
You've got the what behind your name. You've got this endorsement. Don't doubt yourself that you're not ready. You're ready."' (MI, personal communication, June 8, 2018).

\section{Find strengths and voice.}

Some of the women recommended personally developing themselves and others through searching and being reflective about what one already has possession of - strengths and voice. EX explained it in the clearest way: "And then the other thing I would say is you find your own voice. You have your own voice... But find your own voice. And test it...And it goes back to my belief that you work towards people's strengths. Because I've yet to see somebody want to work on a weakness. I just don't see it. I think it goes against human nature" (EX, personal communication, June 8,2018 ). Testing the voice is the probably the most critical exercise in leadership. Because some of these women had problems with confidence, they are able to predict that owning a voice and using it will be challenging to some women. Therefore, EX reassures that this exercise is possible and valuable.

\section{Explore possibilities.}

One area that linked to personal development appeared to be that women should be openminded about the possibilities in leadership. The impression I left one interview with is that women are not often so open. ML first offered: "But I guess that's the first thing I would say is, if you are considering going into leadership as a female teacher or whatnot or not considering it, to just be open-minded. I try to point out to different faculty members, 'You know, have you ever thought about-- because there's A, B, and C that I think you would make phenomenal leader'" (ML, personal communication, June 26, 2018). ML went further to reflect about the differences in how men and women approached their roles as leaders. She admitted her perspective was limited as a female, but she saw that females often seemed to hinder their own progress by not 
considering every possibility. She wished that to be different, in her own life as well as others. She also considered that gender might not factor into it: "And I think it-- that depends more on your personality traits and skill sets and characteristics versus your gender. But I'd say be openminded and just consider others' thoughts and opinions as far as, maybe, qualities that they see. And I could say that I am-- I could say don't ever stop reaching for what could be-- you don't know what's around the corner" (ML, personal communication, June 26, 2018).

MP took the question about recommendations from a different angle, one I did not hear much about in my interviews: disparity in male and female salaries. Only two women who had worked in the same district at one time mentioned it. I suspect it did not come up more often because salaries in the education field are somewhat fixed; there is often no room for negotiation or maneuvering. MP gave an example that illustrated how women must think in order to be open to the possibilities: "I also remember a conversation I had with [a female colleague] within this last year where we talking around salaries. And something was thrown out, and I said, 'That is way too high. That is way too-- that salary is way too high. I am not worth that much money.' And she got so mad. She was like, 'Do you think you would ever hear a man say that?' She's like, 'The answer is no. You would never hear a man say that. Why would you say that?' And [laughter] I didn't have an answer. I don't know. It just seemed completely unreasonable" (MP, personal communication, July 2, 2018). MP reflected about her reaction to the challenge from the female colleague and it made her rethink how she viewed herself and her worth. The challenge also made MP think about how men think about the possibilities in different ways.

\section{Future Research}

As I scoured the data and the research problem more and more deeply over time, I concluded many things about it and the research I and other researchers have conducted. In the 
data analysis phase, the discoveries I made about what the women thought was important showed through and I was fortunate to be able to highlight it. However, as a result, many more research problems and questions came about. There are many opportunities for future research and I will discuss some of the obvious ones in this section.

\section{Interview Male Educational Leaders}

A thought I kept having as I left each interview and as I continued to work with male administrators in my own job was that it would be interesting to interview the men with the same questioning and find out how they would answer. A comparison with this study could be done; the data could produce information that would further indicate what it would take to encourage more women to pursue educational leadership. I wondered how similarly and how differently men would answer the same questions.

\section{Examine Competitiveness}

As the women spoke of obstacles they encountered, I heard some mention experiences they had when it came to other women competing with them for jobs or positions. There was an undercurrent with a few of them that it bothered them and they felt it to be an unnecessary and preventable side effect. Perhaps a qualitative study looking into those occurrences would help women and others gain insight about these occurrences.

\section{Examine Leaders as Nurturers}

Many of the women talked about how women are naturally nurturing individuals; that some people may not view nurturing as a worthwhile quality in a leader. I wondered why this quality would truly be at odds with leadership or if it was just a perception the women noticed as they moved along their paths. Either way, it would be interesting to research that aspect. The 
study could be done in a variety of ways and the findings could provide insight about how nurturing plays a role in leadership, positively, negatively, or indifferently.

\section{Explore Male Success in Leadership}

As the participants and I pondered the causes of why women do not go into educational leadership at the same rate as men, it occurred to me to ask myself: Are men successful in that path because of the women subordinates? In leadership, no man or woman can do it by themselves. What are the causes of their success?

\section{Study "Bossy" Women}

At times, some of the women may have struggled with being in charge; many of them expressed zero desire to take it on as a responsibility. I found myself wanting to ask them all more about how they see themselves as a boss and how they cope with supervising, which is a necessary part of leadership. As they spoke of their journeys and the reasons why they chose to go into the field, I sensed that there might be some internal battles and coming-to-terms the interviewees dealt with.

\section{Implications for Practice/Practitioners}

It is my hope that the findings of this study will lead to recommendations on how to encourage more capable and qualified women to enter educational leadership and make significant contributions. There are connections throughout this study that could be useful in determining steps that human resource departments and school boards may take in order to address the research problem.

In addition, the findings may lead to a greater understanding of why and how women become educational leaders and may possibly lead to recommendations for encouraging more women to seek out and obtain those positions. Because men are qualified to be effective 
educational leaders, too, a policy may be implemented and necessary so that human resources departments may make educated decisions about recruiting, mentoring, and coaching with all prospective employees, but ensuring that women are represented in that pool of applicants, too.

As previously discussed, there are already recommendations in circulation. Many studies do go further than just identifying and discussing the problem. Those results often lead researchers to offer strategies and recommendations about how society may fix the problem. Christman and McClellan (2008) insisted that if organizations want to increase the number of women serving as leaders in schools, then researchers must analyze how women arrived at that point and how they can stay (p. 3). Gupton (2009) took that advice and produced a study with the purpose in mind reflect about women in the roles since the 1900s to the present. Taking the historical perspective led to garnering advice for prospective candidates (p. 1). When Brown and Irby (1993) compiled their collection of fourteen articles in Women as School Executives: A Powerful Paradigm, in which they challenged society to think about the way things are currently and then proposed that women's qualities are aligned with dynamic leadership, they also offered strategies for everyone who may feel compelled to change the current state of perception.

Implementing methods that encourage women to identify themselves as educational leaders, be selected as potential educational leaders, and pursue and apply for positions in educational leadership is necessary to increase the numbers of women in these roles. Through implementation, recommendations could be made to school districts about how to foster an environment that encourages more women to pursue higher-level educational leadership positions.

As states struggle with the shortage of female educational leaders, the possibilities about who will make decisions regarding decisions about policy and implementation rises. It is 
possible that state boards of education would be involved in providing guidance to school district boards, school district human resources departments, school administrators, and women in education (teachers and leaders). This cooperation may not be ideal, though, depending upon the reputation of the state board and their experience in implementing policies that help expand or propagate services for students. Local control may be more desirable for decision making because school district boards may have a better understanding of the climate and culture of the school districts and its needs. A policy that serves to increase the number of female candidates and employees in educational leadership is one that may take some finesse to introduce and implement, depending upon the environment. Constituents often have preconceived notions, prejudices, or ignorance about policy issues. School employee unions may need to be part of the conversation as well, in a supportive role that helps the policy implementation be successful. It appears that it would be in their best interest to help foster activity that helps women advance as much as possible. On the other hand, unions may not do much in the way of promoting such an effort, as many school leaders are not union, dues-paying members.

Another way the research of the gap areas could affect change could be through an action plan that addresses the inequities; researchers could look into how to take the following steps as an assistance to these issues:

- Form and facilitate groups of all ages that examine how to recruit and actively acknowledge the inequity of women in business and in leadership. For example, Harvard Business School implemented a Gender Initiative, which purposefully “...supports research, education, and knowledge dissemination to accelerate the advancement of women leaders and promote gender equity in business and society" (2015). 
- Continue to set up and have conversations about awareness both locally and globally, focusing on problem solving.

- Teach students about how to have conversations about gender bias and encourage them to try to experiment in fields that are not traditionally pursued by women.

\section{Chapter VI Summary}

Chapter VI reported the findings of the study at length. Taking a thematic approach, gender influence on leadership and gender identity and leadership roles, styles, skill, and qualities were discussed. In addition, recommendations from the women who participated in this study were conveyed to the audience. I explored the avenues of future research and what the findings could mean for educational leadership and practitioners. References are provided. 


\section{REFERENCES}

A., \& Henderson, J. (1998). Aristophanes. Cambridge, MA: Harvard University Press.

Albright, M. (2016, February 12). Madeleine Albright: My undiplomatic moment. The New York Times. Retrieved from https://www.nytimes.com/2016/02/13/opinion/madeleine-albright-my-undiplomaticmoment.html

Armstrong, D. \& Mitchell, C. (2017). The double bind for women: Exploring the gendered nature of turnaround leadership in a principal preparation program. Educational Management Administration \& Leadership. 45, 825-841.

Bass, L. (2012). When care trumps justice: the operationalization of black feminist caring in educational leadership. International Journal of Qualitative Studies in Education (QSE). 25(1), 73-87.

Beatty, B. R. (2000). The emotions of educational leadership: breaking the silence. International Journal of Leadership in Education, 3(4), 331-357.

Belenky, M. F., Clinchy, B. M., Goldberger, N. R., \& Tarule, J. M. (1986). Women's ways of knowing. New York, NY: Basic Books.

Bhopal, K. (2010). Gender, identity, and experience: Researching marginalised groups. Women's Studies International Forum, 33(3), 188-195.

Blackmore, J. (2013). A feminist critical perspective on educational leadership. International Journal of Leadership in Education, 16(2), 139-154.

Blair, D. (2018). Giving a voice to women in K-12 educational leadership: A narrative analysis. Dissertation Abstracts International Section A: Humanities and Social Sciences, 78(7A)(E), 1-172. 
Boggs, L. M. (2010). Rules of engagement: Navigating gender in the superintendency. Dissertation Abstracts International Section A: Humanities and Social Sciences, 70(11A), 4126 .

Brown, G., \& Irby, B. J. (Eds.). (1993). Women as school executives: A powerful paradigm. Huntsville, TX: Sam Houston Press.

Christman, D. \& McClellan, R. (2008). Living on barbed wire: Resilient women administrators in educational leadership programs. Educational Administration Quarterly, 44(1), 3-29.

Clifford, C. (2007). Are girls still marginalized? Discrimination and gender inequality today. Foreign Policy Association. Retrieved from http://foreignpolicyblogs.com/2007/05/29/are-girls-still-marginalized-discrimination-andgender-inequality-in-today $\%$ E2\%80\%99s-society/.

Coleman, M. (2005). Gender and secondary school leadership, International Studies in Educational Administration, 33(2), n.p.

Creighton University. (2017). What is educational leadership? Retrieved from http://online.creighton.edu/edd/doctorate-leadership/resources/what-is-educationalleadership

Creswell, J. W. (2014). Research design: Qualitative, quantitative, and mixed methods approaches (4th ed.). Thousand Oaks, CA: SAGE.

Cubillo, L. \& Brown, M. (2003). Women into educational leadership and management: international differences? Journal of Educational Administration, 41(3), 278-291.

Dana, J. A. \& Bourisaw, D. M. (2006). Women in the superintendency: Discarded leadership. Lanham, MD: Rowman \& Littlefield Education. 
Davis, D. J., Mack, L. R., Washington, M. L., \& Cantey, N. I. (2010). Educational leadership and the continued need for minority academic and professional organizations in the Obama age. Academic Leadership, 8(3), para. 5.

Dwyer, S.C. \& Buckle, J.L. (2009). The space between: On being an insider-outsider in qualitative research. International Journal of Qualitative Methods, 8(1), 54-63.

Etikan, I., Musa, S. A., \& Alkassim, R. S. (2016). Comparison of convenience sampling and purposive sampling. American Journal of Theoretical and Applied Statistics 5(1): 1-4.

Finneran, C. A. (2018). Building the leadership capacity of women in K-12 education:

Successful strategies that create the next generation of women school and district leaders. Dissertation Abstracts International Section A: Humanities and Social Sciences, 78(7A)(E).

Fowler, A. J. (2012). A case study of one Iowa elementary school principal's journey into administration (Doctoral dissertation). Retrieved from ProQuest Dissertations Publishing (3535657.)

Frkal, R. A. (2016). Creating dialogic conditions for transformative learning in an adult women's leadership program: A communication perspective (Doctoral dissertation). Retrieved from ProQuest Dissertations Publishing. (10164147)

Gaetane, J-M. (2013). The subtlety of age, gender, and race barriers: A case study of early career African American female principals. Journal of School Leadership, 23, 615-639.

Glass, T. E. (2016). Where are all the women superintendents? AASA: The School Superintendents Association. Retrieved from http://www.aasa.org/SchoolAdministratorArticle.aspx?id=14492 
Glesne, C. (2016). Becoming qualitative researchers: an introduction. Boston: Pearson. Greenleaf, R.K. (1970). The servant as leader. Retrieved from https://www.essr.net/ jafundo/mestrado_material_itgjkhnld/IV/Lideran\%C3\%A7as/The \%20Servant\%20as\%20Leader.pdf

Grogan, M. (2011). Re(considering) gender scholarship in educational leadership. In W. S.

Newcomb \& K. C. Mansfield (Eds.), Women interrupting, disrupting, and revolutionizing educational policy and practice (pp. 3-20). IAP Information Age Publishing.

Grogan, M. \& Shakeshaft, C. (2011). Women and educational leadership. San Francisco, CA: Jossey Bass.

Growe, R. \& Montgomery, P. (1999). Women and the leadership paradigm: Bridging the gender gap. Retrieved from http://nationalforum.com/Electronic\%20Journal\%20Volumes/Growe,\%20Roslin\%20W omen $\% 20$ and $\% 20$ the $\% 20$ Leadership $\% 20$ Paradigm $\% 20$ Bridging $\% 20$ the $\% 20$ Gender $\% 20$ Gap.pdf

Gupton, S. L. (2009). Women in educational leadership in the U.S.: Reflections of a 50 year veteran. Forum on Public Policy Online, 2009(2), 1-20.

Harvard Business School (2015). The gender initiative. Retrieved from https://www.hbs.edu/gender/about/Pages/default.aspx

Hatt, B. (2017). Research paradigms [Class handout]. Educational Administration and Foundations, Illinois State University, Normal, IL.

Hill Collins, P. (2000). Black feminist thought: Knowledge, consciousness, and the politics of empowerment. New York, NY: Routledge. 
Horsford, S. D. (2012). This bridge called my leadership: an essay on Black women as bridge leaders in education. International Journal of Qualitative Studies in Education (QSE), 25(1), 11-22.

Horsford, S. D. \& Tillman, L. C. (2012). Inventing herself: Examining the intersectional identities and educational leadership of Black women in the USA. International Journal of Qualitative Studies in Education, 25(1), 1-9.

Ibarra, H., Ely, R. J., \& Kolb, D. M. (2013). Women rising: The unseen barriers. Retrieved from https://hbr.org/2013/09/women-rising-the-unseen-barriers, para. 5.

Jones, J. R. (2013), Her story: A qualitative study of the journey of the African American woman superintendent (Doctoral dissertation). Retrieved from ProQuest Dissertations Publishing. (3550243)

Karelaia, N. \& Guillén, L. (2014). Me, a woman and a leader: Positive social identity and identity conflict. Organizational Behavior and Human Decision Processes, 125(2), 204219.

Khine, M. S. \& Hayes, B. (2010). Investigating women's ways of knowing: An exploratory study in the UAE. Issues in Educational Research, 20(2), 105-117.

Kirkham, S. (2005) Losing out in caring roles. The Times Educational Supplement, p. 8.

Komives, S. R., Owen, J. E., Longerbeam, S. D., Mainella, F. C., \& Osteen, L. (2005). Developing a leadership identity: A grounded theory. Project MUSE 46(6), 593-611. 
Lebo, D. L. (1994). Women and their perceptions of home and work roles: Relationships between ways of knowing and ways of coping (Doctoral dissertation). Retrieved from ProQuest Dissertations Publishing. (9427094).

Liang, J. G. \& Peter-Hawkins, A. L. (2017). "I am more than what I look alike": Asian American women in public school administration. Educational Administration Quarterly, 53(1) 4069.

Loder, T. L. (2005). African American women principals' reflections on social change, community othermothering, and Chicago public school reform. Urban Education, 40(3), 298-320.

Lopez, R. (2010). Race and gender as variables that impact leadership and its perspectives in education. Feature Edition, 2010(4), 21-35.

Lovette-Colyer, E. \& Lovette-Colyer, M. (2017). Self-Work on Gender for Leadership Educators: Reflections from Our Experiences. New Directions for Student Leadership, 2017(154), 71-81.

Lumby, J. \& Morrison, M. (2010). Leadership and diversity: theory and research. School Leadership \& Management, 30(1), 3-17.

Lumby, J. (2011). Gender representation and social justice: ideology, methodology and smokescreens. Gender and Education, 23(7), 921-934.

Lumby, J. (2015). School leaders' gender strategies: Caught in a discriminatory web. Educational Management Administration \& Leadership, 43(1), 28-45. 
Merriam, S. B. (2009). Qualitative research: A guide to design and implementation. San Francisco: Jossey-Bass.

Miles, M. B., Huberman, A. M., \& Saldana, J. (2014). Qualitative data analysis: A methods sourcebook. Thousand Oaks, CA: SAGE.

Murakami, E. T. \& Tornsen, M. (2017). Female secondary school principals: Equity in the development of professional identities. Educational Management Administration \& Leadership, 45(5), 806-824.

Murphey, K., Moss, G. Hannah, S. \& Weiner, R. (2005). Women in educational leadership: Finding common ground. Women in Educational Leadership, 3(4), 273-284.

Orr, R. \& Luszcz, M. (1994). Rethinking women’s ways of knowing: Gender commonalities and intersections with postformal thought. Journal of Adult Development, 1(4), 225-233.

Patton, M. Q. (1990). Qualitative research and evaluation methods, $2^{\text {nd }}$ ed. Los Angeles, CA: SAGE.

Patton, M. Q. (2015). Qualitative research and evaluation methods, 4t ed. Los Angeles, CA: SAGE.

Rashid. N. (2010). Women differences in seeking educational leadership and management. Journal of Educational Research, 13(1), 207.

Reed, L. C. (2012). The intersection of race and gender in school leadership for three black female principals. International Journal of Qualitative Studies in Education (QSE), 25(1), 39-58.

Reed, L. \& Evans, A. E. (2008). “What you see is [not always] what you get!” Dispelling race and gender leadership assumptions. International Journal of Qualitative Studies in Education (QSE), 21(5), 487-499. 
Reid, P. T., Lewis, L. J., Wyche, K. F. (2014). An intersectional framework for a multicultural analysis of gender. APA Handbook of Multicultural Psychology, Vol. 1: Theory and research. F. T. L. Leong, (Ed); L. Comas-Díaz (Ed); G. C. Nagayama Hall (Ed); V. C. McLoyd (Ed); J. E. Trimble (Ed). Washington, DC, US: American Psychological Association.

Regan, H. B. \& Brooks, G. H. (1995). Out of women's experience: Creating relational leadership. Thousand Oaks, CA: Corwin Press.

Reinhartz J, \& King, F. L. (1993). Rethinking the paradigm: Women in leadership roles. In G. Brown \& B. J. Irby (Eds.), Women as school executives: A powerful paradigm (pp. 7-12). Huntsville, TX: Sam Houston Press.

Sanchez-Hucles, J. V. \& Davis, D. D. (2010). Women and women of color in leadership: Complexity, identity, and intersectionality. American Psychologist, 65(3), 171-181.

Scott, R. (2015). Best way to save the world? Put women in charge. Forbes. Retrieved from https://www.forbes.com/sites/causeintegration/2015/12/01/best-way-to-save-the-worldput-women-in-charge/\#3d32524f4971

Shakeshaft, C. (1989) Women in educational administration. Newbury Park, CA. Corwin Press.

Shea, H. D. and Renn, K. A. Gender and leadership: A call to action. New Directions for Student Leadership, 2017(154), 83-94.

Simon, S. (2015). Fire in the Belly or Rocks in the Head? Why do some teachers dream of becoming a school principal? Leading \& Managing, 21(1), 53-68.

Sinclair, A. (2004). Discourse: studies in the cultural politics of education. Journey Around Leadership, 25(1), 7-19. 
Sinclair, S. \& Carlsson, R. (2013). What will I be when I grow up? The impact of gender identity threat on adolescents' occupational preferences. Journal of Adolescence, 36(3), 465-474.

Steinem, G. (1981, May). The politics of talking in groups. Ms., 9, 43, 45, 84, 86-89.

Stryker, S. \& Burke, P.J. (2000). The past, present, and future of an identity theory. Social Psychology Quarterly, 63(4), 284-297.

Superville, D. R. (2016). Few women run the nation's school districts. Why? PBS News Hour. Retrieved from http://www.pbs.org/newshour/updates/women-run-nations-schooldistricts/\#.WG5vt5eoxwQ.email

Teagan, E. D. L. (1996). Gender distinctions in the moral and cognitive development of adults: The interaction of ways of knowing, decision-making, communication, and leadership behavior of women administrators in higher education (Doctoral dissertation). Retrieved from ProQuest Dissertations Publishing. (9639039).

Terpenny, J. P. (2014). Mary Poppins was a very wise woman: Insights for effective leadership in academia. Proceedings of the ASEE Annual Conference \& Exposition (121st ASEE Annual Conference and Exposition), 1-11.

Tesch, R. (1990). Qualitative research: Analysis types and software tools. New York, NY: Falmer.

Title IX of the Education Amendments of 1972, 20 U.S.C. A§ 1681 et seq.

Throne, R. (2012). Practitioner research in doctoral education. Dubuque, IA: Kendall Hunt.

Throne, R. (2017). What is positionality in practitioner research? Retrieved from http://dissertationscholar.blogspot.com/2013/04/what-is-positionality-in-practitioner.html 
Vantieghem, W., Vermeersch, H., \& Van Houtte, M. (2014). Why “Gender” disappeared from the gender gap: (Re-)introducing gender identity theory to educational gender gap research. Social Psychology of Education, 17, 357-381.

Waldron-Asuncion, A. (2017). Successful African American women school leaders in Florida. Dissertation Abstracts International Section A: Humanities and Social Sciences, 77(7A)(E).

Wallace, J. \& Wallin, D. (2015). “The voice inside herself”: Transforming gendered academic identities in educational administration. Gender and Education, 27(4), 412-429.

Warner, L. R. (2016). Theories of gender identity. The Wiley Blackwell Encyclopedia of Gender and Sexuality Studies, 1-6.

Weiner, J. M. \& Burton, L. J. (2016). The Double bind for women: Exploring the gendered nature of turnaround leadership in a principal preparation program. Harvard Educational Review, 86(3), 339-365.

Wheat, C. A. \& Hill, L. H. (2016). Leadership identities, styles, and practices of women university administrators and presidents. Research in the Schools, 23(2), 1-16.

Young, M. D. (2005). Shifting away from women's issues in educational leadership in the US: Evidence of a backlash? International Studies in Educational Administration (ISEA), $33(2), 31-42$.

Zenger, J. and Folkman, J. (2012). Are women better leaders than men? Harvard Business Review. Retrieved from https://hbr.org/2012/03/a-study-in-leadership-women-do 


\section{APPENDIX A: INFORMED CONSENT FORM}

Date: April 19, 2018

Dear Potential Participant:

I am a graduate student under the direction of Associate Professor Elizabeth T. Lugg in the Educational Administration \& Foundations department at the College of Education at Illinois State University. Because the number of female educational leaders is disproportionate to the number of males, I am conducting a qualitative study about the experiences of female educational leaders. By inquiring about these experiences, I hope to make recommendations about how to recruit and interest more women to go in to those roles. Because you are a current (or retired) female educational leader, I would like to interview you and ask you questions about your experiences. The study will be conducted from summer 2018 and into fall 2018.

I invite your participation, which will involve participating in a face-to-face recorded interview. I will ask you approximately five questions and the interview may take approximately sixty minutes. You can also skip questions you do not feel comfortable answering. You must be over 18 years of age to participate. There are risks you should be aware of: a potential risk could be to your privacy, reputation, and employment if you currently work in a school setting and have negative experiences to share. In addition, throughout the interview, you are not expected to discuss any material that is emotionally sensitive or will make you feel uncomfortable in any capacity. However, since this research is attempting to explore female educational leaders' experiences, it is possible that you may have and will recall certain negative experiences. To prevent any discomfort, I will ensure that all the data you provide remains confidential. Also, counseling services will be provided should in case you need it. At any point during the interview, you have the right to skip over any question that makes you feel uncomfortable or distressed or you may choose to discontinue the interview and withdraw from the study at any time and without penalty. Please be advised that the results of this study will be published, but your name will not be used. I will take all precautions to maintain confidentiality by using pseudonyms.

The collected data will be coded and analyzed by me as part of the qualitative study. There are no direct benefits to you; however, your participation will help us gain useful knowledge about the nature of female educational leaders' experiences. The results of this study will mainly be disseminated through a dissertation. The gathered information will benefit the participants by providing them an avenue to use their voices as female educational leaders. The findings should yield a greater understanding of why and how women become educational leaders, including examining how they identify themselves as leaders and lead to recommendations for encouraging more women to seek out and obtain those positions. All stakeholders involved in education should benefit from the findings: school board members, women, teachers, administrators, families, students, legislators.

Your participation in this study is voluntary. You are not required to participate in this study and may stop your participation at any time by denying the researcher access to the data. Reported 
data will be kept confidential and any information that might allow someone to identify you will not be disclosed to anyone other than this researcher.

If at any time, prior to, during, or after your participation is completed, you have any questions or concerns regarding this study, please discuss them with Amanda Jarvis, the Co-Principal Investigator, (XXX) XXX-XXXX or Dr. Elizabeth T. Lugg, the Principal Investigator, at (309) 438-8989 or the Research Ethics \& Compliance Office at Illinois State University at (309) 4382529 or rec@ilstu.edu.

Sincerely,

Amanda Jarvis

You will be given a copy of this consent form for your records.

I consent to participating in the above study.

Signature

Date

If you have any questions about your rights as a subject/participant in this research, or if you feel you have been placed at risk, you can contact the Research Ethics \& Compliance Office at Illinois State University at (309) 438-2529 or via email at rec@ilstu.edu. 


\section{APPENDIX B: INTERVIEW PROTOCOL}

Date:

Place:

Interviewer:

Interviewee:

Instructions for the interviewer:

- Explain the purpose of the interview is data collection for a qualitative study that is examining the nature of the experiences of female educational leaders, in order to address the problem of disparity in numbers of them compared to males.

- Explain that the interviewer will ask a series of questions and that the interviewee should please feel free to share whatever she is comfortable with at the time.

- Explain who may have access to the collected data.

- Record the interview on an approved recording device and save for transcription.

Interview Questions:

What is the nature of female educator experiences in becoming PK-12 educational leaders?

a. What was your path to leadership?

b. What are your thoughts about women and educational leadership?

c. How do you identify yourself as a leader?

d. How do you define what makes a good leader?

e. What recommendations do you have for increasing the number of women in leadership positions?

Possible probes:

Tell me more...

What do you mean by that?

Please explain...

Could you elaborate?

Please describe...

Can we unpack this point...?

So what I hear you saying is...

Statement of Thanks:

I want to thank you for spending time with me today. I appreciate your willingness to share your experience with me. Your participation will help further the studies in social sciences. 
APPENDIX C: DATA ACCOUNTING LOG-INTERVIEWS

\begin{tabular}{|l|l|l|l|l|}
\hline Date & Role & Interviewee & Time & Duration \\
\hline $05 / 31 / 2018$ & Principal & TU & $2: 30 \mathrm{pm}$ & $59: 05$ \\
\hline $06 / 01 / 2018$ & Principal & NM & $11: 30 \mathrm{am}$ & $58: 32$ \\
\hline $06 / 01 / 2018$ & Assistant superintendent & DI & $1: 30 \mathrm{pm}$ & $64: 22$ \\
\hline $06 / 04 / 2018$ & Assistant superintendent & EX & $8: 00 \mathrm{pm}$ & $84: 08$ \\
\hline $06 / 05 / 2018$ & Building administrator & MT & $10: 30 \mathrm{am}$ & $58: 07$ \\
\hline $06 / 05 / 2018$ & Principal & KH & $12: 00 \mathrm{pm}$ & $47: 27$ \\
\hline $06 / 05 / 2018$ & Building administrator & BP & $9: 00 \mathrm{pm}$ & $58: 33$ \\
\hline $06 / 07 / 2018$ & Director & BT & $3: 00 \mathrm{pm}$ & $67: 47$ \\
\hline $06 / 08 / 2018$ & Director & MI & $10: 30 \mathrm{am}$ & $59: 10$ \\
\hline $06 / 11 / 2018$ & Director & MB & $10: 00 \mathrm{am}$ & $72: 35$ \\
\hline $06 / 25 / 2018$ & Building administrator & ON & $1: 00 \mathrm{pm}$ & $38: 17$ \\
\hline $06 / 26 / 2018$ & Building administrator & ML & $9: 30 \mathrm{am}$ & $48: 00$ \\
\hline $06 / 27 / 2018$ & Building administrator & KD & $11: 00 \mathrm{am}$ & $41: 55$ \\
\hline $07 / 02 / 2018$ & Assistant superintendent & DC & $9: 00 \mathrm{am}$ & $36: 02$ \\
\hline $07 / 02 / 2018$ & Assistant superintendent & MP & $2: 30 \mathrm{pm}$ & $50: 18$ \\
\hline & & & & \\
\hline & & & & \\
\hline & & & & \\
\hline
\end{tabular}

